NBER WORKING PAPER SERIES

\title{
ROBOTS AND JOBS: \\ EVIDENCE FROM US LABOR MARKETS
}

\author{
Daron Acemoglu \\ Pascual Restrepo \\ Working Paper 23285 \\ http://www.nber.org/papers/w23285 \\ NATIONAL BUREAU OF ECONOMIC RESEARCH \\ 1050 Massachusetts Avenue \\ Cambridge, MA 02138 \\ March 2017
}

We thank David Autor, Lorenzo Caliendo, Amy Finkelstein, Matthew Gentzkow and participants at various seminars and conferences for comments and suggestions; Joonas Tuhkuri for outstanding research assistance; and the Institute for Digital Economics and the Toulouse Network of Information Technology for financial support. The views expressed herein are those of the authors and do not necessarily reflect the views of the National Bureau of Economic Research.

NBER working papers are circulated for discussion and comment purposes. They have not been peer-reviewed or been subject to the review by the NBER Board of Directors that accompanies official NBER publications.

(C) 2017 by Daron Acemoglu and Pascual Restrepo. All rights reserved. Short sections of text, not to exceed two paragraphs, may be quoted without explicit permission provided that full credit, including $\odot$ notice, is given to the source. 
Robots and Jobs: Evidence from US Labor Markets

Daron Acemoglu and Pascual Restrepo

NBER Working Paper No. 23285

March 2017

JEL No. J23,J24

\begin{abstract}
As robots and other computer-assisted technologies take over tasks previously performed by labor, there is increasing concern about the future of jobs and wages. We analyze the effect of the increase in industrial robot usage between 1990 and 2007 on US local labor markets. Using a model in which robots compete against human labor in the production of different tasks, we show that robots may reduce employment and wages, and that the local labor market effects of robots can be estimated by regressing the change in employment and wages on the exposure to robots in each local labor market - defined from the national penetration of robots into each industry and the local distribution of employment across industries. Using this approach, we estimate large and robust negative effects of robots on employment and wages across commuting zones. We bolster this evidence by showing that the commuting zones most exposed to robots in the post-1990 era do not exhibit any differential trends before 1990. The impact of robots is distinct from the impact of imports from China and Mexico, the decline of routine jobs, offshoring, other types of IT capital, and the total capital stock (in fact, exposure to robots is only weakly correlated with these other variables). According to our estimates, one more robot per thousand workers reduces the employment to population ratio by about $0.18-0.34$ percentage points and wages by $0.25-0.5$ percent.
\end{abstract}

Daron Acemoglu

Department of Economics, E52-446

MIT

77 Massachusetts Avenue

Cambridge, MA 02139

and CIFAR

and also NBER

daron@mit.edu

Pascual Restrepo

Department of Economics

Boston University

270 Bay State Rd

Boston, MA 02215

and Cowles Foundation, Yale

pascual.restrepo@yale.edu 


\section{INTRODUCTION}

In 1930, John Maynard Keynes famously predicted the rapid technological progress of the next 90 years, but also conjectured that "We are being afflicted with a new disease of which some readers may not have heard the name, but of which they will hear a great deal in the years to come - namely, technological unemployment" (Keynes, 1930). More than two decades later, Wassily Leontief would foretell similar problems for workers writing "Labor will become less and less important... More and more workers will be replaced by machines. I do not see that new industries can employ everybody who wants a job" (Leontief, 1952). Though these predictions did not come to pass in the decades that followed, there is renewed concern that with the striking advances in automation, robotics, and artificial intelligence, we are on the verge of seeing them realized (e.g., Brynjolfsson and McAfee, 2012; Ford, 2016). The mounting evidence that the automation of a range of low-skill and medium-skill occupations has contributed to wage inequality and employment polarization (e.g., Autor, Levy and Murnane, 2003; Goos and Manning, 2007; Michaels, Natraj and Van Reenen, 2014) adds to these worries.

These concerns notwithstanding, we have little systematic evidence of the equilibrium impact of these new technologies, and especially of robots, on employment and wages. One line of research investigates how feasible it is to automate existing jobs given current and presumed technological advances. Based on the tasks that workers perform, Frey and Osborne (2013), for instance, classify 702 occupations by how susceptible they are to automation. They conclude that over the next two decades, 47 percent of US workers are at risk of automation. Using a related methodology, McKinsey puts the same number at 45 percent, while the World Bank estimates that 57 percent of jobs in the OECD could be automated over the next two decades (World Development Report, 2016). Even if these studies were on target on what is technologically feasible, ${ }^{1}$ these numbers do not correspond to the equilibrium impact of automation on employment and wages. First, even if the presumed technological advances materialize, there is no guarantee that firms would choose to automate; that would depend on the costs of substituting machines for labor and how much wages change in response to this threat. Second, the labor market impacts of new technologies depend not only on where they hit but also on the adjustment in other parts of the economy. For example, other sectors and occupations might expand to soak up the labor freed from the tasks that are now performed by machines, and productivity improvements due to new machines may even expand employment in affected

\footnotetext{
${ }^{1}$ Arntz, Gregory, and Zierahn (2016) argue that within an occupation, many workers specialize in tasks that cannot be automated easily, and that once this is taken into account, only about 9 percent of jobs in the OECD are at risk.
} 
industries (Acemoglu and Restrepo, 2016).

In this paper we move beyond these feasibility studies and estimate the equilibrium impact of one type of automation technology, industrial robots, on local US labor markets. The International Federation of Robotics - IFR for short - defines an industrial robot as "an automatically controlled, reprogrammable, and multipurpose [machine]" (IFR, 2014). That is, industrial robots are fully autonomous machines that do not need a human operator and that can be programmed to perform several manual tasks such as welding, painting, assembling, handling materials, or packaging. Textile looms, elevators, cranes, transportation bands or coffee makers are not industrial robots as they have a unique purpose, cannot be reprogrammed to perform other tasks, and/or require a human operator. ${ }^{2}$ Although this definition excludes other types of capital that may also replace labor (most notably software and other machines), it enables an internationally and temporally comparable measurement of a class of technologies -industrial robots - that are capable of replacing human labor in a range of tasks.

Industrial robots are argued to have already deeply impacted the labor market and are expected to transform it in the decades to come (e.g., Brynjolfsson and McAfee, 2012; Ford, 2016). Indeed, between 1993 and 2007 the stock of robots in the United States and Western Europe increased fourfold. As Figure 1 shows, in the United States the increase amounted to one new industrial robot for every thousand workers and in Western Europe to 1.6 new industrial robots for every thousand workers. The IFR estimates that there are currently between 1.5 and 1.75 million industrial robots in operation, a number that could increase to 4 to 6 million by 2025 (see Boston Consulting Group, 2015). The automotive industry employs 39 percent of existing industrial robots, followed by the electronics industry (19 percent), metal products (9 percent), and the plastic and chemicals industry (9 percent).

To motivate our analysis, we start with a simple model where robots and workers compete in the production of different tasks. Our model builds on Acemoglu and Autor (2011) and Acemoglu and Restrepo (2016), but extends these frameworks so that the share of tasks performed by robots varies across industries and there is trade between labor markets specializing in different industries. Greater penetration of robots into the economy affects wages and employment negatively because of a displacement effect (by directly displacing workers from tasks they were previously performing), but also positively because of a productivity effect (as other industries

\footnotetext{
${ }^{2}$ Our measure also excludes "dedicated industrial robots," which are defined as automatically controlled machines suited for only one industrial application. Examples of dedicated industrial robots include the storage and retrieval systems in automated warehouses, assemblers of printed circuit boards, and machine loading equipment. Although dedicated industrial robots might have a similar impact as industrial robots, the IFR does not collect data on their numbers.
} 
and/or tasks increase their demand for labor). Our model shows that the impact of robots on employment and wages in a labor market can be estimated by regressing the change in these variables on the exposure to robots, a measure defined as the sum over industries of the national penetration of robots into each industry times the baseline employment share of that industry in the labor market. These specifications form the basis of our empirical investigation.

Our empirical work focuses on local labor markets in the United States, which we proxy by commuting zones. ${ }^{3}$ We construct our measure of exposure to robots using data from the IFR on the increase in robot usage in 19 industries (roughly at the two-digit level outside manufacturing and at the three-digit level within manufacturing) and their baseline employment shares from the Census before the onset of recent robotic advances. Our measure of exposure to robots leverages the fact that commuting zones vary in their distribution of industrial employment, making some commuting zones more exposed to the use of robots than others.

A major concern with our empirical strategy is that the adoption of robots in a given US industry could be related to other trends affecting that industry or to economic conditions in the commuting zones that specialize in that industry. Both possibilities would confound the impact of robots. To address this concern, we use the industry-level spread of robots in other advanced economies - meant to proxy improvements in the world technology frontier of robots - as an instrument for the adoption of robots in US industries. This strategy is similar to that used by Autor, Dorn and Hanson (2013) and Bloom, Draca and Van Reenen (2015) to estimate the impact of Chinese imports. Though not a panacea for all sources of omitted variable bias, this strategy allows us to focus on the variation that results solely from industries in which the use of robots has been concurrent in most advanced economies. ${ }^{4}$ Moreover, because IFR industrylevel data starts in 2004 in the United States, but in 1993 in several European countries, this instrumental-variables approach enables us to estimate the impact of industrial robots over a longer period of time.

Using this strategy, we estimate a strong relationship between a commuting zone's exposure

\footnotetext{
${ }^{3}$ Though not all equilibrium responses take place within commuting zones (the most important omitted ones being trade with other local labor markets, which we model explicitly below; migration, which we directly investigate; and the response of technology and new tasks to changes in factor prices emphasized in Acemoglu and Restrepo, 2016), recent research suggests that much of the adjustment to shocks, both in the short run and the medium run, takes place locally (e.g., Acemoglu, Autor and Lyle, 2005, Moretti, 2011, Autor, Dorn and Hanson, 2013).

${ }^{4}$ Our strategy would be compromised if changes in robot usage in other advanced economies are correlated with adverse shocks to US industries. For instance, there may be common shocks affecting the same industries in the US and Europe, such as import competition or rising wages, and which could cause industries to adopt robots in response. Also, the decline of an industry in the United States may encourage both domestic producers in the United States and their foreign competitors to adopt robots.
} 
to robots and its post-1990 labor market outcomes. In the most exposed areas, between 1990 and 2007 both employment and wages decline in a robust and significant manner (compared to other less exposed areas). Quantitatively, our estimates imply that the increase in the stock of robots (approximately one new robot per thousand workers from 1993 to 2007) reduced the employment to population ratio in a commuting zone with the average US exposure to robots by 0.37 percentage points, and average wages by 0.73 percent, relative to a commuting zone with no exposure to robots. These numbers are large but not implausible. ${ }^{5}$ For example, they imply that one more robot in a commuting zone reduces employment by 6.2 workers, which is consistent with case study evidence on the relative productivity of robots, as we discuss below.

To understand the aggregate implications of these estimates, we need to make additional assumptions about how different commuting zones interact and on whether to focus on the entire decline in employment or just the part in industries most exposed to robots. If we focus on the entire decline in employment and assume, unrealistically, that commuting zones are closed economies without any interactions, the numbers in the above paragraph also give us the aggregate effects of robots on US employment and wages. However, in practice, the more intensive use of robots in a commuting zone reduces the costs of the products now produced using robots in the entire US economy, and thus trigger some expansion of employment and wages in other commuting zones. Our model, by incorporating trade between commuting zones, enables us to quantify this effect. Our estimates incorporating these trade interactions imply somewhat smaller negative employment effects and considerably smaller negative wage effects from robots. The exact magnitudes now depend on the elasticities of substitution between different products and between goods produced in different commuting zones, on the amount of cost savings from robots and on the elasticity of the labor supply. Nevertheless, for reasonable variations of these parameters, the implied magnitudes remain negative and sizable. With our preferred choice of parameters, the estimates imply that one more robot per thousand workers reduces aggregate employment to population ratio by about 0.34 percentage points (or equivalently one new robot reducing employment by 5.6 workers as opposed to 6.2 workers without trade) and wages by about 0.5 percent (as opposed to 0.73 percent without trade). Finally, if we just focus on the

\footnotetext{
${ }^{5}$ If the adoption of other labor-saving technologies is taking place in the same industries at the same time as robots, our estimates would have to be interpreted as the joint impact of this ensemble of technologies. Though the fact that our results are essentially unchanged when we control for the replacement of routine jobs, offshoring, the increase in overall capital intensity and IT technology (and that our measure is uncorrelated with these other trends) is reassuring in this respect, we cannot rule out this possibility. In fact, some other changes, such as the adoption of new digital or monitoring technologies, may be taking place in the same industries precisely as a result of their adoption of robots. A possible interpretation of our results would therefore be that they correspond to the labor market effects of robots and other technological changes triggered by the adoption of robots.
} 
decline in industries most exposed to robots (and thus presume that negative effects in some of the other industries are due to other factors such as local demand spillovers), the aggregate effects can be as low as one more robot per thousand workers reducing aggregate employment to population ratio by about 0.18 percentage points (or equivalently one new robot reducing employment by 3 workers) and aggregate wages by about 0.25 percent.

To bolster confidence in our interpretation, we show that our estimates remain negative and significant when we control for broad industry composition (including shares of manufacturing, durables, and construction), for detailed demographics, and for competing factors impacting workers in commuting zones - in particular, exposure to imports from China (as in Autor, Dorn and Hanson, 2013), exposure to imports from Mexico, the decline in routine jobs following the use of software to perform information processing tasks (as in Autor and Dorn, 2013), and offshoring of intermediate inputs (based on Feenstra and Hanson, 1999; and Wright, 2014). We also document that our measure of exposure to robots is unrelated to past trends in employment and wages from 1970 to 1990, a period that preceded the onset of rapid advances in robotics technology circa 1990.

Several robustness checks further support our interpretation. First, we find no similar negative impact from other measures of IT and capital (thus partly motivating our focus on robots). Second, we show that the automobile industry, which uses the largest number of robots per worker, is not driving our results. Third, we document that the results are robust to including differential trends by various baseline characteristics, linear commuting zone trends, and potentially mean-reverting dynamics in employment and wages.

We also document that the employment effects of robots are most pronounced in manufacturing, and in particular, in industries most exposed to robots; in routine manual, blue collar, assembly and related occupations; and for workers with less than college education. Interestingly, and perhaps surprisingly, we do not find positive and offsetting employment gains in any occupation or education groups. We further document that the effects of robots on men and women are similar, though the impact on male employment is more negative.

Besides the papers that we have already mentioned, our work is related to the empirical literature on the effects of technology on wage inequality (Katz and Murphy, 1992), employment polarization (Autor, Levy and Murnane, 2003; Goos and Manning, 2007; Autor and Dorn, 2013; Michaels, Natraj and Van Reenen, 2014), aggregate employment (Autor, Dorn and Hanson, 2015; Gregory, Salomons and Zierahn, 2016), the demand for labor across cities (Beaudry, Doms and Lewis, 2006), and firms' organization and demand for workers with different skills (Caroli and Van Reenen, 2001, Bartel, Ichniowski, and Shaw, 2007, and Acemoglu et al., 2007). 
Most closely related to our work is the pioneering paper by Graetz and Michaels (2015). Focusing on the variation in robot usage across industries in different countries, they estimate that industrial robots increase productivity and wages, but reduce the employment of low-skill workers. Although we rely on the same data, we use a different empirical strategy, which enables us to go beyond cross-country, cross-industry comparisons, exploit plausibly exogenous changes in the spread of robots, and estimate the equilibrium impact of robots on local labor markets. Our micro data also enable us to control for detailed demographic and compositional variables when focusing on commuting zones, check the validity of our exclusion restrictions with placebo exercises, and study the impact of robots on industry and occupation-level outcomes, bolstering the plausibility of our estimates.

The rest of the paper is organized as follows. Section 2 presents a simple model of the effect of robots on employment and wages, which both clarifies the main economic forces and enables us to derive two simple equations, summarizing the theoretical relationship between changes in employment and wages and robots. These equations are then mapped to data in Section 3. Section 4 introduces the various data sources we use in our analysis, provides descriptive statistics, and also describes the relationship between the use of robots at the industry level across nine European countries and the United States, which is the basis of the first-stage relationship and reduced-form models we will estimate. Section 5 presents our empirical results. Section 6 concludes, while the Appendix presents proofs, additional theoretical results especially useful in interpreting our empirical findings when there are trade links between commuting zones, and various further robustness checks to our empirical results.

\section{Robots, Employment and Wages: A Model}

In this section, we present a model building on Acemoglu and Restrepo (2016) to exposit the potential effects of robots on employment and wages, and derive our estimating equations for the empirical analysis. To build intuition, we first ignore any interaction between local labor markets (commuting zones), and then enrich this framework by introducing trade between commuting zones. Our trade model can be viewed as combining the frameworks of Armington (1969) and Anderson (1979) with our modeling of robots (see also Caliendo and Parro, 2015, and Burstein et al., 2017). 


\subsection{Robots in Autarky Equilibrium}

The economy consists of $|\mathcal{C}|$ commuting zones. Each commuting zone $c \in \mathcal{C}$ has preferences defined over an aggregate of the consumption of the output of $|\mathcal{I}|$ industries, given by

$$
Y_{c}=\left(\sum_{i \in \mathcal{I}} \alpha_{i} Y_{c i}^{\frac{\sigma-1}{\sigma}}\right)^{\frac{\sigma}{\sigma-1}}
$$

where $\sigma>0$ denotes the elasticity of substitution across goods produced in different industries, while the $\alpha_{i}$ 's are share parameters designating the importance of industry $i$ in the consumption aggregate (with $\sum_{i \in \mathcal{I}} \alpha_{i}=1$ ).

In the autarky equilibrium, each commuting zone can consume only its own production of each good, denoted by $X_{c i}$ for the output of industry $i$ in commuting zone $c$. Hence, for all $i \in \mathcal{I}$ and $c \in \mathcal{C}$, we have

$$
Y_{c i}=X_{c i}
$$

We choose the consumption aggregate in each commuting zone as numeraire (with price normalized to 1) and denote the price of the output of industry $i$ in commuting zone $c$ by $P_{X c i}$.

Each industry produces output by combining a continuum of tasks indexed by $s \in[0, S]$. We denote by $x_{c i}(s)$ the quantity of task $s$ utilized in the production of $X_{c i}$. These tasks must be combined in fixed proportions so that

$$
X_{c i}=A_{c i} \min _{s \in[0, S]}\left\{x_{c i}(s)\right\}
$$

where $A_{c i}$ designates the productivity of industry $i$. Differences in the $A_{c i}$ 's and the $\alpha_{i}$ 's will translate into different industrial compositions of employment across commuting zones.

We model industrial robots (or simply, robots) as performing some of the tasks previously performed by labor. Specifically, in industry $i$ tasks $\left[0, M_{i}\right]$ are "technologically automated" and can be performed by robots, and crucially, these technological opportunities are common across all commuting zones. We normalize the productivity of robots in every task to 1 , and further simplify the model by assuming that the productivity of labor in each task is constant as well and equal to $\gamma>0 .{ }^{6}$ Consequently, the production function for task $s$ in industry $i$ in commuting zone $c$ can be written as

$$
x_{c i}(s)=\left\{\begin{array}{cc}
r_{c i}(s)+\gamma l_{c i}(s) & \text { if } s \leq M_{i} \\
\gamma l_{c i}(s) & \text { if } s>M_{i},
\end{array}\right.
$$

\footnotetext{
${ }^{6}$ Other, more conventional, types of technological changes raising the productivity of labor in existing tasks can be modeled as increasing $\gamma$. It is straightforward to verify that an increase in $\gamma$ will not generate the displacement effects caused by robots (and this might be one possible explanation for why, in our empirical work, we find very different effects from robots and other types of capital).
} 
where $l_{c i}(s)$ denotes labor used in the production of task $s$ in industry $i$ in commuting zone $c$, while $r_{c i}(s)$ is the number of robots used in the production of this task. Because tasks greater than $M_{i}$ have not been automated, the use of robots in their production is impossible.

Finally, we specify the supply of robots and labor in each commuting zone as follows

$$
\begin{aligned}
W_{c} & =\mathcal{W}_{c} Y_{c} L_{c}^{\varepsilon}, \text { with } \varepsilon \geq 0 ; \text { and } \\
Q_{c} & =\mathcal{Q}_{c}\left(\frac{R_{c}}{Y_{c}}\right)^{\eta}, \text { with } \eta \geq 0,
\end{aligned}
$$

where $R_{c}$ denotes the total number of robots, $L_{c}$ is the total amount of labor, $Q_{c}$ is the price of robots, and $W_{c}$ is the wage rate in commuting zone $c$. These specifications imply that $1 / \varepsilon$ is the Frisch elasticity of labor supply, while $1 / \eta$ is the elasticity of the supply of robots. The reason why robots may have an upward sloping supply is that they are produced using both scarce skills and materials. For example, in the United States robots have to be installed by local integrators, which have specific expertise that is likely in short supply, making the cost of increasing the local usage of robots convex in the number of robots installed (Green Leigh and Kraft, 2017).

An equilibrium is defined as a set of prices $\left\{W_{c}, Q_{c}\right\}_{c \in \mathcal{C}}$ and quantities $\left\{L_{c}, R_{c}\right\}_{c \in \mathcal{C}}$ such that in all commuting zones, firms maximize profits, labor and robot supplies are given by (2) and the markets for labor and robots clear, i.e.,

$$
\sum_{i \in \mathcal{I}} \int_{[0,1]} l_{c i}(s)=L_{c} \quad \text { and } \quad \sum_{i \in \mathcal{I}} \int_{[0,1]} r_{c i}(s)=R_{c} .
$$

We prove in the Appendix that an equilibrium exists and is unique.

We simplify our discussion here by assuming that it is profitable for firms to use robots in all tasks that are "technologically automated". ${ }^{7}$ Formally, let us define $\pi_{c}=1-\frac{Q_{c} \gamma}{W_{c}}$ as the cost-saving gains from using robots rather than labor in a task. We impose:

Assumption $1 \pi_{c}>0$ for all $c \in \mathcal{C}$.

This assumption allows us to focus on the case of interest in which improvements in automation (increases in $M_{i}$ ) are binding and affect wages and employment. Using this assumption, we can derive an expression for the demand for labor $L_{c}^{d}$.

Proposition 1 The demand for labor $L_{c}^{d}$ in commuting zone c satisfies:

$$
d \ln L_{c}^{d}=-\sum_{i \in \mathcal{I}} \ell_{c i} \frac{d M_{i}}{1-M_{i}}-\sigma \sum_{i \in \mathcal{I}} \ell_{c i} d \ln P_{X c i}+d \ln Y_{c}
$$

\footnotetext{
${ }^{7}$ See Acemoglu and Restrepo (2016) for the general case in which tasks are combined with a general elasticity of substitution; the comparative advantage of labor relative to robots varies across tasks (e.g., $\gamma$ depends on $s$ ); and Assumption 1 does not hold, so that firms may prefer not to adopt robots in all tasks that can be automated.
} 
where $\ell_{c i}$ denotes the share of employment in industry $i$ in commuting zone $c$.

Like all other results in this section, the proof of this proposition is provided in the Appendix. Equation (4) highlights three different forces shaping labor demand. The first is the displacement effect: holding prices and output constant, robots displace workers and reduce the demand for labor, because with robots it takes fewer workers to produce a given amount of output. The second and the third terms make up the productivity effect, but they work through different channels. The second can be viewed as the price-productivity effect: as automation (the further deployment of robots) lowers the cost of production in an industry, that industry expands and thus increases its demand for labor. As might be expected, this expansion is greater when the elasticity of substitution between different industries, $\sigma$, is higher. The third term in equation (4) captures the scale-productivity effect. The reduction in costs results in an expansion of total output, also raising the demand for labor in all industries (since industries are $q$-complements in (1)). The crucial difference between the price-productivity and scale-productivity effect is that the first results from the expansion of the output of industry $i$, while the latter is a consequence of the expansion of all industries (and hence of $Y_{c}$ ).

Proposition 1 provides a partial equilibrium characterization - the changes in prices and output $\left(d \ln P_{X c i}\right.$ and $\left.d \ln Y_{c}\right)$ depend on the changes in the prices and quantities of robots and labor in the commuting zone as well as on changes in $M_{i}$. The next proposition presents its general equilibrium analogue. In this and our subsequent analysis, we denote the share of labor in total output in commuting zone $c$ by $s_{c L}$, and the share of labor in the output of industry $i$ in commuting zone $c$ by $s_{i c L}$.

Proposition 2 In autarky, the impact of robots on employment and wages is given by

$$
\begin{aligned}
d \ln L_{c} & =-\frac{1+\eta}{1+\varepsilon} \sum_{i \in \mathcal{I}} \ell_{c i} \frac{d M_{i}}{1-M_{i}}+\frac{1+\eta}{1+\varepsilon} \pi_{c} \sum_{i \in \mathcal{I}} \ell_{c i} \frac{s_{i c L}}{s_{c L}} \frac{d M_{i}}{1-M_{i}} \\
d \ln W_{c} & =-\eta \sum_{i \in \mathcal{I}} \ell_{c i} \frac{d M_{i}}{1-M_{i}}+(1+\eta) \pi_{c} \sum_{i \in \mathcal{I}} \ell_{c i} \frac{s_{i c L}}{s_{c L}} \frac{d M_{i}}{1-M_{i}} .
\end{aligned}
$$

This proposition characterizes the total equilibrium impact of robots. In both the employment and wage equations, the first term is the general equilibrium version of the displacement effect, while the second term is the productivity effect (combining the price-productivity and scale-productivity effects), expressed as a function of the changes in the robotics technology. These total equilibrium implications are obtained by solving out changes in quantities and prices of industrial output and robots in terms of the changes in $M_{i}$ 's, which explains the presence of the local supply elasticities, $1 / \varepsilon$ and $1 / \eta$, and the cost share parameters, the $s_{i c L}$ 's and 
$s_{c L}$ 's. Similar to our partial equilibrium characterization in Proposition 1, the impact on employment and wages could be negative because of the displacement effect or positive because of the productivity effect. Crucially, the magnitude of the productivity effects depends on $\pi_{c}$, which encapsulates the cost savings from the substitution of robots for human labor. If this term is close to 0 , the productivity effects will be limited.

Proposition 2 summarizes the effects of robots as a function of the changes in the robotics technology, $d M_{i}$. More convenient for our empirical work is to link the responses of employment and wages to changes in the adoption of robots. When $M_{i} \approx 0-$ a reasonable approximation to the US economy circa 1990 - this can be done in the following fashion: ${ }^{8}$

$$
\sum_{i \in \mathcal{I}} \ell_{c i} \frac{s_{i c L}}{s_{c L}} \frac{d M_{i}}{1-M_{i}} \approx \sum_{i \in \mathcal{I}} \ell_{c i} \frac{d M_{i}}{1-M_{i}} \approx \frac{1}{\gamma} \sum_{i \in \mathcal{I}} \ell_{c i} \frac{d R_{i}}{L_{i}}=\text { US exposure to robots }
$$

Together with equations (5) and (6), this formula shows that the full impact of robots on a local labor market can be summarized by our measure of the US exposure to robots, which is computed from the increase in the use of robots in each US industry divided by that industry's baseline employment, and sums these changes using baseline employment shares as weights. The term "exposure to robots" emphasizes that the variable that matters in theory, and that will be investigated in our empirical work, is how exposed to robots a commuting zone is in terms of its baseline employment shares in different industries, the $\ell_{c i}$ 's (and the changes in penetration of robots into different industries, the $d R_{i}$ 's). Advances in robotics technology will have a greater effect in commuting zones that have a greater share of their employment in industries where robots are making greater inroads.

\subsection{Robots When Commuting Zones Trade}

The autarky model transparently shows the displacement and productivity effects of robots, but ignores crucial linkages across commuting zones. When a commuting zone adopts more robots, it will have lower costs and sell more to other commuting zones. Such linkages change both the sensitivity of employment and wages to the adoption of robots and their aggregate implications (because lower costs in a commuting zone reduce the cost of living and expand employment in other commuting zones).

To incorporate trade between commuting zones, we assume that the output $X_{c i}$ is not only consumed locally, but also exported to all commuting zones. Because there are no trade costs,

\footnotetext{
${ }^{8}$ The first relationship follows because when $M_{i} \approx 0, s_{i c L} \approx s_{c L}$. The second relationship is derived from the following argument. Cost minimization implies $X_{c i}\left(1-M_{i}\right)=\gamma L_{c i}$. Integrating this over commuting zones and rearranging, we obtain total industry output as $X_{i}=\gamma L_{i} /\left(1-M_{i}\right)$. Similarly for robots, we have $X_{i} M_{i}=R_{i}$. Totally differentiating this last expression and using the fact that $M_{i} \approx 0$, we obtain $d M_{i} \approx d R_{i} / X_{i}$. Substituting from the labor cost minimization equation, this expression can be rewritten as $\gamma d M_{i} /\left(1-M_{i}\right) \approx d R_{i} / L_{i}$.
} 
the price of the product of industry $i$ sourced from commuting zone $c$ will be the same everywhere and is denoted by $P_{X c i}$. Denoting the amount of good $i$ exported from commuting zone $c$ to destination $d$ by $X_{c d i}$, market clearing imposes that, for all $c$ and $i$,

$$
X_{c i}=\sum_{d \in \mathcal{C}} X_{c d i}
$$

Preferences in each commuting zone are again defined by the same aggregate over consumption goods as in (1), but now these consumption goods are themselves assumed to be aggregates of varieties sourced from all commuting zones, given by

$$
Y_{c i}=\left(\sum_{s \in \mathcal{C}} \theta_{s i} X_{s c i} \frac{\lambda-1}{\lambda}\right)^{\frac{\lambda}{\lambda-1}}(\text { for all } c \text { and } i)
$$

where $\lambda$ is the elasticity of substitution between varieties sourced from different commuting zones, and the share parameters, the $\theta_{s i}$ 's, indicate the desirability of varieties from different sources (e.g., cars from Detroit may be more valuable than cars from New York City). We have that, for each $i \in \mathcal{I}, \sum_{s \in \mathcal{C}} \theta_{s i}=1$. Throughout, we also assume that $\lambda>\sigma$, so that varieties of the same good from different commuting zones are more substitutable than different products are in the consumption aggregator. We also take $\sigma \geq 1$.

Because all commuting zones share the same sourcing technology, (8), and face the same prices for varieties, the $P_{X_{c i}}$ 's, they will also have the same prices of the consumption aggregates of different industries, the $P_{Y i}$ 's.

An equilibrium is defined in the same way as in the closed economy, but now requires, in addition, that trade is balanced for each commuting zone $c \in \mathcal{C}$, i.e.,

$$
Y_{c}=\sum_{i \in \mathcal{I}} X_{c i} P_{X c i}
$$

We show in the Appendix that an equilibrium in this model with trade across commuting zones also exists, and moreover, is unique provided that the $M_{i}$ 's are sufficiently small, which is the empirically relevant case for our focus.

The next proposition gives the analogue of Proposition 1 in the presence of trade between commuting zones.

Proposition 3 In the trading equilibrium, the demand for labor $L_{c}^{d}$ in commuting zone $c$ satisfies:

$$
d \ln L_{c}^{d}=-\sum_{i \in \mathcal{I}} \ell_{c i} \frac{d M_{i}}{1-M_{i}}-\lambda \sum_{i \in \mathcal{I}} \ell_{c i} d \ln P_{X c i}+(\lambda-\sigma) \sum_{i \in \mathcal{I}} \ell_{c i} d \ln P_{Y i}+d \ln Y
$$


The similarities to and differences from Proposition 1 are instructive. The first terms in equations (4) and (9), the displacement effects, are identical. The next three terms in (9) now make up the productivity effect. The second term is the price-productivity effect, and because $\lambda>\sigma$, it is more powerful than in the autarky equilibrium. Intuitively, when an industry in commuting zone $c$ reduces its costs and hence price (for example, because of more intensive use of robots), this will also enable it to gain market share relative to the varieties of the same good produced in other commuting zones. The third term, however, dampens the productivity effect because the greater use of robots in industry $i$ reduces the cost of production not only in commuting zone $c$, but in all commuting zones. Finally, the last term is the equivalent of the scale-productivity effect in this case, but works through the expansion of total output in the economy rather than output in commuting zone $c$.

The analogue of Proposition 2, which provides the general equilibrium counterparts of the partial equilibrium effects summarized in Proposition 3, is more involved, and is provided in Proposition A3 in the Appendix.

\section{Empirical Specification}

We now discuss the implications of the autarky and the trading equilibria for our empirical strategy.

When $M_{i} \approx 0$, both our autarky and trade models imply that the effects of robots on employment and wages can be estimated using the following two equations:

$$
d \ln L_{c}=\beta_{c}^{L} \sum_{i \in \mathcal{I}} \ell_{c i} \frac{d R_{i}}{L_{i}}+\epsilon_{c}^{L} \quad \text { and } \quad d \ln W_{c}=\beta_{c}^{W} \sum_{i \in \mathcal{I}} \ell_{c i} \frac{d R_{i}}{L_{i}}+\epsilon_{c}^{W},
$$

where $\epsilon_{c}^{L}$ and $\epsilon_{c}^{W}$ are unobserved shocks, and $\beta_{c}^{L}$ and $\beta_{c}^{W}$ are random (heterogeneous) coefficients. In the autarky equilibrium, equation (7) implies that these coefficients are given as

$$
\beta_{c}^{L}=\left(\frac{1+\eta}{1+\varepsilon} \pi_{c}-\frac{1+\eta}{1+\varepsilon}\right) \frac{1}{\gamma} \quad \text { and } \quad \beta_{c}^{W}=\left((1+\eta) \pi_{c}-\eta\right) \frac{1}{\gamma} .
$$

In this autarky setting, aggregate effects of robots are also given by averages of these heterogeneous coefficients.

More realistic and relevant for our investigation is the setting with trade between commuting zones. In this case, when in addition $\pi_{c} \approx \pi$, the expressions in Proposition A3 can be simplified to yield the following approximations to $\beta_{c}^{L}$ and $\beta_{c}^{W}$ :

$$
\begin{aligned}
& \beta_{c}^{L} \approx\left(\frac{1+\eta}{1+\varepsilon}\left(s_{c L} \lambda+\left(1-s_{c L}\right) \sigma\right) \pi_{c}-\frac{1+\eta}{1+\varepsilon} \frac{s_{c L} \lambda+1-s_{c L}}{s_{c L}}\right) \frac{\nu_{c}}{\gamma} \\
& \beta_{c}^{W} \approx\left(\left((1+\eta) \frac{(1+\varepsilon) \lambda-1}{1+\varepsilon}-\left(1+\eta\left(1-s_{c L}\right)\right)(\lambda-\sigma)\right) \pi_{c}-\left(\eta(\lambda-1)+\frac{\varepsilon(1+\eta)}{(1+\varepsilon) s_{c L}}\right)\right) \frac{\nu_{c}}{\gamma},
\end{aligned}
$$


where

$$
\nu_{c}=\frac{(1+\varepsilon) s_{c L}}{(1+\varepsilon) s_{c L} \lambda+(1+\eta)\left(1-s_{c L}\right)} .
$$

In the presence of trade, because more intensive use of robots in a commuting zone $c$ affects other commuting zones, the estimates of $\beta^{L}$ and $\beta^{W}$ are not directly informative about aggregate employment and wage effects. However, estimates of these regression coefficients can be combined with standard values of labor supply $(1 / \varepsilon)$ and trade $(\sigma$ and $\lambda)$ elasticities to recover estimates of the other underlying parameters, and aggregate effects can then be computed from these parameter estimates.

In fact, again focusing on the case where $\pi_{c} \approx \pi$, the Appendix shows that the aggregate employment and wage effects are

$$
\begin{aligned}
\text { aggregate employment effects } & =\frac{1+\eta}{1+\varepsilon}(\pi-1) \frac{1}{\gamma} \mathbb{E}_{c} \sum_{i \in \mathcal{I}} \ell_{c i} \frac{d R_{i}}{L_{i}} \\
\text { aggregate wage effects } & =((1+\eta) \pi-\eta) \frac{1}{\gamma} \mathbb{E}_{c} \sum_{i \in \mathcal{I}} \ell_{c i} \frac{d R_{i}}{L_{i}},
\end{aligned}
$$

with $\mathbb{E}_{c} \sum_{i \in \mathcal{I}} \ell_{c i} \frac{d R_{i}}{L_{i}}$ denoting the average exposure to robots across commuting zones. Therefore, to estimate the aggregate impact of robots, all we need are estimates of the Frisch elasticity of labor supply $(1 / \varepsilon)$, the elasticity of local supply of robots $(1 / \eta)$, the physical productivity of labor relative to robots $(\gamma)$, and the average cost savings from the introduction of robots $(\pi)$.

The models in equation (10) can be readily estimated using OLS with the US exposure to robots variable described above. However, there are two related reasons why the US exposure to robots could be correlated with the error terms, the $\epsilon_{c}^{L}$ 's and $\epsilon_{c}^{W}$ 's, leading to biased estimates. First, some industries may be adopting robots in response to other changes that they are undergoing, which could directly impact their labor demand (in the model, this would correspond to changes in the $A_{c i}$ terms, which are included in the error terms being correlated with $d R_{i} / L_{i}$ ). Second, any shock to labor demand in a commuting zone affects the decisions of the industries located in that commuting zone, including their decisions concerning the adoption of robots (in the model, these effects would be captured by changes in $\sum_{i} A_{c i}, \mathcal{Q}_{c}$, or $\mathcal{W}_{c}$, which could be correlated with $d R_{i} / L_{i}$ for industries disproportionately located in the affected commuting zones). ${ }^{9}$

To address both issues, we estimate the models in equation (10) using a measure of the exogenous exposure to robots, which we compute using the adoption of industrial robots among

\footnotetext{
${ }^{9} \mathrm{An}$ example for the first concern would be the automobile industry adopting more robots in the United States because of higher wage push from its unions. An example for the second concern would be a recession in Detroit, Michigan also impacting the automobile industry that has a large footprint there. Though a jackknife procedure might take care of the second concern, our instrumentation strategy will deal with both in a more direct manner.
} 
industries in nine other European economies from 1993 to 2007. By combining these data with the more limited US data, we compute two-stage least squares estimates of $\beta^{L}$ and $\beta^{W}$. Although our use of the exogenous exposure to robots is not a panacea against all kinds of endogeneity concerns, we believe that this variable, when used either directly or as an instrument, has a better basis for being taken as orthogonal to the terms in $\epsilon_{c}^{L}$ and $\epsilon_{c}^{W}$.

\section{Data, Descriptive Statistics and First Stage}

In this section, we introduce the various data sources we use in our empirical analysis, describe the construction of the exposure to robots variable, provide basic descriptive statistics, and also describe the first-stage relationship between the exogenous exposure to robots variable computed from European economies and the US exposure to robots.

\subsection{Data Sources}

Our main data consist of counts of the stock of robots by industry, country and year from the IFR, which is based on yearly surveys of robot suppliers. The IFR data cover 50 countries from 1993 to 2014, corresponding to about 90 percent of the industrial robots market. However, the stock of industrial robots by industry going back to the 90 s is only available for a subset of countries: Denmark, Finland, France, Germany, Italy, Norway, Spain, Sweden, and the United Kingdom. These countries account for 41 percent of the world industrial robot market. Although the IFR reports data on the total stock of industrial robots in the United States from 1993 onwards, it does not provide industry breakdowns until 2004. ${ }^{10}$ Outside of manufacturing, we have consistent data for the use of robots in six broad industries (roughly at the two-digit level): agriculture, forestry and fishing; mining; utilities; construction; education, research and development; and other non-manufacturing industries (e.g., services and entertainment). In manufacturing, we have consistent data on the use of robots for a more detailed set of 13 industries (roughly at the three-digit level): food and beverages; textiles; wood and furniture; paper; plastic and chemicals; glass and ceramics; basic metals; metal products; metal machinery; electronics; automotive; other vehicles; and other manufacturing industries (e.g. recycling). Table A1 in the Appendix shows the evolution of robots usage in these industries in the nine European countries in our sample and in the United States.

The IFR data also have some shortcomings. First, not all robots are classified into one of the 19 industries. About 30 percent of robots are unclassified, and this fraction has declined

\footnotetext{
${ }^{10}$ Though the IFR also reports data by industry for Japan, these data underwent a major reclassification. We follow the recommendations of the IFR and exclude Japan from our analysis.
} 
throughout our sample. We allocate these unclassified robots to industries in the same proportions as in the classified data. Second, as noted in footnote 2, IFR data do not contain information on dedicated industrial robots. Third, the data for Denmark is not classified by industry before 1996. For the missing years, we construct estimates of the number of industrial robots by deflating the 1996 stocks by industry using the total growth in the stock of robots of the country. Finally, the IFR only reports the overall stock of robots for North America. Though this aggregation introduces noise in our measures of US exposure to robots, this is not a major concern, since the United States accounts for more than 90 percent of the North American market, and our IV procedure should purge the US exposure to robots from this type of measurement error. ${ }^{11}$

We combine the IFR data with employment counts by country and industry in 1990 from the EUKLEMS dataset (see Jägger, 2016) to measure the number of industrial robots per thousand workers by country, industry and time. ${ }^{12}$

In our regression analysis, we focus on the 722 commuting zones defined by Tolbert and Sizer (1996). These zones cover the entire US continental territory except for Alaska and Hawaii. For each commuting zone, we use public use data from the 1970 and 1990 Censuses to obtain the share of employment by industry. In terms of outcomes, we use the public use data from the 1970, 1990, and 2000 Censuses and the 2007 American Community Survey (see Ruggles et al., 2010) to construct measures of employment, employment by industry and occupation, and demographics for each commuting zone. We also use the Census and American Community Survey to compute the average hourly and weekly wage within demographic $\times$ commuting zone cells, which we use to estimate the impact of robots on the wage of comparable individuals. We use 800 demographic cells defined by age, education, race, gender, birthplace and relationship to the household head. ${ }^{13}$ We complement these data with employment counts from the County Business Patterns CBP for 1990, 2000 and 2007, which we again aggregate at the commuting zone level. ${ }^{14}$ The Census

\footnotetext{
${ }^{11} \mathrm{~A}$ more conceptual problem is that robots in different sectors may have very different capabilities and values, and thus focusing on the number of robots may not be meaningful. The results in Table 6 , which show that the quantitative effects of robots in the automobile industry and other industries are very similar, are reassuring in this respect.

${ }^{12}$ To obtain comparable data, we first use information on hours worked to obtain a count of equivalent US workers by industry in 1990. We then compute the number of robots by industry, country and year divided by US equivalent worker in 1990. Because the data for Norway are missing from the EUKLEMS, we use the distribution of employment in the remaining Scandinavian countries in our sample (Denmark, Finland, and Sweden) to impute the Norwegian distribution. Our results are robust to excluding Norway, and are not driven by trends in the use of robots in any single country.

${ }^{13}$ Because wage income is top coded in the Census and American Community Survey, we follow Acemoglu and Autor (2011) and set all top coded wage incomes to 1.5 times their value.

${ }^{14} \mathrm{CBP}$ data are extracted from the Business Register, a file of all known US companies that is maintained
} 
measures employment from the household side, while the CBP approaches it from the employer side, making the two data sources complementary.

To control for potentially confounding changes in trade patterns, we utilize data on the exposure to Chinese imports from Autor, Dorn and Hanson (2013), and we construct similar measures of the exposure to imports from Mexico and exports from Germany, Japan and Korea (the countries that are adopting robots most rapidly). Our trade exposure measures combine the distribution of employment across four-digit industries in the commuting zone and industrylevel imports and exports from the United Nations Comtrade database (which gives bilateral trade data at six-digit product level, which we aggregate to the four-digit level following Autor, Dorn and Hanson, 2013). Following a similar procedure, we construct a measure of offshoring using data on the share of intermediate inputs that are imported by each four-digit industry. The offshoring data are from Wright (2014), who updates Feenstra and Hanson's (1999) to cover the entire period from 1993 to 2007. Finally, we control for the importance of routine jobs in a commuting zone (our measure is the fraction of employment in a commuting zone in routine occupations as defined in Autor and Dorn, 2013); and we also construct measures of the presence of declining industries, growth of capital stock and growth of IT capital in a commuting zone (as described below).

Finally, we use data compiled by Green Leigh and Kraft (2016), who scraped the web to obtain the locations of robot integrators - which are companies that install and program robots for different industrial applications. Using these data, we construct estimates of the number of (robot) integrators in each commuting zone.

\subsection{Exposure to Robots}

Figure 1 plots the evolution of the mean and the 30th percentile of robot usage across the nine European economies described in the previous subsection. It also includes the average density in the United States - recall that aggregate data for the United States are available since 1993, but broken down by industry only since 2004. In our sample of European countries, robot usage starts near 0.6 robots per thousand workers in the early 1990s and increases rapidly to 2.6 robots per thousand workers in the late 2000s. In the United States, robot usage is lower but follows a similar trend; it starts near 0.4 robots per thousand workers in the early 1990s and increases by the US Census Bureau; see http://www.census.gov/econ/cbp/index.html. Because the CBP information on employment by industry is sometimes reported as an interval, we use the fixed-point imputation strategy developed by Autor, Dorn and Hanson (2013) to obtain estimates for these cells. The CBP data provide employment counts at the county level, which we aggregate to the commuting zone level using the crosswalks these authors used, which is available here http://www.ddorn.net/data.htm. 
rapidly to 1.4 robots per thousand workers in the late 2000s. The US trends are closely mirrored by the 30th percentile of robot usage among the European countries in our data.

These observations motivate the construction of our exposure to robots variable as

$$
\begin{aligned}
& \text { Exposure to robots } \\
& \text { from } 1993 \text { to } 2007_{c}
\end{aligned}=\sum_{i \in \mathcal{I}} \ell_{c i}^{1970}\left(p_{30}\left(\frac{R_{i, 2007}}{L_{i, 1990}}\right)-p_{30}\left(\frac{R_{i, 1993}}{L_{i, 1990}}\right)\right)
$$

where the sum runs over all the industries in the IFR data, $\ell_{c i}^{1970}$ stands for the 1970 share of commuting zone $c$ employment in industry $i$, which we compute from the 1970 Census, and $p_{30}\left(\frac{R_{i, t}}{L_{i, 1990}}\right)$ denotes the 30 th percentile of robot usage among European countries in industry $i$ and year $t$. Our main measure of (exogenous) exposure to robots is based on the 1970 values for the distribution of employment across industries, which enables us to focus on historical and persistent differences in the specialization of commuting zones in different industries, and to avoid any mechanical correlation or mean reversion with changes in overall or industry-level employment outcomes. ${ }^{15}$

We construct the US exposure to robots in an analogous fashion:

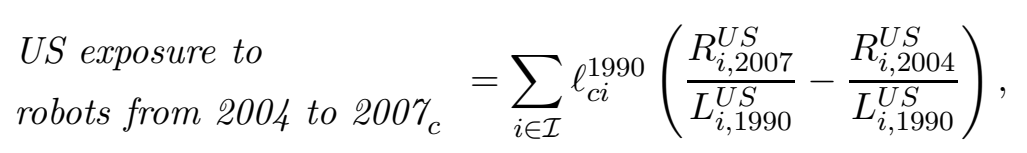

where we use the 1990 distribution of employment across industries, $\ell_{c i}^{1990}$, as the baseline for this measure to match it more closely to theory (and the mean reversion concern mentioned above is not pertinent in this case, since this measure will be instrumented by the exogenous exposure to robots described above).

Figure 4 gives a first glimpse of the relationship between European and US changes in industry-level robot usage. The figure shows that with a few exceptions (basic metals, metal machinery and other manufacturing), the industries that adopted more robots in Europe between 1993 and 2007 also adopted more robots in the United States between 2004 and 2007. The same relationship holds for the period between 2004 and 2007.

Figure 2 plots data on the use of robots (in Europe) for the set of industries covered in the IFR data. For each industry, we also show the rise in Chinese imports per thousand workers, the percent increase in the capital stock, and the percent increase in IT capital stock (both computed from data by the Bureau of Economic Analysis). To ease the comparison, we normalize these

\footnotetext{
${ }^{15}$ Table A13 in the Appendix shows that our main results are very similar when we use the distribution of employment across industries in 1990 or in 1980 to construct our exposure measure. The use of the 30th percentile is motivated by the patterns shown in Figure 1, where aggregate US robot usage tracks the 30th percentile of the distribution among European countries. Table A14 in the Appendix presents results in which we use the mean, the mean among countries closest to the US in terms of robot adoption (Denmark, Finland, France and Sweden), and other percentiles of the distribution to construct our exposure measure.
} 
measures and present numbers relative to the industry with the largest increase for the variable in question. The figure reveals that the industries that are adopting more industrial robots are not the same industries affected by Chinese import competition, nor are they the same ones experiencing unusually rapid growth in total capital or IT capital. This strengthens our presumption that the use of industrial robots is a technological phenomenon that is largely unrelated to other trends affecting industries in developed countries.

Panel A of Figure 3 depicts the geographic distribution of commuting zones with high exposure to robots - the source of variation that we will exploit to identify the impact of industrial robots on employment and wages. The color scale indicates which commuting zones have experienced greater increases in the exogenous exposure to robots measure from 1993 to 2007. The figure reveals significant variation: while in some areas our measure predicts a small increase in the stock of robots, between 0.12-0.3 robots per thousand workers, in other regions - especially but not only in the rustbelt - it predicts a much larger increase of 1-4.87 robots per thousand workers.

Figures 2 and 4 highlight that automobile manufacturing is the sector with the highest robot penetration in both Europe and the United States. Below, we document in detail that our results are not driven by the automobile industry. Panel B of Figure 3 takes a first step in this direction and shows the geographical variation in the exposure to robots once we exclude the automobile industry. The measure of robot penetration that excludes automobile manufacturing still exhibits considerable variation, equivalent to about 68 percent of the original variation in robot penetration across commuting zones.

Importantly, although manufacturing industries use $80 \%$ of the industrial robots in the US, our measure of exposure to robots is not simply picking up areas with a higher employment in manufacturing. The share of manufacturing employment explains only about 18 percent of the variation in exposure to robots across commuting zones. The bulk of the variation plotted in Figure 3 arises from differences in the industrial mix across commuting zones. Furthermore, consistent with the message from Figure 2, Panels D-F show that the geographic distribution of exposure to robots is very different from exposure to Chinese imports, exposure to Mexican imports, routine jobs and offshoring. The (population-weighted) cross-commuting zone correlation between our measure and exposure to Chinese imports and offshoring is small as noted in Figure 3, and essentially disappears once we include our standard demographic controls and the share of manufacturing in the area (-0.052 for exposure to Chinese imports and -0.002 for offshoring, respectively). The correlation of our measure with exposure to Mexican imports and routine jobs is somewhat higher, but is again weakened once we condition on our key covariates 
(it is reduced to 0.26 and 0.11 , respectively). These weak correlations are reassuring against concerns that the effects of robots would be highly confounded by other major changes affecting local US labor markets.

\subsection{Descriptive Statistics}

Table 1 provides basic descriptive statistics from our various different data sources. Column 1 gives sample means and standard deviations for our basic variables. Panel A focuses on our key left-hand side variables, while Panel B provides information on some of our right-hand side variables.

Columns 2-6 give a first glimpse of the source of variation we are going to focus on for much of our empirical analysis; they provide means and standard deviations by quartiles of the (exogenous) exposure to robots variable computed from the nine European economies described above. ${ }^{16}$ Two patterns are notable. First, differences in the levels of employment to population ratio in 1990 and hourly wage in 1990 between commuting zones at different quartiles of the exposure to robots variable are relatively small. ${ }^{17}$ Second and more importantly, from 1990 to 2007, commuting zones at these different quartiles show very different trends in employment and wages. Though these are not entirely monotone across quartiles, we can clearly see smaller increases in employment to population ratio and hourly wages in commuting zones at higher quartiles, indicating that employment and wages have declined in areas with greater exposure to robots compared to low exposure areas.

In Panel B, we see that there are some significant differences in other labor market variables for commuting zones that are highly exposed to robots. The share of employment in manufacturing in 1990 (and in particular in durable manufacturing) is much higher at higher quartiles; this is not surprising since the use of industrial robots outside manufacturing remains small, with few exceptions in agriculture, construction, mining, and research and development. We can also see the slight correlation between exposure to robots and exposure to Chinese imports, exposure to Mexican imports, the share of routine jobs and offshoring in Panel B, already depicted in Figure 3. Despite the weak correlation between exposure to robots and these measures, we will include them, as well as a variety of other demographic variables, on the right-hand side of our regression models in order to control for any confounding trends.

\footnotetext{
${ }^{16}$ In what follows, we drop the qualifier "exogenous" and refer to this variable as the exposure to robots. This should cause no confusion since we always refer to the "endogenous" exposure to robots as US exposure to robots.

${ }^{17}$ Throughout, we express changes in employment, employment to population ratio and wage growth in percentage points; so the number 0.294 in the third row of the first column, for example, means that employment to population ratio in the Census data increased by 0.29 percentage points between 1990 and 2007 .
} 


\subsection{First Stage}

Figure 5 provides a visual representation of our first-stage relationship in the form of a residual plot. The first stage, which will be used in our instrumental variables exercises and is shown in this figure, links the US exposure to robots to the (exogenous) exposure to robots computed from the European data. More precisely, our first stage takes the form

$$
\sum_{i \in \mathcal{I}} \ell_{c i}^{1990}\left(\frac{R_{i, 2007}^{U S}}{L_{i, 1990}^{U S}}-\frac{R_{i, 2004}^{U S}}{L_{i, 1990}^{U S}}\right)=\pi \sum_{i \in \mathcal{I}} \ell_{c i}^{1970}\left(p_{30}\left(\frac{R_{i, 2007}}{L_{i, 1990}}\right)-p_{30}\left(\frac{R_{i, 1993}}{L_{i, 1990}}\right)\right)+\Gamma X_{c, 1990}+\nu_{c}
$$

where $X_{c, 1990}$ is a vector of controls, and as noted above, $p_{30}$ denotes the 30 th percentile. Because we only measure the use of robots in the US from 2004 to 2007, but our outcomes and instrument span the whole 1990-2007 period, we convert the increase in robots per thousand workers between 2004 and 2007 in the US to a 17 -year equivalent change. ${ }^{18}$ The solid (black) line in this figure corresponds to the regression relationship with covariates as in column 4 of Table 2 below (with the shaded area around it showing the two-standard deviation error bands). The dashed (red) line depicts the same regression relationship when the top 1 percent of commuting zones with the highest exposure to robots is excluded from the regression (as in column 7 of Table 2).

Our first stage, shown in Figure 5, reflects the fact that there is a high level of correlation between the usage of robots by European industries and US industries. However, the crosssectional variation in the US exposure to robots measure relies on differences in the baseline distribution of employment across commuting zones rather than the actual number of robots per worker installed in each region. Ideally, we would use the change in the number of robots installed between 1990 (or 1993) and 2007 in each commuting zone as our endogenous regressor. Unfortunately, robots data at the commuting zone level are not available, but we can use the data on integrators compiled by Green Leigh and Kraft (2016) to verify that there is greater activity associated with more intensive robotic installation in areas where our (exogenous) exposure to robots variable takes a higher value.

This is done in Figure 6 and Table A2 in the Appendix. In the figure, we show the residual plot of the log of one plus the number of integrators in a commuting zone against our exposure to robots variable (as in Figure 5, after the covariates from our main specification in column 4 of Table 2 are partialled out). The dashed (red) line once again corresponds to this regression relationship after the commuting zones with the highest exposure to robots are excluded. In both

\footnotetext{
${ }^{18}$ Alternatively, we can pursue a two-sample IV strategy using the relationship between the 2004-2007 US exposure to robots and the 2004-2007 exogenous exposure to robots; this leads to similar but slightly larger estimates.
} 
cases we see a very strong association between our exposure to robots variable and the presence and number of integrators in a commuting zone. Table A2 shows that the same relationship holds and is strongly significant in the other specifications used in Table 2 and when we use the number of integrators on the left-hand side or estimate a Poisson count regression to model the behavior of the number of integrators. We interpret this relationship as indicating that there has been a pronounced increase in robots-related activity in commuting zones that are more exposed to robots according to our measure.

\section{$5 \quad$ Results}

In this section we present our main empirical results on employment and wages, and investigate their robustness.

\subsection{Baseline Results for Employment}

Table 2 presents our main results for employment. As our outcome variable, we use change in the employment to population ratio between 1990 and 2007. We end our sample in 2007 to avoid the potentially confounding effects of the Great Recession. ${ }^{19}$ As explained in the previous section, our main specifications use the (exogenous) exposure to robots between 1993 and 2007 on the right-hand side, and should thus be interpreted as the reduced-forms of equation (10). Throughout, unless stated otherwise, our main specifications are in changes and are weighted by the working-age population in a commuting zone in 1990; the standard errors are clustered at the state level and robust against heteroscedasticity. In addition, the models in Table 2 are for long differences and thus have one observation per commuting zone.

In Panel A, we focus on private employment from the Census, which comprises persons in salaried private-sector jobs, while Panel B looks at employment counts from the CBP. Though these two variables measure somewhat different concepts, our results are very similar with both (results with total employment to population ratio from the Census are also similar and are presented in Table A4). ${ }^{20}$

\footnotetext{
${ }^{19}$ Equation (10) has change in log employment on the left-hand side. We estimate exactly this relationship in Table A4, but opt for employment to population ratio as our baseline because it is the standard specification in the literature. Table A4 also shows that robots have no robust effect on population or migration.

In addition, Table A3 in the Appendix presents similar results for different sample periods, including 1990-2010, which spans the first three years of the Great Recession, and 1990-2014.

${ }^{20}$ Table A4 in the Appendix presents results using other employment outcomes, including all census employment to population ratio, log of census private employment counts, employment rate for working-age population, the unemployment rate for working-age population, the participation rate for working-age population, total hours of work, changes in population and net migration rates. The results are in line with those presented in the text,
} 
Column 1 presents our most parsimonious specification, which only includes Census division dummies as covariates. We estimate a strong negative relationship between the exposure to robots and employment changes in a commuting zone with a coefficient of -0.92 (standard error $=0.30)$ in Panel A. The same specification has a larger coefficient, -1.43 (standard error $=0.50$ ), in Panel B.

In column 2 we control for baseline differences in demographics in 1990. Specifically, we control for population; the share of working-age population (between 16 and 65 years); the share of population with college and the share of population with completed high school; and the share of Blacks, Hispanics and Asians. Since our model is in changes, this specification amounts to allowing for differential trends by these demographic characteristics. These controls reduce our coefficient estimates slightly to -0.78 in Panel A and -1.17 in Panel B.

In column 3, we also control for the baseline shares of employment in manufacturing, durable manufacturing and construction, as well as the share of female employment in manufacturing. These controls allow for differential trends by the baseline industrial structure of a commuting zone, and are meant to ensure that our exposure to robots variable does not capture possible secular declines in manufacturing or other sectoral trends. ${ }^{21}$ As expected from the fact that our measure of exposure to robots exhibits considerable variation within manufacturing, controlling for broad industry shares has a very small impact on our coefficient of interest, which now stands at -0.77 (standard error $=0.18$ ) in Panel $\mathrm{A}$ and -1.23 (standard error $=0.37$ ) in Panel B.

In column 4 we control for other labor market shocks that affected workers during our period of analysis: imports from China, imports from Mexico, the potential disappearance of routine jobs and offshoring. In particular, we control for a measure of exposure to imports from China between 1990 and 2007 (as in Autor, Dorn and Hanson, 2013), for exposure to imports from Mexico between 1991 and 2007, for the share of employment in routine jobs measured in 1990 (as in Autor Dorn and Hanson, 2015), and for a measure of offshoring of intermediate inputs (Feenstra and Hanson, 1999; and Wright, 2004). Consistent with the patterns shown in Figure 3, controlling for Chinese imports, Mexican imports, routine jobs and offshoring has little impact on our estimates; in Panel A, the coefficient on the exposure to robots declines slightly to -0.75 (standard error $=0.17$ ), while in Panel B it remains essentially unchanged at -1.31 (standard error $=0.35)$. The coefficients on the Chinese and Mexican import variables, routine jobs and

except that the results for unemployment, participation and total employment hours are less precise in some specifications.

${ }^{21}$ We control for the share of female employment in manufacturing because female employment in manufacturing has been on a much faster decline than total manufacturing employment since 1990, partially reflecting the disappearance of light manufacturing jobs. Leaving this variable out does not have an appreciable impact on our employment and wage results. 
offshoring variables are shown in Table A5 in the Appendix. ${ }^{22}$

Column 5 shows very similar results in an unweighted regression for the same specification as in column 4. In Panel A, this leads to a slightly larger estimate, -1.12 (standard error $=0.26$ ), while it has essentially no effect on the estimate in Panel B, which remains at -1.12 (standard error $=0.41)$.

Figure 7 provides residual regression plots for our specifications from column 4 in Panels A and B, with the regression estimate depicted with the solid (black) line. The presence of a number of commuting zones with very large changes in exposure to robots is evident from the figures. Most notably, the commuting zone including Detroit, Michigan, is the one with the greatest exposure to robots because of its large share of employment in automotive manufacturing - the industry with the largest increase in robots as we have seen in the previous section.

Columns 6 and 7 demonstrate that the negative relationship between exposure to robots and employment is not due to these commuting zones. Column 6 estimates the same relationship as in Column 4 using the robust regression procedure of $\mathrm{Li}$ (1985), which downweights both outliers and "cluster points" that have a disproportionate impact on the slope of the regression line. The relationship is similar to that shown in column 4. In column 7 we pursue another line of attack and exclude from the regression commuting zones with exposure to robots above the 99th percentile (a total of eight commuting zones, which are: Detroit, Michigan; Lansing City, Michigan; Saginaw City, Michigan; Defiance, Ohio; Lorain, Ohio; Muncie, Indiana Racine, Wisconsin; and Wilmington, Delaware). The coefficient estimates are again similar in Panel A and somewhat larger in Panel B. The dashed (red) line in Figure 7 depicts the estimate from column 7.

Panels A and B of Table 3 turn from long differences (a single change between 1990 and 2007 per commuting zone) to a specification with stacked differences (two changes of 10-year periods per commuting zone). Stacked-differences specifications are useful because they exploit the differential increase in robots across industries between the 1990s and 2000s, and also enable us to directly control for commuting zone-level trends in employment and wages. Panel $\mathrm{A}$ is for the Census (private) employment to population ratio, while Panel B is for the CBP employment to population ratio. For brevity, we omit the equivalents of columns 1 and 2 from Table 2. The

\footnotetext{
${ }^{22}$ Another potentially relevant variables is exports (or imports into the United States) from other advanced economies that are also rapidly adopting robots (in practice, Germany, South Korea and Japan), which might directly compete against high-exposure-to-robots industries in the United States. We prefer not to include this variable because it is likely to be mechanically correlated with our exposure to robots measure and thus is a "bad control". In any case, its inclusion does not have a major impact on our results as shown in Table A6 in the Appendix. For example, the equivalent of column 4 when this variable is included as well leads to a coefficient of -0.77 (standard error $=0.18$ ) in Panel A and of -1.31 (standard error $=0.35$ in Panel B.
} 
first five columns of this table are thus direct analogues of our long-differences specifications in Table 2, and they show not just similar qualitative results but point estimates that are close to those in Table 2 as well. Most importantly, column 6 now includes a full set of commuting zone fixed effects; this is equivalent to linear commuting zone trends in this change specification (something that would not be possible in the long-differences specifications of Table 2). Though this specification is very demanding and exploits a different source of variation, we find very similar estimates of the effect of robots on employment with both the Census and the CBP employment to population ratio variables. For example, the coefficient estimate for the Census variable in this case is -0.61 (standard error $=0.11$ ), while for the CBP variable it is -1.92 $($ standard error $=0.34)$.

\subsection{Baseline Results for Wages}

We next turn to the impact of robots on wages. Because robots affect employment, they are also likely to influence the composition of employed workers. To minimize the impact of such compositional changes, we estimate a variant of equation (10) that fully takes into account the differences in the observable characteristics of employed individuals. In particular, our estimating equation is now

$$
\ln W_{c g, 2007}-\ln W_{c g, 1990}=\beta^{W} \cdot \text { Exposure to robots } 1993-2007_{c}+\epsilon_{c g}^{W},
$$

where $W_{c g, t}$ is the hourly wage for workers in demographic group $g$ who reside in commuting zone $c$ at time $t$. We define 800 demographic cells by a combination of gender, age, education, race, birthplace and relation to the household head, so that the outcome $\ln W_{c g, 2007}-\ln W_{c g, 1990}$ is the wage change for workers with the same observable characteristics. ${ }^{23}$ Each demographic group is weighted by its size in that commuting zone in 1990, thus controlling for potential changes in the composition of employed workers between 1990 and 2007.

Our main wage results, with log hourly wages and log weekly wages, are reported in Panels $\mathrm{C}$ and D of Table 2. We find precisely-estimated, statistically significant, negative and fairly

\footnotetext{
${ }^{23}$ This specification is equivalent to a regression of log wages at the individual level in which we control for a full set of dummies for the 800 demographic cells. We present it and estimate it in its grouped form both because of continuity with our employment results and also because of the ease of implementing the regression in this form.

We have a total of 163,114 observations in these regressions, since more than a third of the 577,600 cells are empty (i.e., there are no workers with the specified combination of characteristics in the commuting zone). In Table A7 in the Appendix we show that the results are very similar for hourly wages in levels as well. This table also shows that estimating our employment models within these narrowly-defined demographic cells rather than on commuting zone-level data leads to very similar results.
} 
stable effects on wages in all seven columns. For instance, in our main specification in column 4, which controls for commuting zone demographic characteristics, industry shares, Chinese imports, Mexican imports, routine jobs and offshoring, we estimate a coefficient of -1.48 (standard error $=0.32$ ). The estimates in columns 1-3 are also similar. The coefficient estimate becomes slightly more negative when we downweight outliers in column 6 or exclude the commuting zones with the highest exposure to robots in column 7 . Figure 8 provides a residual regression plot of our results in columns 4 and 6 . The figure shows that outliers are not responsible for the negative and precisely-estimated relationship between exposure to robots and wages.

Panels $\mathrm{C}$ and D of Table 3 show estimates from the stacked differences specifications. The results are again comparable to the long-differences specifications, though somewhat more negative. For example, in our baseline specification reported in column 2, the coefficient estimate for $\log$ hourly wages is -1.92 (standard error $=0.37$ ), as compared to -1.48 in Table 2 . When we include commuting zone fixed effects in column 6 , the coefficient changes to -2.52 (standard error $=0.49)$.

\subsection{Two-Stage Least Squares Estimates}

So far, all of our estimates are reduced forms for equation (10). We next use our measure of the US exposure to robots to compute two-stage least squares estimates of $\beta^{L}$ and $\beta^{W}$.

Table 4 reports our IV estimates using the same seven specifications reported in Table 2. Panel A presents estimates for the first stage introduced in equation (15). The IV results for our baseline employment outcomes are reported in Panels B and C of Table 4, while those for wages are in Panels D and E. Because our first stage yields a coefficient of 2.03, the resulting IV estimates are half our reduced-form estimates shown in Tables 2. With the Census (private) employment to population ratio, our main long-differences specification, reported in column 4, gives a IV estimate of 0.37 which is once again highly significant (standard error $=0.11$ ). The results are similar in the other columns, ${ }^{24}$ and also for wages. For example, with the estimate for log hourly wages in column 4 of Panel D is -0.73 (standard error $=0.22$ ).

\subsection{Quantitative Magnitudes}

The implications of our estimates for local employment and wages - meaning the implications for a high exposure commuting zone relative to a low or zero exposure one - are straightforward to compute directly from our IV estimates. In particular, our baseline estimates from column

\footnotetext{
${ }^{24}$ In Table A8 in the Appendix, we also show standard two-stage least squares estimates for two shorter periods, 2004-2007 and 2004-2010, using the CBP data. The results are broadly similar to the IV estimates reported here.
} 
4 in Panels B and D of Table 4 imply that as a result of the US increase in robots adoption (approximately one more robot per thousand workers between 1993 and 2007), a commuting zone with a value of exposure to robots equal to the average for the United States experienced 0.37 percentage points lower employment to population ratio and 0.73 percent lower wage growth compared to a commuting zone with no exposure to robots. These numbers can also be expressed as one more robot reducing employment by 6.2 workers and one more robot per thousand workers reducing average yearly wages by about $\$ 200$ in the affected commuting zone. ${ }^{25}$ These are sizable effects, but as we explain, not implausible. Crucially, as we discuss further below, these numbers include both the direct effects of robots on employment and wages in a commuting zone and any indirect, spillover effects that might arise because of a resulting decline in local demand. ${ }^{26}$

The more challenging question is how much (and whether) employment and wages in the aggregate decline in response to the adoption of industrial robots. Let us first ignore any spillovers from local demand (which we will discuss after we present the effects of robots on different industries). If we also assume, unrealistically, that there is no trade between commuting zones, then the aggregate implications of robots are identical to the local estimates discussed in the previous paragraph - one more robot per thousand reducing aggregate employment to population ratio by 0.37 percentage points and average wages by 0.73 percent.

In contrast to this hypothetical benchmark, the relevant computation of the aggregate implications of robots should account for trade between commuting zones. As highlighted by our theoretical analysis, the commuting zones that adopt more robots will export their more cheaplyproduced output and indirectly create employment in other industries in the rest of the country. Though the impact of a commuting zone on the rest of the economy is multifaceted, we have also seen from equation (12) that, when $M_{i} \approx 0$ and $\pi_{c} \approx \pi$ so that there are only a few robots in the economy and robot prices relative to wages are not too different across commuting zones, the

\footnotetext{
${ }^{25}$ The increase of one more robot per thousand workers between 1993 and 2007 is equivalent to an increase of 120,000 robots over the same time period, or 0.6 robots per thousand people. Consequently, our estimates imply that these 0.6 robots per thousand people led to a 0.5 percentage points lower employment to population ratio, which is equivalent to one robot reducing employment by $6.2(=0.005 \times 1000 / 0.6)$ workers.

${ }^{26}$ These magnitudes can be compared to the size of the effects from exposure to imports from China. Table A5 in the Appendix shows that in our long-differences specification, the exposure to China variable has a negative but insignificant coefficient. However, in the stacked-differences specification, which corresponds to the one used in Autor, Dorn and Hanson (2013), it is negative and significant. Using this latter estimate, the implied quantitative magnitude from the national rise in Chinese imports for a commuting zone with the average exposure to Chinese imports (compared to a no exposure commuting zone) is a decline of roughly 1 percentage point in the employment to population ratio, which is about three times the 0.37 percentage points implied decline from the adoption of robots. The exposure to Mexican imports and offshoring variables are not significant in either the long-differences or the stacked-differences specifications. The share of employment in routine jobs in 1990 is significant, but there is not a comparable quantitative magnitude we can compute in this case.
} 
aggregate effects depend simply on the elasticity of labor supply $(1 / \varepsilon)$, the supply elasticity of robots $(1 / \eta)$, the physical productivity of labor relative to robots $(\gamma)$ and $\pi$. In what follows, we use our regression estimates and external information to discipline these parameters. We choose $\varepsilon=0.43$, which is the inverse of the macro extensive margin elasticity of labor supply (from Chetty et al., 2011). The use of the macro elasticity enables us to capture both the extensive margin of labor supply and any adjustment in employment resulting from wage rigidities or the availability of social programs such as disability or unemployment insurance. Next, we choose three parameters that do not directly matter in equation (12), but are relevant for pinning down the rest of the parameters from our regression coefficient estimates. These are: (1) $\sigma=1$ as the elasticity of substitution between different industries (e.g., Oberfield and Raval, 2014); (2) $\lambda=7$ for the elasticity of substitution between traded varieties, which follows the recent trade literature (e.g., Simonovska and Waugh, 2014; and Head and Meyer, 2015); and (3) the standard choice of $s_{c, L}=0.66$ for the initial value of the labor share in all commuting zones. Finally, we take the average value of the profitability of using industrial robots relative to labor, $\pi$ equal to 0.3 , which implies that adopting robots increases profits by about 30 percent relative to using labor. This estimate for $\pi$ is in line with the estimates in the recent report by the Boston Consulting Group, BCG (2015).

These parameter choices and our regression coefficient estimates together enable us to back out the relative physical productivity of labor as $\gamma=153$, and the inverse elasticity of supply of robots as $\eta=1.5 .{ }^{27}$ We next argue that both of these numbers are plausible. Our estimate for $\gamma$ implies that, on average, a robot performs work equivalent to $1000 / \gamma=6.5$ workers, which is in the range of estimates from the recent case studies (e.g., BCG, 2015). A value of $\eta=1.5$ corresponds to an elasticity of the supply of robots of about 0.66. Suppose that robots in a commuting zone are supplied by combining the services of local integrators (which are inelastic) and nationally supplied parts and materials (which are fully elastic to the commuting zone). Green Leigh and Kraft (2016) report the share of integrators to be about 2/3 and that of parts and materials as $1 / 3$, which implies an elasticity of robot supply of 0.5 , close to the value of 0.66 obtained from our estimates.

Using these numbers, we compute the aggregate employment and wage effects of robots from equation (12). Our baseline estimates are that one more robot reduces aggregate employment

\footnotetext{
${ }^{27}$ An alternative strategy would be to specify either $\gamma$ or $\eta$, and compute the implied value of $\pi$. Even though for the same parameter value choices, this strategy would lead to equivalent implications, we do not pursue it because, as we explain below, the implied aggregate effects are sensitive essentially only to changes in $\pi$, and we find it more transparent to show this clearly by varying $\pi$ directly rather than having it vary as a result of different choices for the other parameters.
} 
by about 5.6 workers (10 percent lower than the local effect), and one more robot per thousand workers reduces wages in the aggregate by about 0.5 percent (30 percent lower than the local effect). Though these aggregate effects are still quite large, they are broadly consistent with the rest of our results, which do not show significant offsetting employment increase in other industries and occupations within a commuting zone. Our estimates also imply a modest 0.13 percent increases in GDP from an increase of one robot per thousand workers.

These aggregate effects are not sensitive to reasonable variations in the values used for $\lambda, \sigma$ and $\varepsilon$. For example, reducing $\lambda$ to 5 or increasing it to 10 makes essentially no difference to the main conclusions. Similarly, reducing $\sigma$ to 0.5 , or increasing it to 2, also leaves the aggregate effects unchanged (in all of these cases the aggregate employment effect is a reduction of 5.6 workers for every robot and the aggregate wage effect remains about a 0.5 percent decline for every robot in thousand workers). The insensitivity of our quantitative magnitudes to different values of $\sigma$ and $\lambda$ is not surprising in view of the explicit expressions for aggregate effects in equation (12), where they do not directly appear, and the fact that the implied values for $\gamma$ and $\eta$ are not very sensitive to the values of these parameters. Even though the inverse of the Frisch elasticity, $\varepsilon$, directly appears in (12), reasonable variations in this parameter also have very little impact on the aggregate impact of robots. For example, reducing it to 0.35 , or increasing it to 0.5 , makes little difference (the former, for example, leads to slightly larger and the latter to slightly smaller wage declines in the aggregate, with very similar employment declines in both cases). In contrast, variations in $\pi$ - the cost-saving gains from the use of robots-lead to somewhat greater changes to our conclusions. For example, reducing $\pi$ to 0.1 makes the aggregate effects essentially the same as the local effects, while increasing $\pi$ to 0.5 reduces the aggregate effects to 4.65 fewer workers for every additional robot and 0.2 percent lower wages for every additional robot per thousand workers. This highlights that, given our estimates, the only way of reversing the conclusions about the negative aggregate effects of robots on employment and wages is to assume that robot adoption is very profitable, so that there are very large productivity effects that offset the significant displacement effects. Since cost savings of more than 50 percent are not just very large but beyond what any case study evidence we have found supports, we interpret the range of quantitative magnitudes reported above as broadly robust.

\subsection{Placebo Checks}

There are two main threats to our interpretation of our estimates as the causal impact of robots on employment and wages. First, the industries that have been adopting more robots over the last two decades (in the United States and Europe) could have already been on a downward 
trend. Second, the commuting zones that house the industries that are adopting more robots may be affected by other negative shocks. In either case, our estimates would confound the impact of the use of robots on labor markets with these pre-existing industry or commuting zone trends.

In Table 5 we address both issues through a series of placebo checks that show no pre-existing trends in employment or wages before 1990 in the commuting zones that were highly exposed to robots. ${ }^{28}$ Panel A presents estimates of our baseline equations for change in the employment to population ratio between 1970 and 1990 on the left-hand side to check whether trends before the onset of robots are still correlated with our exposure to robots measure. The columns in this table have an identical structure to those in Table 2. Our baseline specification in column 4 shows that the coefficient of robot exposure on past employment trends is a precisely estimated zero. The remaining specifications show no evidence of pre-existing trends in employment either, and yield small point estimates (the only exception is a negative coefficient in the unweighted specification in column 5 which is not precisely estimated). Panels B and C present analogous specifications for log hourly wages and log weekly wages. There is a negative and significant estimate in column 1 of Panel B, and negative and marginally significant estimates in column 2 of Panel B and column 1 of Panel C. However, once industry controls are included in columns 3 onwards, there is no evidence of either a negative or a positive pre-trend for wages in any of the specifications.

These results are also summarized in Figure 9, which presents the residual plots for employment to population ratio and log hourly wages from the specifications in columns 4 and 7 . The lack of a significant relationship before 1990 is clearly visible from this figure.

\subsection{Robustness Checks}

We now investigate the robustness of our employment and wage results to a range of different specifications and controls. For brevity, we focus on the reduced-form models using the (exogenous) exposure to robots variable.

As shown in Figure 4, from 1993 to 2007 the automobile industry has adopted considerably more robots than any other industry. Table 6 investigates the role of this sector by separating the exposure to robots coming from the automobile industry from the rest. As a result, the exposure to robots measure includes only variation coming from industries other than automobiles, while we include the exposure to robots from the automobile industry separately. The four panels in

\footnotetext{
${ }^{28}$ Because there is no natural placebo check with stacked differences, for these exercises we focus on the longdifferences specifications. Also because the CBP data do not go that far back, we focus on Census data for the placebo checks.
} 
this table are the same as in Table 2. The first three columns present the baseline, the unweighted and the outlier-robust specifications in long differences, while the next three columns are for the same specifications in stacked differences as in Table 3. In Panel A, with the Census (private) employment to population ratio, all six specifications lead to very similar estimates of the effects of robot exposure in the automobile industry and other industries to our baseline estimates in Tables 2 and 3. These estimates show that our baseline results are not driven by the automobile industry alone, and in fact, on the basis of these results, the effects of robots in the automobile industry and other sectors appear not to be appreciably different. The estimates in Panels $\mathrm{C}$ and D for hourly and weekly wages are also comparable to our baseline results. The only exceptions to this pattern are the long-differences estimates in columns 1 to 3 of Panel B, which use the CBP employment to population ratio as the dependent variable. In these specifications, the estimates of the impact of exposure to robots in other industries are not precise and no longer statistically significant at conventional levels, but they remain negative and similarly sized to our baseline estimates. (The exposure to robots in automobiles continues to be significant with coefficient estimates similar to the analogous specifications in Table 2.) However, in the next three columns when we turn to specifications with stacked differences, we find both variables to be significant with somewhat larger coefficients.

Overall, we interpret the results in this table as bolstering the interpretation that the patterns documented so far correspond to the effects of robots on the labor market, rather than a consequence of the potential decline of the automobile industry.

Several other robustness checks are reported in the Appendix. Table A10 shows that our results are robust to allowing for mean-reverting dynamics in employment and wages by including lagged dependent variables on the right-hand side of our specifications. Table A11 goes one step further and includes a very large set of covariates, ${ }^{29}$ and then applies the two-step lasso shrinkage method of Chernozhukov, Belloni and Hansen (2014). By maximizing an objective function that penalizes the use of additional covariates, this method selects the subset of covariates that best explain the variation in the dependent variable. We then compute our estimates controlling for the selected covariates. Reassuringly, the results from this exercise are very similar to those in our baseline specifications in Tables 2 and 3. Table A12 further shows that our long-differences results are robust to the inclusion of state-fixed effects.

Finally, recall that because the United States is at the 30th percentile of the overall adoption

\footnotetext{
${ }^{29}$ These covariates include all of our baseline covariates and lagged employment and participation levels, all of them interacted with Census division dummies and period dummies (in the stacked difference specification). These models allow the impact of covariates to vary across regions and over time, but disciplines the additional flexibility by penalizing the inclusion of additional covariates or interactions.
} 
of robots among advanced economies, we used the 30th percentile of the distribution of robots across European economies and combined this with employment shares in 1970 to construct our exposure to robots variable. Table A13 shows that the results are similar when we use baseline industry shares from 1990 instead of 1970, while Table A14 confirms that using other moments of this distribution (such as the mean, median or the 90th percentile) has no major effect on our results either. Overall, these tables show that the exact construction of our (exogenous) exposure to robots variable has little impact on our main results.

\subsection{Isolating the Impact of Robots}

Another threat to the interpretation of our estimates as capturing the effects of robots on employment and wages is that there may be concurrent changes impacting commuting zones in which exposure to robots is high. For example, industries that are adopting robots may also be increasing their capital intensity or investing much more in IT, which could have a direct impact on employment and wages. Though Figure 2 did not show a strong correlation between the adoption of robots and overall capitalintensity or IT capital, we cannot fully rule out such confounding changes. ${ }^{30}$

Table 7 takes a more direct approach by showing that controlling for a range of related trends has no impact on our estimates. Panel A directly controls for the role played by industries in decline (in terms of employment). More specifically, we construct a Bartik-style measure that interacts the national level decline in employment across the industries in the IFR data from 1970 to 1990 with the share of the commuting zone employment in that industry in 1990. The first three columns are for the Census (private) employment to population ratio, while the next three columns are for log hourly wages. Though the declining industries variable is negative and significant in a few specifications, the coefficient estimates for the exposure to robots variable hardly change from our baseline specifications. These results are thus encouraging for our interpretation that the exposure to robots variable is not proxying for declining industries.

Panels B and C turn to the question of whether some simultaneous industry-level changes could be responsible for some of the effects we estimate. To do this, we construct a Bartik-style measure of the percent increase in the capital stock (Panel B) and a measure of the change in computer usage at work per worker in each commuting zone (Panel C). We then include these variables together with our exposure to robots variable. ${ }^{31}$ In both cases, the inclusion of

\footnotetext{
${ }^{30}$ In light of our placebo checks in Table 5 which do not show any pre-trends, one might reason that any such concurrent changes might be a consequence of the adoption of robots (e.g., the adoption of robots inducing organizational changes and the adoption of other technologies).

${ }^{31}$ We construct this measure for the growth of total capital stock by combining data from the Bureau of Labor
} 
these variables has little effect on our estimates of the impact of robots. ${ }^{32}$ Also interestingly, these variables themselves are either not significant or when they are significant, they have a positive effect, which suggests that other types of capital equipment and even computers tend to increase the demand for labor. This result underscores the possibility - though certainly does not prove - that industrial robots might have a very different impact on employment and wages than other types of recent technologies.

\subsection{Effects on Men and Women}

Table 8 investigates the employment and wage effects by gender. For brevity, we focus on the same specifications as in Tables 6. Qualitatively, we see similar results for men and women - in all cases negative, precisely estimated and statistically significant at 1 percent or less. Quantitatively, however, the effects on employment for men are about 1.5-2 times larger than those for women. For example, with our baseline specification in long differences, shown in column 1 , the effect for men is -1.01 , while for women it is -0.52 . Interestingly, the wage effects are of comparable size for the two groups.

\subsection{Effects by Industry, Occupation, Education and Wage Percentile}

Figure 10 presents estimates of the effects of exposure to robots on employment in different industries. We present point estimates and confidence intervals from three specifications: two longdifferences specifications analogous to columns 4 and 6 in Table 2 and one stacked-differences specification analogous to column 2 in Table 3. We see that the effects of robots concentrate in manufacturing and especially in heavily-robotized industries, which include automobile manufac-

Statistics on the percent increase in the capital stock for three-digit industries together with the distribution of employment across these industries in a commuting zone.

The measure of computers per worker by commuting zone comes from the Harte-Hanks dataset, which is a private, establishment-level survey on technology use. It provides detailed information about specific technologies. For this study, there are 121,966 observations in 1990 and 473,091 in 2006 (see Doms and Lewis, 2006). We aggregate these data to the commuting-zone level by establishment location.

We have also experimented and obtained very similar results with Bartik-style measures of computer adoption based on the Harte-Hanks data aggregated at the industry level, CPS data on computer use at the industry level, and Bureau of Economic Analysis data on investments on IT at the industry level. These results can be found in Table A9 in the Appendix.

${ }^{32}$ That the inclusion of these variables does not change the coefficient on our exposure to robots variable is not surprising in view of the fact that they are not correlated with our measure once condition on the other covariates. For example, controlling for the covariates in our baseline specification in column 4 of Table 2, the correlation between our measure and the capital intensity measure is -0.13 , while the correlation between our measure and the computer measure is -0.03 . This lack of strong correlation between exposure to robots and these capital utilization and computer variables can also be seen in Figure 2, and is even more reassuring for our interpretation. 
turing, electronics, metal products, chemicals, pharmaceuticals, plastic, food, glass and ceramics (see Figure 4). We also see negative but smaller effects in construction, business services, wholesale, and services and retail. Only three sectors show positive effects in some specifications (but these effects are not consistent or robust). These are finance, the public sector and nonrobotized manufacturing, which includes recycling, basic metals, textiles, paper, furniture and transportation equipment other than automobiles.

Figure 11 presents analogous results for employment by occupation. We see negative effects of robots on essentially all occupations, with the exception of managers for which we estimate a zero effect in our baseline specification (though there are also negative effects in some other specifications as depicted in the figure). Predictably, the major categories experiencing substantial declines are routine manual occupations, blue-collar workers, operators and assembly workers, and machinists and transport workers. ${ }^{33}$

Figure 12 looks at the impact of robots on employment and wages in different education groups. ${ }^{34}$ We see negative employment and wage effects for workers with less than high school, with a high school degree, and with some college (this is true both for men and women). We also find a small and marginally significant negative effect on employment for workers with college, and no effect on employment and wages for workers with post-college degrees. We find it surprising that there is no positive effect on workers with more than a college degree. One interpretation, consistent with the results in Table 7 , is that, in contrast to other computerassisted technologies, industrial robots may not be complementing any well-defined group of workers in a local labor market.

Figure 13 turns to the effect of robots on the wage distribution. We summarize these effects parsimoniously by depicting the impact of our exposure to robots variable on different percentiles of the wage distribution in a commuting zone. Our results indicate that the negative effects of robots are concentrated in the bottom half of the distribution; as a result, we estimate that robots may have increased the 90-10 wage differential by as much as 1 percentage point between 1990 and 2007 (the overall increase in this differential during this time period is 12 percentage points).

\footnotetext{
${ }^{33}$ Some of the negative effects on non-manufacturing industries and professional and managerial occupations might reflect local demand spillovers as we discuss below.

${ }^{34}$ We do not look at wages by industry or occupation, since these are not natural labor markets, and any change in wages likely reflects (unobserved) compositional changes.
} 


\subsection{Total and Non-Labor Income}

Table 9 turns to various measures of total income and non-labor income from the Bureau of Economic Analysis and the IRS. Non-labor income is particularly interesting, since if our results are explained by some general downward trend in a commuting zone, we may expect a negative association with non-labor income. In contrast, if it is robots that are negatively affecting employment and wages, they should also benefit their owners and possibly capital holders. However, since the owners of robots and capital holders are unlikely to be located in the same commuting zones where robots are being installed, we should expect no significant effects on non-labor sources of income. This is the pattern we find in Table 9. Total income and wage income from the BEA (both in logs and levels) both decline between 1990 and 2007, but there is no negative effect on non-labor sources of income. The bottom three panels show very similar results with the IRS data. Overall, these results show that the effects of robots are felt exactly where they should be, in labor income, with no effects on non-labor incomes.

\subsection{Back to Quantitative Magnitudes}

We conclude our analysis by returning to the quantitative magnitudes discussion. Figure 10 shows that there are negative effects beyond industries with the highest exposure to robots. In particular, we see lower employment in construction, business services, wholesale, and service and retail. A possible reason for these negative effects is that the decline in employment in industries that are adopting the robots may have depressed local demand and spilled over into a contraction in employment in other industries (e.g., as conjectured by Mian and Suf, 2014). Though such negative demand effects may also be present at the national level, as a more conservative estimate of the aggregate employment and wage effects of robots, we now carry out an alternative computation of quantitative magnitudes that leaves out these potential demand spillovers. To do this, we only take the employment decline in the heavily-robotized manufacturing as a share of the population, which is 0.2 percentage points (as opposed to the 0.37 percentage point decline for the total employment to population ratio in column 4 of Table 2). There is, however, no obvious way of purging the wage effects from these local demand spillovers without estimating the underlying structural parameters.

We therefore proceed by choosing a range of parameters, and then also compute the portion of wage effects due to these local spillovers using the structure of our model of cross-commuting zone trade. Specifically, we choose the same parameter values, $\varepsilon=0.43, \sigma=1, \lambda=7, s_{c, L}=0.66$, and $\pi_{c}=0.3$, but also impose $\eta=1.5$, which was estimated from the employment and wage effects in our previous quantitative magnitudes computations. This only leaves $\gamma$ as the unspecified 
parameter. Using the extent of employment decline in the heavily-robotized industries in an

affected commuting zone, $\beta^{L}=0.002$, we can compute the implied value of $\gamma$ as 300 - which implies that every robot can perform the same amount of tasks as 3.3 workers. This is half the replacement rate we obtained above when we estimated $\gamma$ to match the entire decline in employment in a commuting zone (this number is also in the range of estimates from recent case studies reported in BCG, 2015, but we find it somewhat more plausible than the implied value of $1000 / \gamma=6.5$ when we do not take potential local demand spillovers into account).

Armed with these parameters, we can then decompose the total decline in wages as follows: 50 percent of the decline is due to the direct effects of robots and the remaining 50 percent is due to local demand spillovers. Combining these numbers with our trade model and assuming that local demand spillovers will not translate into aggregate effects, we obtain highly conservative, alternative estimates of the aggregate employment and wage consequences of robots. These are: one more robot per thousand workers in the economy reduces aggregate employment population ratio by 0.18 percentage points and aggregate wages by 0.25 percent (or equivalently, one worker reduces employment by 3 workers)

Overall, our summary of the quantitative magnitudes implied by our analysis is that one more robot reduces employment in a commuting zone with the average exposure to robots by 6.2 workers and one more robot per thousand employees reduce wages in such a commuting zone by about 0.73 percent (relative to a commuting zone with no exposure). Translating this into aggregate effects requires a range of assumptions, and our best-case range puts these aggregate effects between 3 and 5.6 workers losing their jobs as a result of the introduction of one more robot in the national economy, and wages declining between 0.25 percent to 0.5 percent as a result of one more robot per thousand employees.

\section{Concluding Remarks}

Automation, robots and artificial intelligence are having an arguably transformative effect on labor markets in the United States and perhaps in many other advanced economies. Robots, in particular industrial robots, are anticipated to spread rapidly in the next several decades and assume tasks previously performed by labor. These momentous changes are accompanied by concerns about the future of jobs and wages. Nevertheless, there is relatively little work on the equilibrium effects of new technologies and especially of robots on labor market outcomes.

In this paper, we estimate the impact of industrial robots on employment and wages in the United States between 1990 and 2007 on US local labor markets. We start with a simple task-based model in which robots compete against human labor in the production of different 
tasks. In this model, both with and without trade between labor markets, robots may have a positive or negative effect on employment and wages. Their positive impact comes from the productivity effect, while their negative impact is due to the direct displacement of workers by robots. More importantly for our purposes, we demonstrate that in this class of models, the local labor market effects of robots can be estimated by regressing the change in employment and wages on the exposure to robots in each local labor market - where the exposure to robots is defined as the sum over industries of the local fraction of the workforce in an industry times the national penetration of robots into that industry.

Our empirical work, in addition to utilizing these equations, attempts to exploit the exogenous component of the exposure to robots, coming from the technological frontier (as proxied by trends other advanced economies). This enables us to purge the exposure to robots variable from potentially endogenous trends reflecting other industry-level developments in the US economy that may also be correlated with robot usage. Using this methodology and proxying local labor markets with commuting zones, we estimate large and robust negative effects of robots on employment and wages. We show that commuting zones most affected by robots in the post-1990 era were on similar trends to others before 1990, and that the impact of robots is distinct and only weakly correlated with the prevalence of routine jobs, the impact of imports from China, imports from Mexico, offshoring, other computer technology, and total capital stock. If there were no trade between commuting zones, our estimates would imply that each additional robot per thousand workers reduces aggregate employment to population ratio by 0.37 percentage points and aggregate wages by about 0.73 percent. If we factor in trade between commuting zones, our estimates instead imply somewhat smaller magnitudes: one additional robot per thousand workers now reduces aggregate employment to population ratio by 0.34 percentage points and aggregate wages by 0.5 percent. If, in addition, we focus only on declines in employment in heavily-robotized manufacturing, and presume that employment losses in other sectors are due to local demand and will not directly translate into national effects, these effects can be as low as 0.18 percentage points for employment and 0.25 percent for wages.

Because there are relatively few robots in the US economy, the number of jobs lost due to robots has been limited so far (ranging between 360,000 and 670,000 jobs, equivalent to a 0.180.34 percentage point decline in the employment to population ratio). However, if the spread of robots proceeds as expected by experts over the next two decades (e.g., Brynjolfsson and McAfee, 2012, especially pp. 27-32, and Ford, 2016), the future aggregate implications of the spread of robots could be much more sizable. For example, BCG (2015) offers two scenarios for the spread of robots over the next decade. In their aggressive scenario, the world stock 
of robots will quadruple by 2025. This would correspond to 5.25 more robots per thousand workers in the United States, and with our estimates, it would lead to a 0.94-1.76 percentage points lower employment to population ratio and 1.3-2.6 percent lower wage growth between 2015 and 2025. Their more conservative scenario involves a less than threefold increase in the stock of robots, and would correspondingly have a more modest impact (a reduction of 0.541 percentage point decline in the employment to population ratio and $0.75-1.5$ percent lower wage growth). Crucially, however, any such extrapolation should acknowledge that some of the general equilibrium effects working through technology might emerge only slowly (Acemoglu and Restrepo, 2016), and the response of employment and wages may be different once the number of robots exceeds a critical threshold.

We view our paper as a first step in a comprehensive evaluation of how robots will affect, and are already affecting, the labor market equilibrium. It is indeed only a first step, because our methodology directly estimates only the effect of robots on employment in a commuting zone relative to other commuting zones that have become less exposed to robots. We then used the structure of a model of trade between commuting zones to infer the aggregate effects of robots. Alternative strategies of estimating the aggregate implications of the spread of robots, either by focusing on cross-country comparisons or by directly or indirectly measuring the flows of goods across local labor markets, would be obviously highly complementary to this approach. Also missing from our study is any technological response to the changes in factor prices resulting from the introduction of robots (e.g., the creation of new labor-intensive tasks as in Acemoglu and Restrepo, 2016). Nonetheless, we do believe that our methodology's ability to estimate withinlabor market responses, which include the creation of jobs in other industries and occupations, is an important advantage, and any national or more comprehensive analysis of the effects of robots will have to start from such local equilibrium impacts. In this respect, we believe as well that the negative effects we estimate are both interesting and perhaps somewhat surprising, especially because they indicate a very limited set of offsetting employment increases in other industries and occupations.

\section{REFERENCES}

Acemoglu, Daron, David Autor and David Lyle (2004) "Women, War, and Wages: The Effect of Female Labor Supply on the Wage Structure at Midcentury," Journal of Political Economy, 112(3): 497-551.

Acemoglu, Daron and David Autor (2011) "Skills, tasks and technologies: Implications for employment and earnings," Handbook of Labor Economics, 4: 1043-1171. 
Acemoglu, Daron , Philippe Aghion, Claire Lelarge, John Van Reenen and Fabrizio Zilibotti (2007) "Technology, Information and the Decentralization of the Firm," The Quarterly Journal of Economics 122(4): 1759-1799.

Acemoglu, Daron and Pascual Restrepo (2016) "The Race Between Machine and Man: Implications of Technology for Growth, Factor Shares and Employment" NBER Working Paper No. 22252.

Anderson, James (1979) "A Theoretical Foundation for the Gravity Equation," Anerican Economic Review, 69(1): 106-160.

Arntz, Melanie, Terry Gregory, and Ulrich Zierahn (2016) "The Risk of Automation for Jobs in OECD Countries," OECD Social, Employment and Migration Working Papers, No. 189, OECD

Armington, Paul S. (1969) "A Theory of Demand for Products Distinguished by Place of Production," Staff Papers International Monetary Fund, 16(1): 159-178.

Autor, David H. and David Dorn (2013) "The Growth of Low-Skill Service Jobs and the Polarization of the U.S. Labor Market," American Economic Review, 103(5): 1553-97.

Autor, David H., David Dorn, and Gordon H. Hanson (2013) "The China Syndrome: Local Labor Market Effects of Import Competition in the United States." American Economic Review 103(6): 2121-68

Autor, David H., David Dorn, \& Gordon H. Hanson (2015) "Untangling Trade and Technology: Evidence from Local Labor Markets," Economic Journal, 125(584): 621-646.

Autor, David H., Frank Levy and Richard J. Murnane (2003) "The Skill Content of Recent Technological Change: An Empirical Exploration," The Quarterly Journal of Economics, 118(4): 1279-1333.

Bartel, Ann, Casey Ichniowski, and Kathryn Shaw "How Does Information Technology Affect Productivity? Plant-Level Comparisons of Product Innovation, Process Improvement, and Worker Skills," The Quarterly Journal of Economics, 122(4): 1721-1758.

Beaudry, Paul , Mark Doms, and Ethan Lewis (2006) "Endogenous Skill Bias in Technology Adoption: City-Level Evidence from the IT Revolution," NBER Working Paper No. 12521.

Bloom, Nicholas, Mirko Draca, and John Van Reenen (2016) "Trade Induced Technical Change? The Impact of Chinese Imports on Innovation, IT and Productivity," The Review of Economic Studies, 83(1): 87-117.

Boston Consulting Group (2015) "The Robotics Revolution: The Next Great Leap in Manufacturing." 
Burstein, Ariel, Gordon Hanson, Lin Tian and Jonathan Vogel (2017) "Tradability and the Labor-Market Impact of Immigration: Theory and Evidence from the U.S." Mimeo, UCLA.

Brynjolfsson, Erik and Andrew McAfee (2014) The Second Machine Age: Work, Progress, and Prosperity in a Time of Brilliant Technologies, W. W. Norton \& Company.

Caliendo, Lorenzo and Fernando Parro (2015) "Estimates of the Trade and Welfare Effects of NAFTA," The Review of Economic Studies, 82(1):1-44.

Caroli, Eve, and John Van Reenen (2001) "Skill Biased Organizational Change? Evidence from a Panel of British and French Establishments." Quarterly Journal of Economics, 116(4): 1449-92.

Doms, Mark and Ethan Lewis (2006) "Labor Supply and Personal Computer Adoption," Federal Reserve Bank of San Francisco Working Paper 2006-18.

Goos, Maarten, and Alan Manning (2007) "Lousy and Lovely Jobs: The Rising Polarization of Work in Britain," The Review of Economics and Statistics, 89(1): 118-133.

Green Leigh, Nancey and Benjamin Kraft (2016) "Local Economic Development and the Geography of the Robotics Industry," Mimeo, Georgia Tech.

Graetz, Georg and Guy Michaels (2015) "Robots at Work," CEP Discussion Paper No 1335.

Feenstra, Robert C., and Gordon H. Hanson (1999) "The Impact of Outsourcing and High-Technology Capital on Wages: Estimates for the United States, 1979?1990." The Quarterly Journal of Economics 114(3): 907-940.

Ford, Martin (2015) The Rise of the Robots, Basic Books, New York.

Frey, Carl B. and Michael A. Osborne (2013) "The Future of Employment: How Susceptible are Jobs to Computerisation?" Mimeo. Oxford Martin School.

Gregory, Terry, Anna Salomons, and Ulrich Zierahn (2016) "Racing With or Against the Machine? Evidence from Europe," ZEW - Centre for European Economic Research Discussion Paper No. 16-053

Head, Keith and Thierry Mayer (2014) "Gravity Equations: Workhorse, Toolkit, and Cookbook." Handbook of International Economics 4: 131.

International Federation of Robotics (2014) Wold Robotics: Industrial Robots.

Jägger, Kirsten (2016) "EU KLEMS Growth and Productivity Accounts 2016 release Description of Methodology and General Notes."

Katz, Lawrence F., and Kevin M. Murphy (1992) "Changes in Relative Wages, 19631987: Supply and Demand Factors." The Quarterly Journal of Economics, 107(1): 35-78. 
Keynes, John Maynard (1930) "Economic Possibilities for our Grandchildren," Chapter in Essays in Persuasion.

Leontief, Wassily (1952) "Machines and Man," Scientific American.

Li, Guoying (1985) "Robust Regression," in Exploring Data Tables, Trends, and Shapes, pp. 281-343.

Michaels, Guy, Ashwini Natraj and John Van Reenen (2014) "Has ICT Polarized Skill Demand? Evidence from Eleven Countries over Twenty-Five Years," Review of Economics and Statistics, 96(1): 60-77.

Moretti, Enrico (2011) "Local Labor Markets," Handbook of Labor Economics, Elsevier.

Ruggles, Steven, Matthew Sobek, Trent Alexander, Catherine A. Fitch, Ronald Goeken, Patricia Kelly Hall, Miriam King, and Chad Ronnander (2010) "Integrated Public Use Microdata Series: Version 3.0 [Machine-readable database]." Minneapolis, Minnesota Population Center.

Simonovska, Ina, and Michael E. Waugh (2014) "The elasticity of trade: Estimates and evidence" Journal of international Economics 92(1): 34-50.

Tolbert, Charles M., and Molly Sizer (1996) "US Commuting Zones and Labor Market Areas: A 1990 Update." Economic Research Service Staff Paper 9614.

World Bank (2016) World Development Report 2016: Digital Dividends.

Wright, Greg C. (2014) "Revisiting the Employment Impact of Offshoring," European Economic Review 66:63-83. 


\section{Figures AND TABLES}

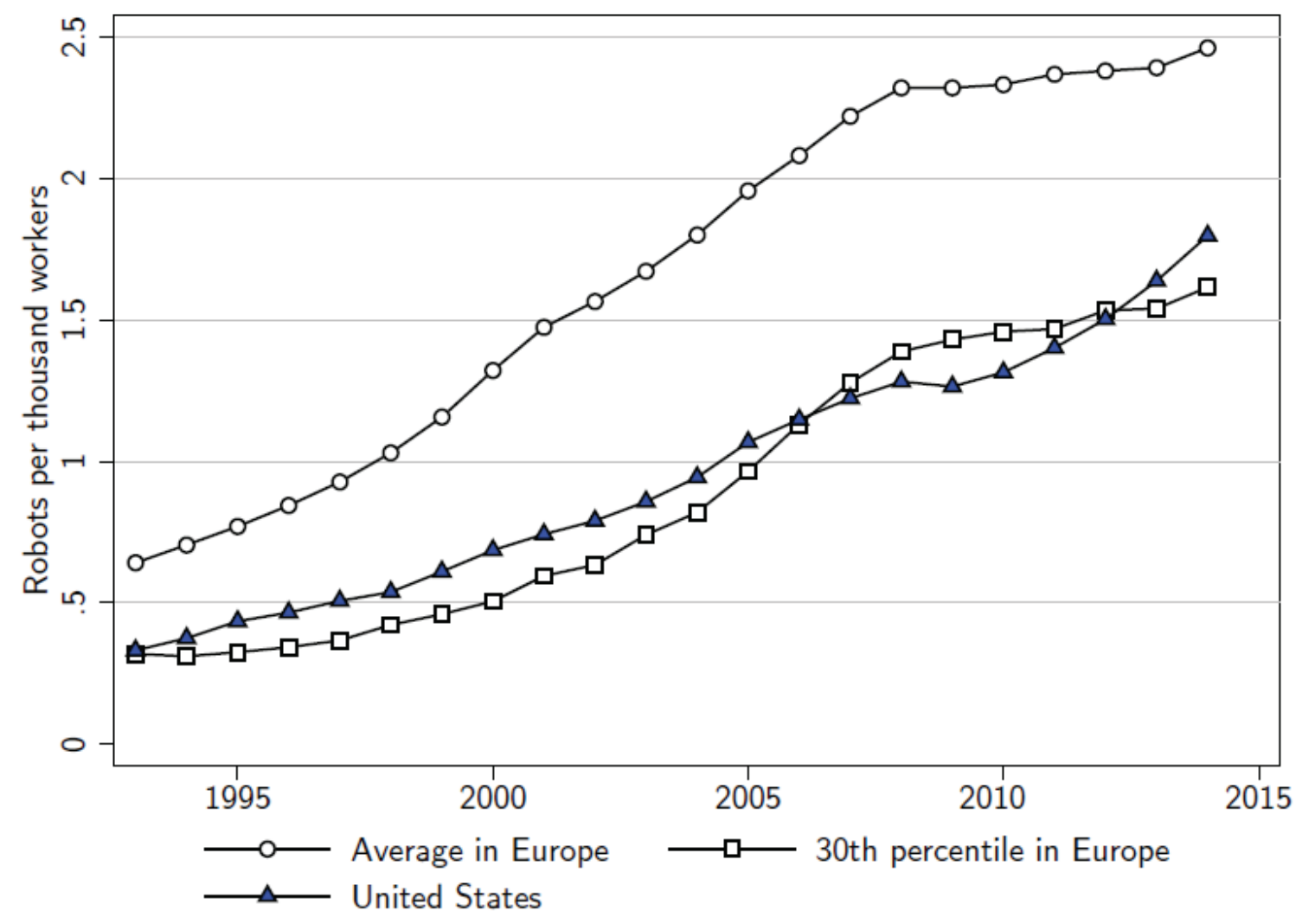

Figure 1: Industrial robots in the United States and Europe.

Note: Industrial robots per thousand workers in the United States and Europe. Data from the International Federation of Robotics (IFR). 


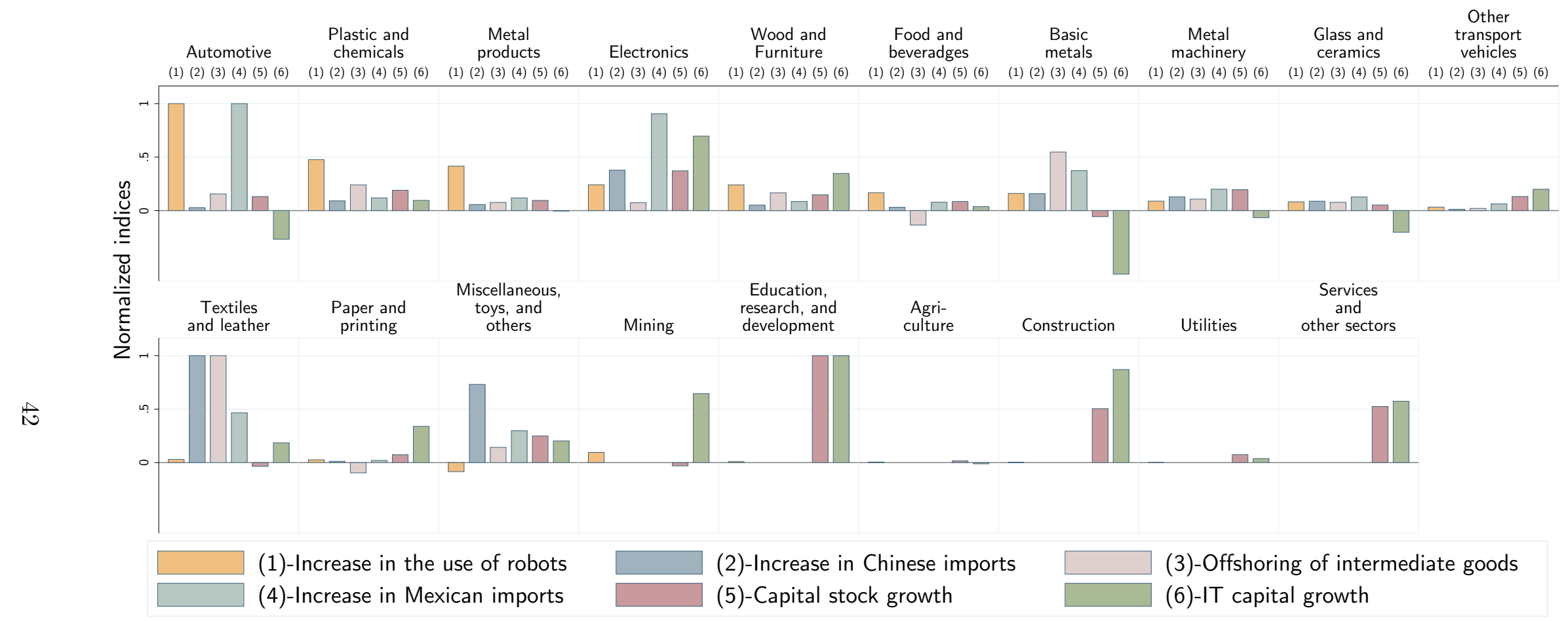

Figure 2: Industry-level Changes in the use of robots, Chinese imports, Capital stock and IT CAPital.

Note: This figure plots the increase in the number of robots per thousand workers between 1993 and 2007, the increase in the dollar value of Chinese imports per worker between 1990 and 2007, the growth of the capital stock between 1990 and 2007, and the growth of the stock of IT capital between 1990 and 2007 for the 19 industries for which we have the IFR data. 

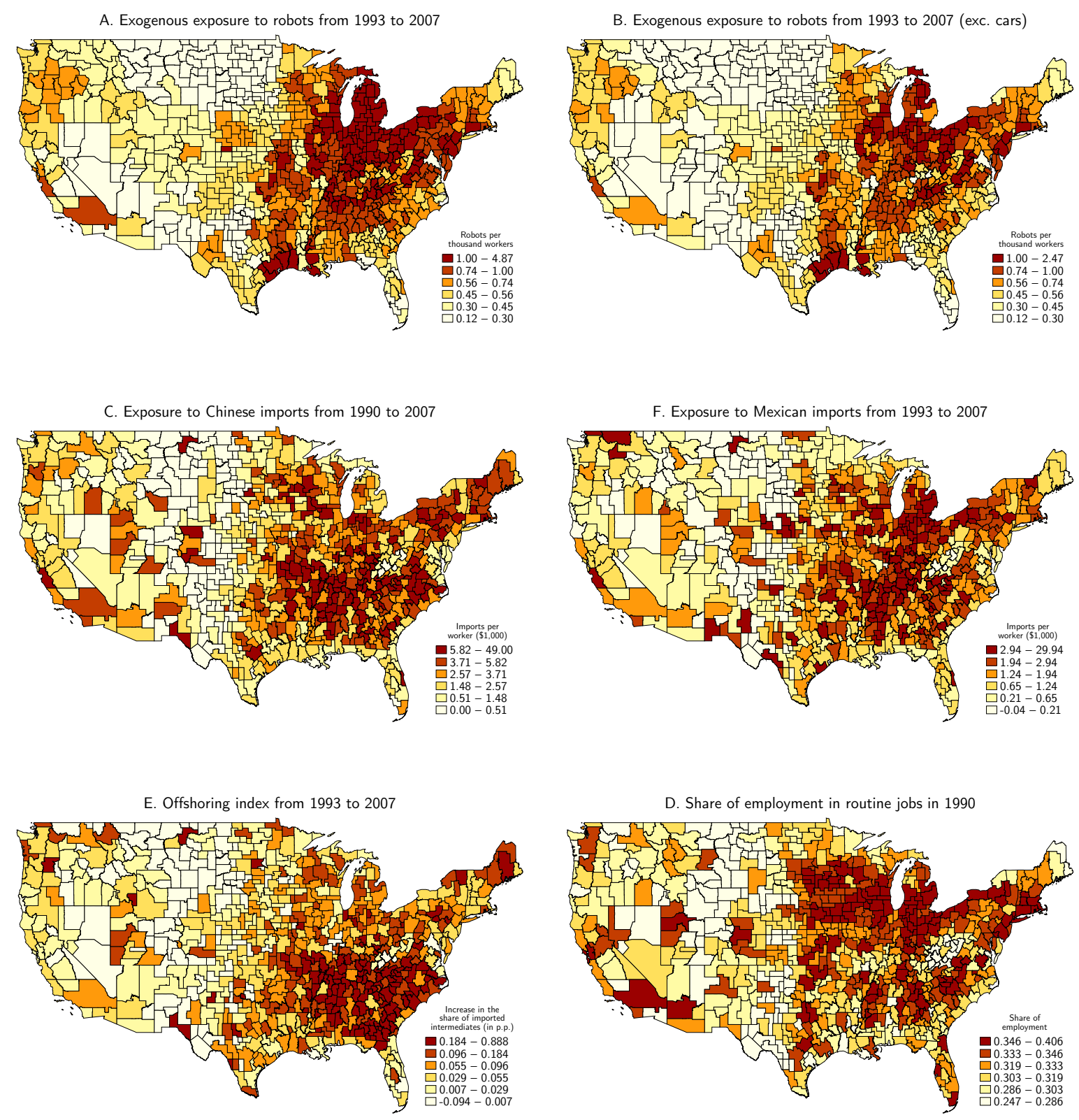

Figure 3: Geographic distribution of the exposure to robots, the exposure to Chinese imports, MEXICAN IMPORTS, ROUTINE JOBS, AND THE EXPOSURE TO OFFSHORING.

Note: The maps depict the distribution of our exposure to robots variable (both with and without the exposure resulting from automotive manufacturing), the exposure to Chinese imports from 1990 to 2007 (from Autor, Dorn and Hanson, 2013), the exposure to Mexican imports from 1991 to 2007, the share of employment in routine jobs (as defined in Autor, Dorn, and Hanson, 2015), and the exposure to the offshoring of intermediate inputs from 1993 to 2007 (from Feenstra and Hanson, 1999, and extended by Wright, 2014). The population-weighted correlation between exposure to robots and the exposure to Chinese imports is 0.049 (and - 0.0518 conditional on the covariates included in column 3 of Table 2). The population-weighted correlation between the exposure to robots and exposure to Mexican imports is 0.43 (and 0.26 conditional on the covariates included in column 3 of Table 2). The population-weighted correlation between exposure to robots and the share of routine jobs is 0.28 (and 0.11 conditional on the covariates included in column 3 of Table 2). The population-weighted correlation between exposure to robots and the exposure to offshoring is 0.054 (and -0.002 conditional on the covariates included in column 3 of Table 2). 

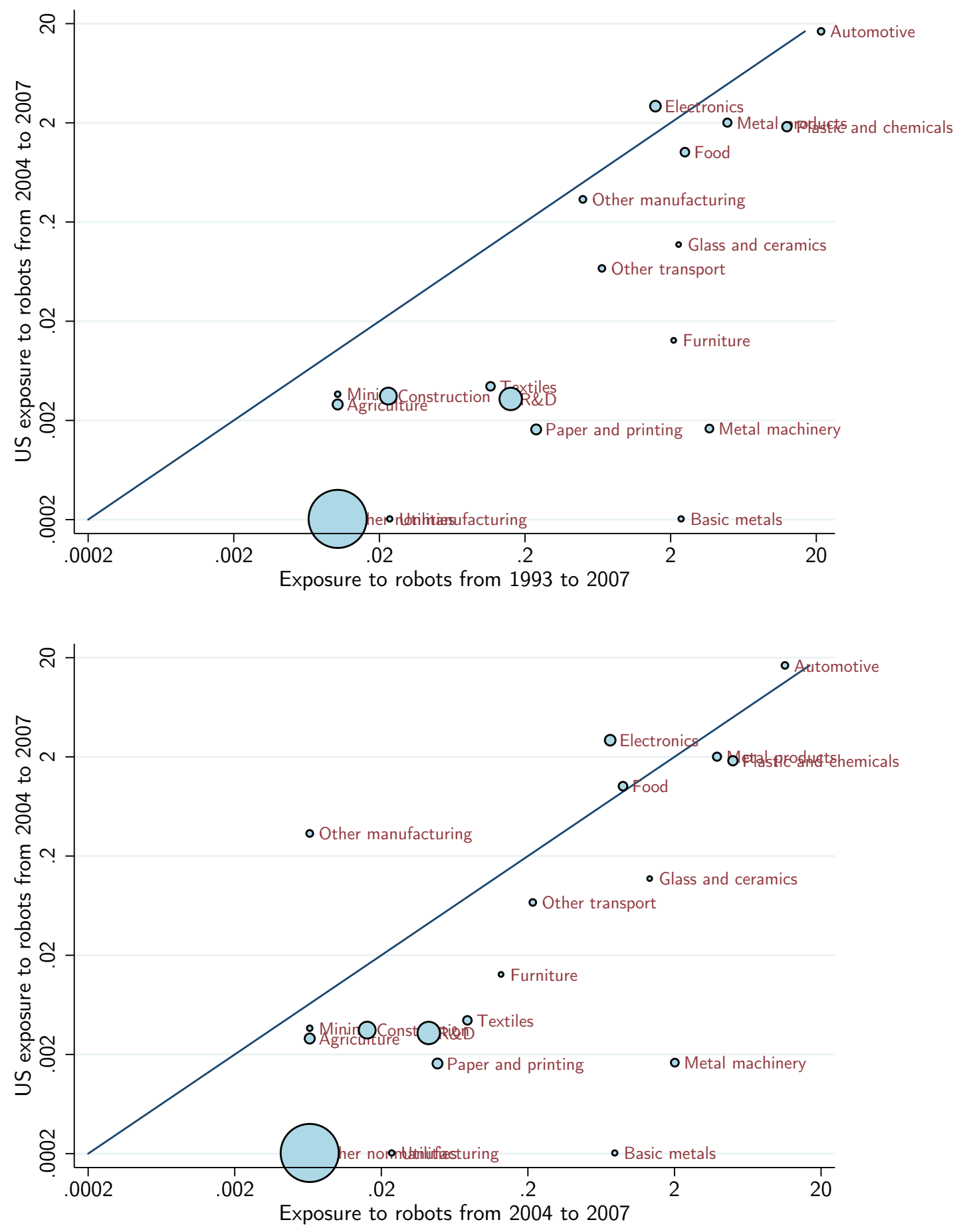

Figure 4: The relationship between robots adoption in Europe and the United States.

Note: The top panel gives the scatter plot of the change in the number of robots per thousand workers in Europe between 1993 and 2007 and in the United States between 2004 and 2007. The bottom panel shows the same relationship using the change in the number of robots per thousand workers in Europe between 2004 and 2007. The solid line corresponds to the $45^{\circ}$ line. Marker size indicates the share of US employment in the corresponding industry. 


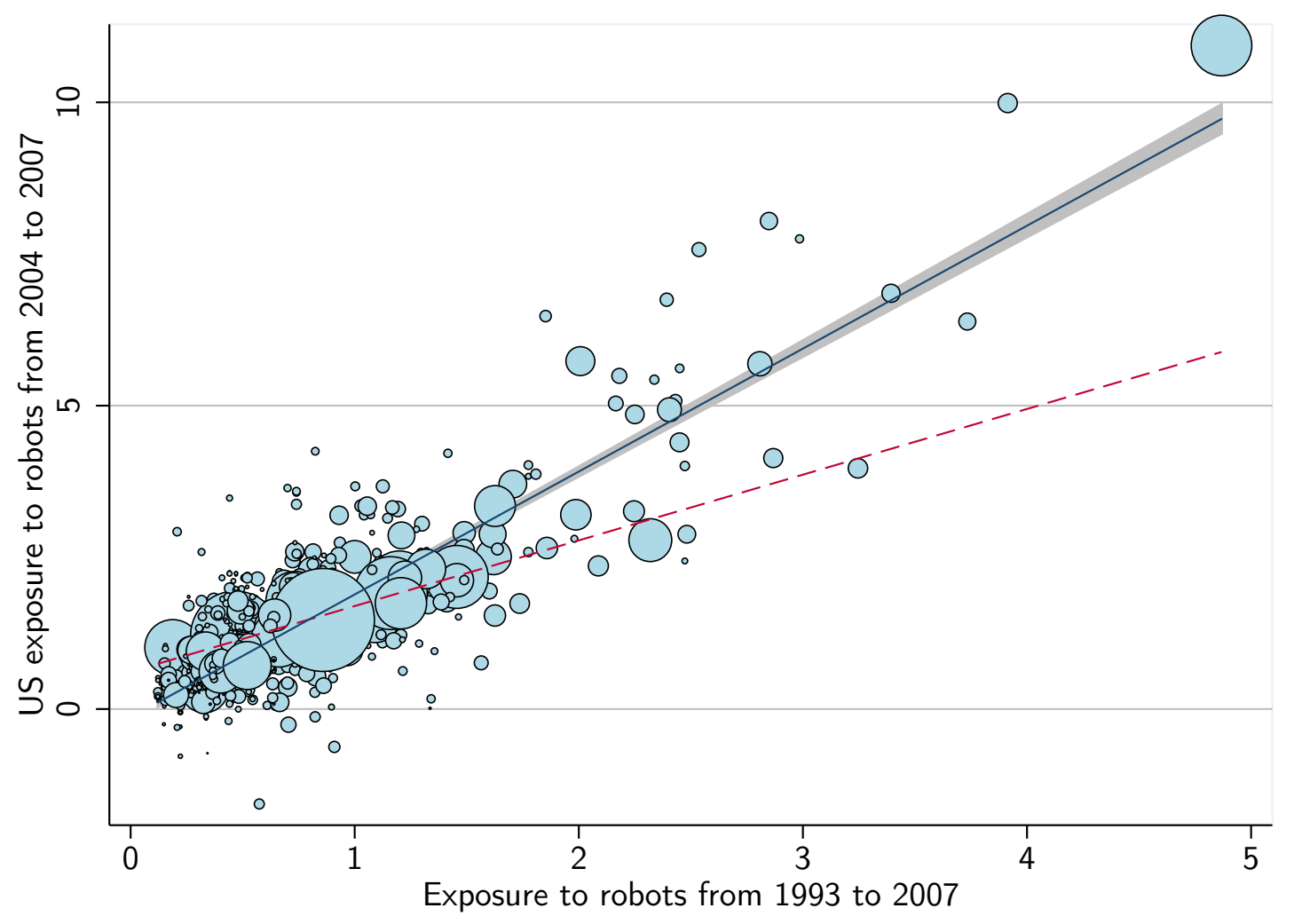

Figure 5: First-Stage Relationship.

Note: The figure shows the residual plot of US exposure to robots between 2004 and 2007 (converted to a 17-year equivalent change) against the exposure to robots between 1993 and 2007 after the covariates in column 4 of Table 2 have been partialled out. The solid line shows the regression coefficient from a weighted regression with commuting zone working-age population in 1990 as weights (coefficient $=2.026$, standard error $=0.275$ ). The dotted (red) line shows the weighted regression coefficient after the top $1 \%$ of the commuting zones with the highest exposure to robots is excluded (coefficient $=1.083$, standard error $=0.135$ ). Marker size indicates the share of the 1990 US working age population in the corresponding commuting zone. 


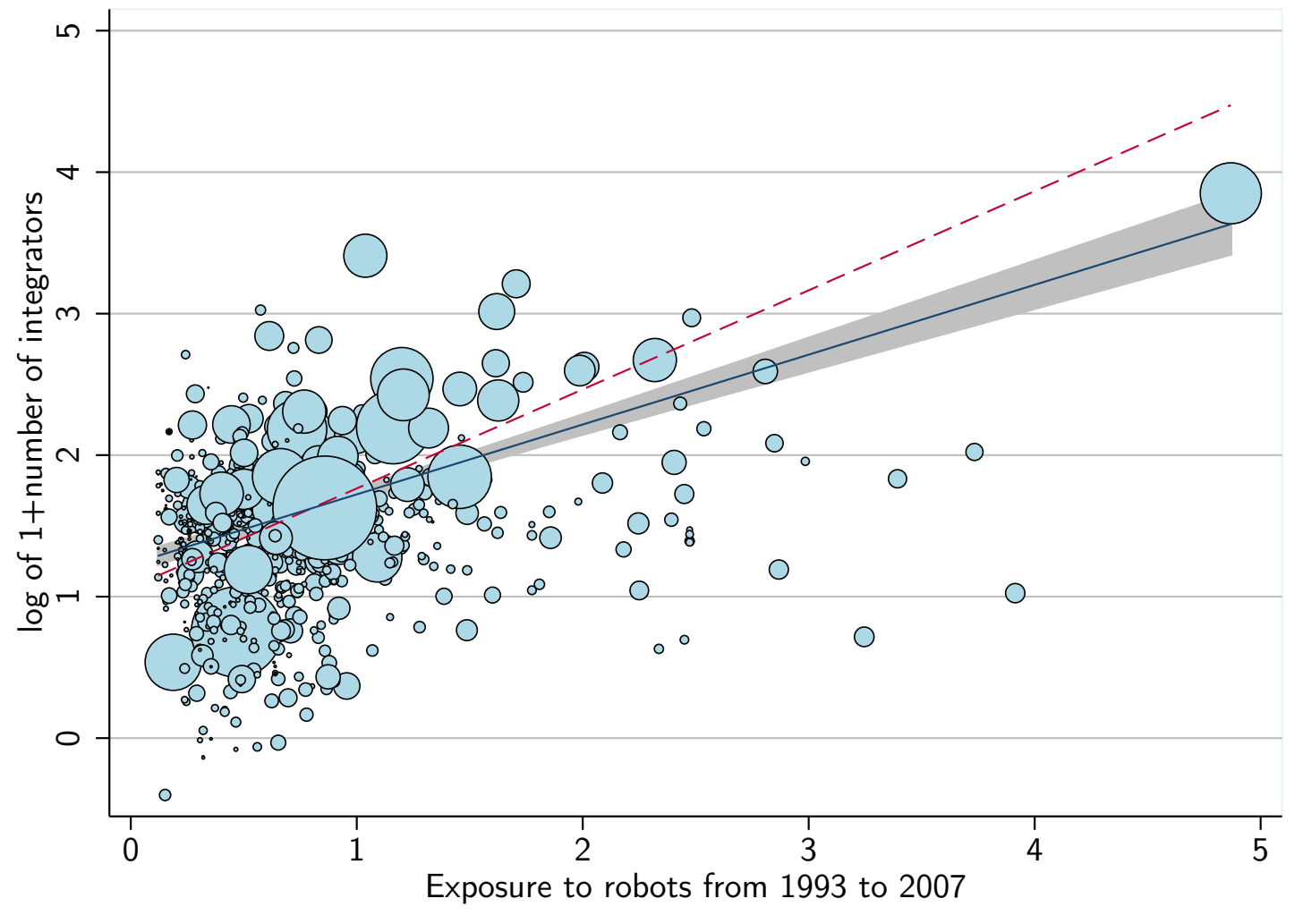

Figure 6: Relationship BetweEn the EXPOSURE to Robots AND THE NUMBer of Robot INTEGRATORS.

Note: The figure shows the residual plot of the log of one plus the number of integrators in a commuting zone against the exposure to robots between 1993 and 2007 after the covariates in column 4 of Table 2 have been partialled out. The data on the location of robot integrators - the companies that program and adapt robots for a given industrial application - is from Green Leigh and Kraft (2016). The solid line shows the regression coefficient from a weighted regression with commuting zone working-age population in 1990 as weights (coefficient $=0.501$, standard error $=0.072$ ). The dotted (red) line shows the weighted regression coefficient after the top $1 \%$ of the commuting zones with the highest exposure to robots is excluded (coefficient $=0.681$, standard error $=0.142$ ). Marker size indicates the share of the 1990 US working age population in the corresponding commuting zone. 

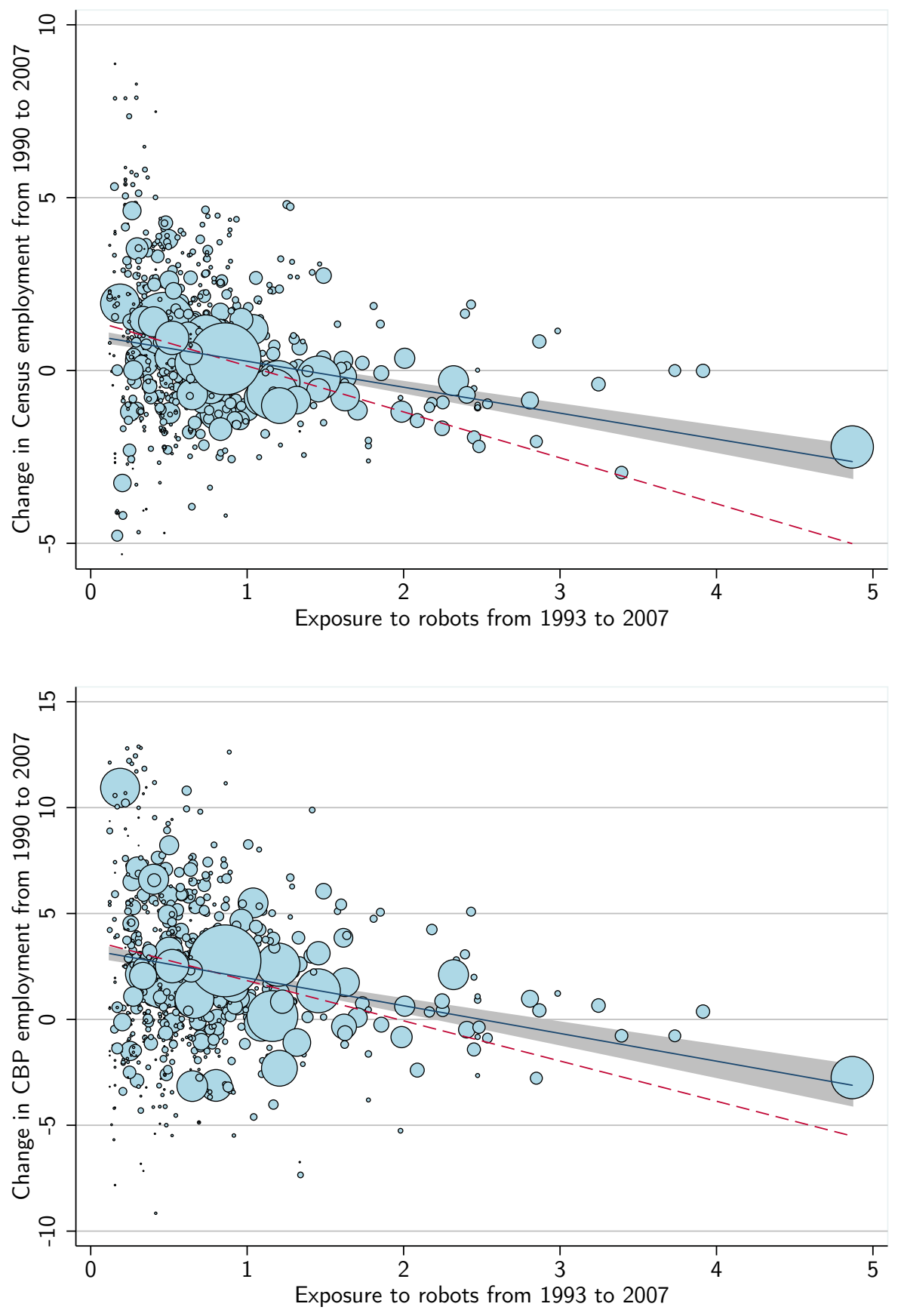

Figure 7: Relationship Between the exposure to Robots and EMPloyment.

Note: The figure shows the residual plot of the change in the employment to population ratio (Census private employment in the top panel; CBP employment in the bottom panel) against the exposure to robots between 1993 and 2007 after the covariates in column 4 of Table 2 have been partialled out. In both panels, the solid line shows the regression coefficient from a weighted regression with commuting zone working-age population in 1990 as weights. The dotted (red) line shows the weighted regression coefficient after the top $1 \%$ of the commuting zones with the highest exposure to robots is excluded. Marker size indicates the share of the 1990 US working age population in the corresponding commuting zone. 

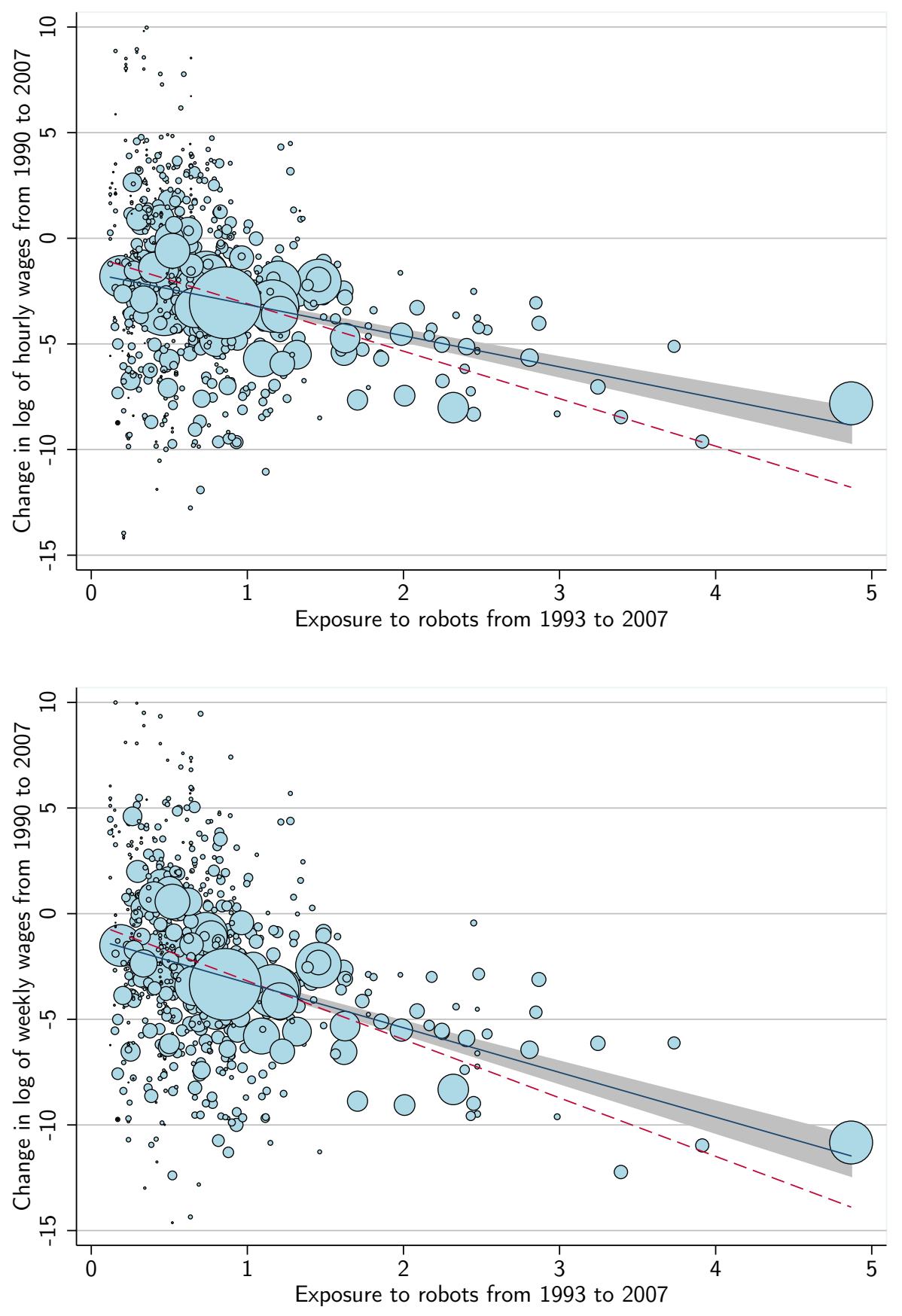

Figure 8: Relationship BetWeEn the EXPosure to RoBots AND WAGES.

Note: The figure shows the residual plot of the change in the log of wages (hourly wages in the top panel; weekly wages in the bottom panel) against the exposure to robots between 1993 and 2007 after the covariates in column 4 of Table 2 have been partialled out. In both panels, the solid line shows the regression coefficient from a weighted regression with commuting zone working-age population in 1990 as weights. The red dot line shows the weighted regression coefficient after the top $1 \%$ of the commuting zones with the highest exposure to robots is excluded. Marker size indicates the share of the 1990 US working age population in the corresponding commuting zone. 

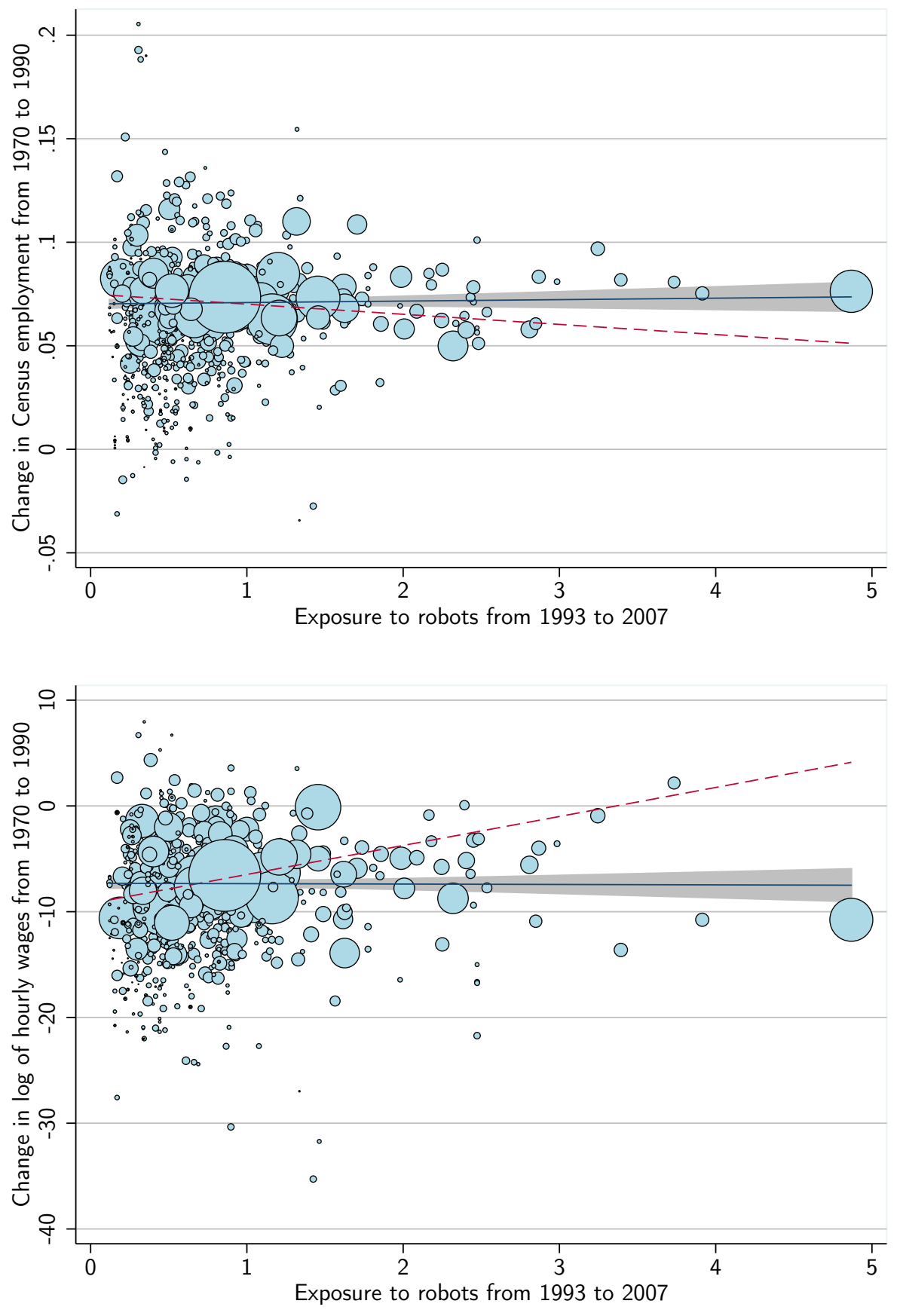

\section{Figure 9: Placebo Checks.}

Note: The figure shows the residual plot of the past change in employment and wages between 1970 and 1990 (Census private employment to population ratio in the top panel; log of hourly wage in the bottom panel) against the exposure to robots between 1993 and 2007 after the covariates in column 4 of Table 2 have been partialled out. In both panels, the solid line shows the regression coefficient from a weighted regression with commuting zone working-age population in 1990 as weights. The dotted (red) line shows the weighted regression coefficient after the top $1 \%$ of the commuting zones with the highest exposure to robots is excluded. Marker size indicates the share of the 1990 US working age population in the corresponding commuting zone. 


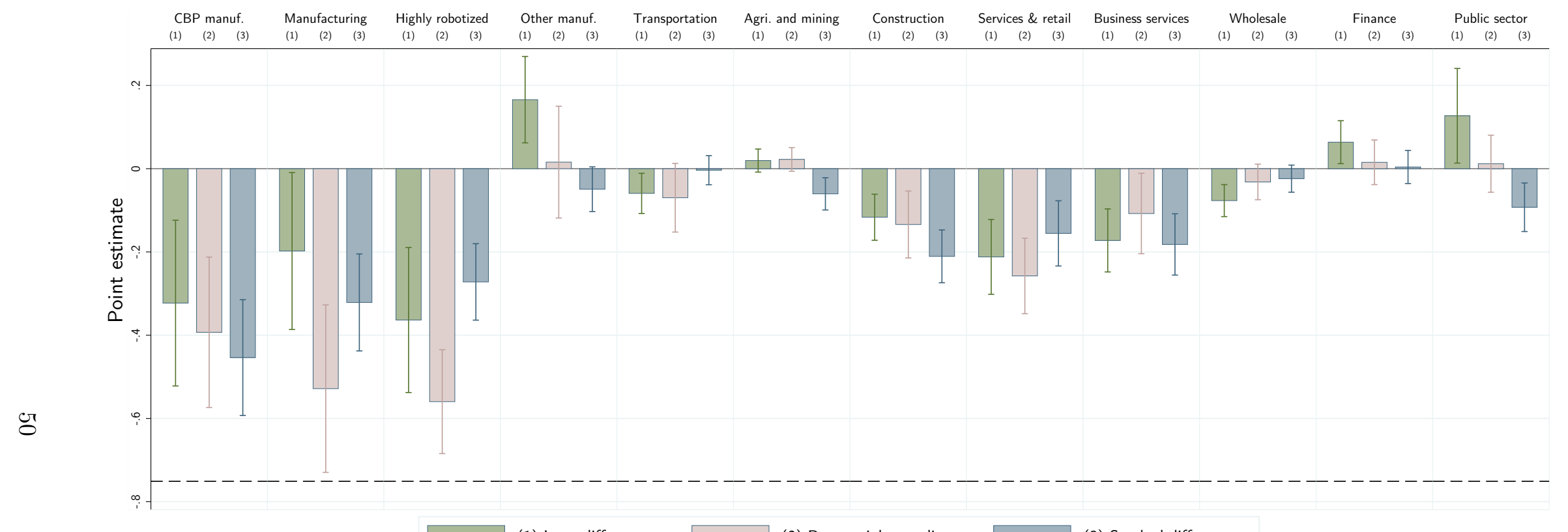

(1)-Long-differences

(2)-Downweights outliers

(3)-Stacked differences

Figure 10: Relationship between the exposure to Robots and industry employment. Note: The figure shows the estimates of the change in industry employment to population ratio against the exposure to robots between 1993 and 2007 conditional on the covariates in column 4 of Table 2. The green bars correspond to a long-differences specification similar to column 4 of Table 2; The rose bars correspond to a long-differences specification similar to column 6 of Table 2, in which we downweigh outliers; the blue bars correspond to a stacked-differences specification similar to column 2 of Table 3. For comparison, we also indicate with a dashed horizontal line the magnitude of the effect on Census private employment to population ratio. 


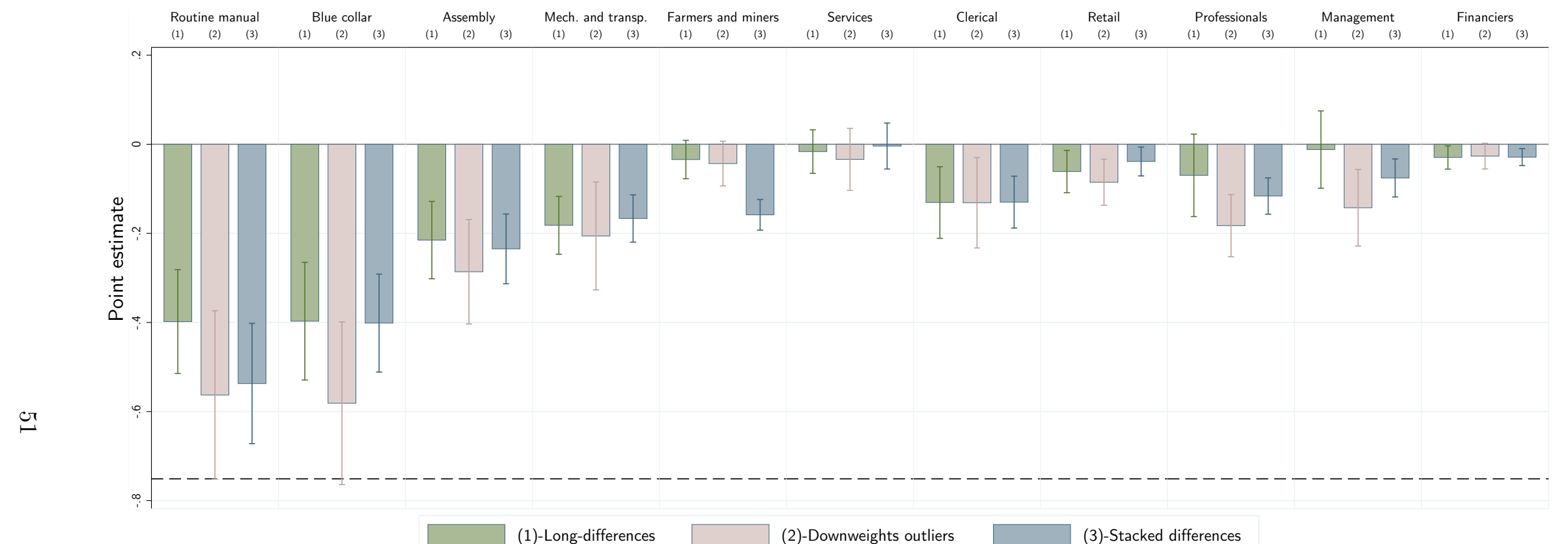

(1)-Long-differences (2)-Downweights outliers

(3)-Stacked differences

Figure 11: Relationship between the exposure to robots and occupation employment. Note: The figure shows the estimates of the change in occupation employment to population ratio against the exposure to robots between 1993 and 2007 conditional on the covariates in column 4 of Table 2. The green bars correspond to a long-differences specification similar to column 4 of Table 2; The rose bars correspond to a long-differences specification similar to column 6 of Table 2, in which we downweigh outliers; the blue bars correspond to a stacked-differences specification similar to column 2 of Table 3. For comparison, we also indicate with a dashed horizontal line the magnitude of the effect on Census private employment to population ratio. 

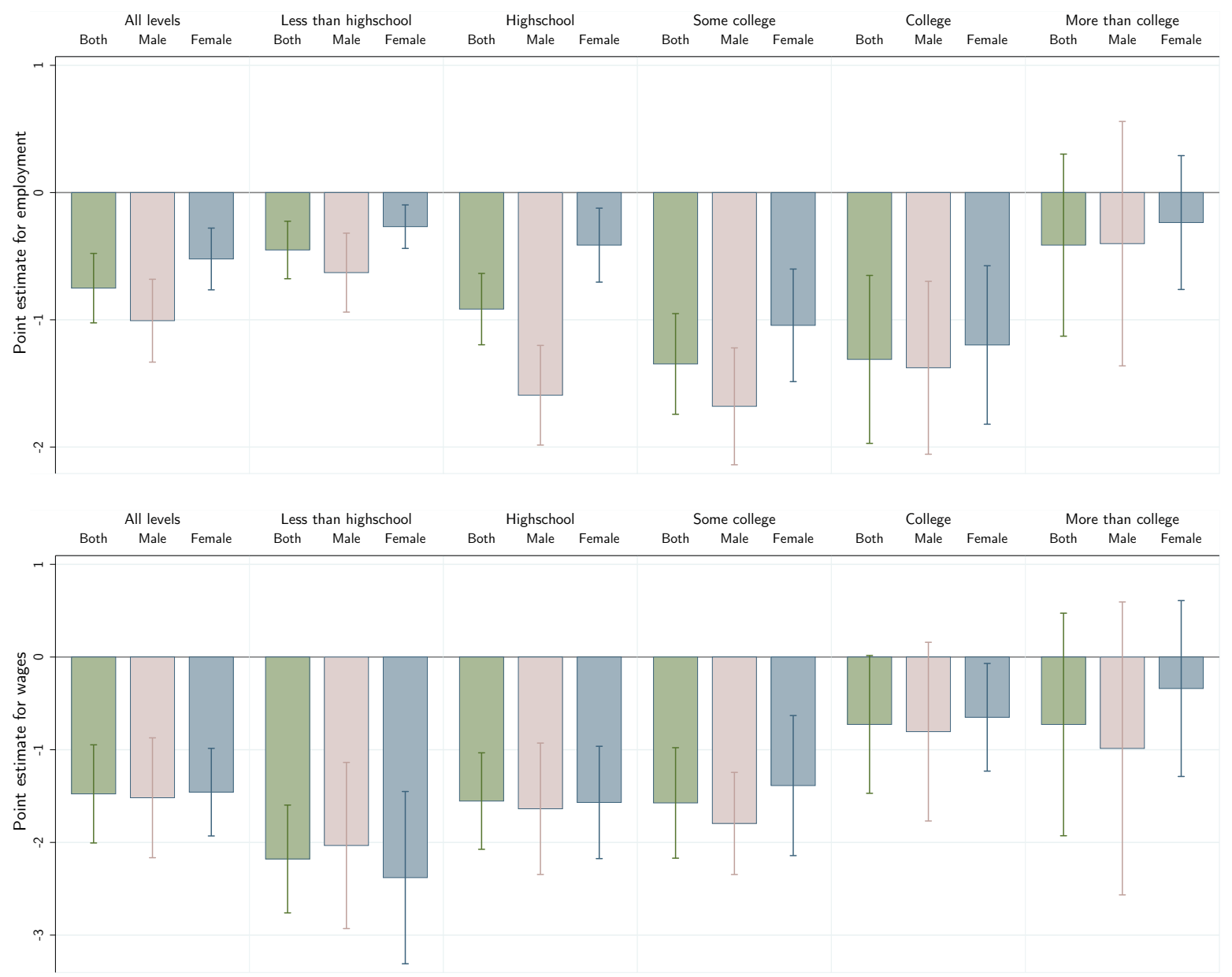

Figure 12: Relationship BetWeEn the EXPOSURE TO ROBOtS AND EMPLOYMENT AND WAGES BY EDUCATION GROUP.

Note: The figure shows the estimates of the change in Census private employment to population ratio (top panel) and log of hourly wage (bottom panel) against the (exogenous) exposure to robots between 1993 and 2007 conditional on the covariates in column 4 of Table 2. The figure shows the estimates separately by education level and gender. The top panel indicates the education level. For each level we present our baseline estimates (analogous to those in column 4 in Table 2) for all people, men and women. 


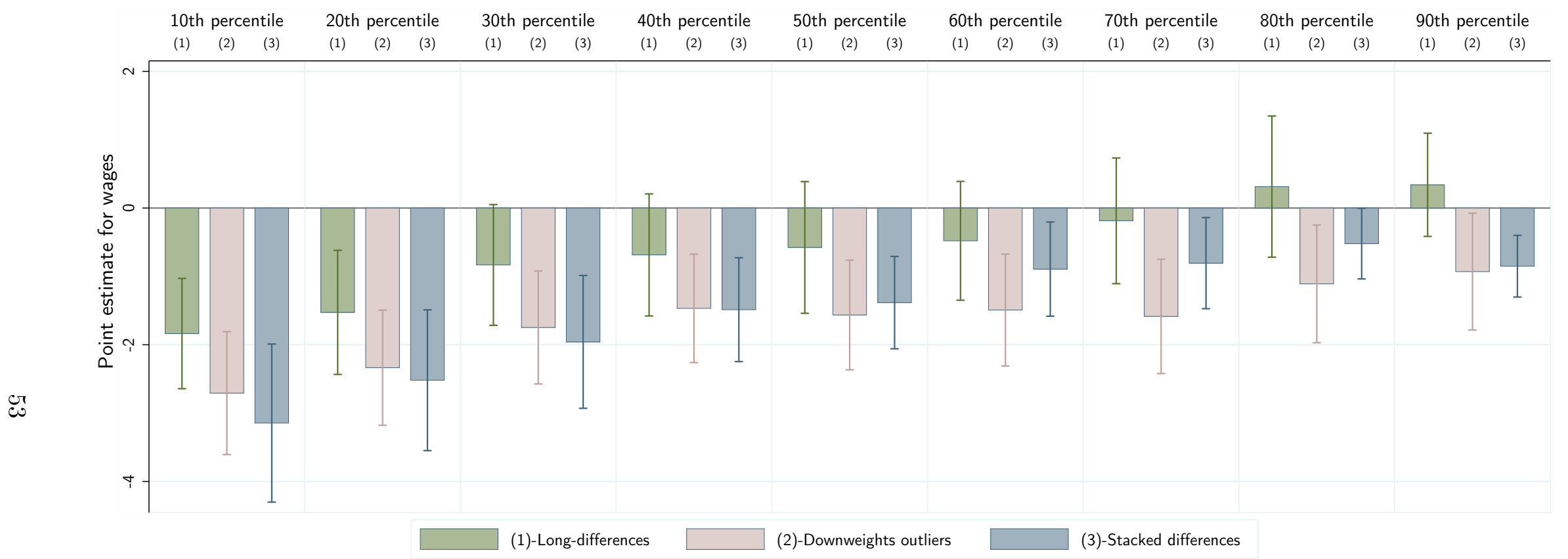

Figure 13: Relationship Between the exposure to Robots and the Wage Distribution.

Note: The figure shows the estimates of the change in the 10th, 20th, ..., and 90th wage deciles against the (exogenous) exposure to robots between 1993 and 2007 conditional on the covariates in column 4 of Table 2. The green bars correspond to a long-differences specification similar to column 4 of Table 2; The rose bars correspond to a long-differences specification similar to column 6 of Table 2, in which we downweigh outliers; the blue bars correspond to a stacked-differences specification similar to column 2 of Table 3. 


\section{TABLE 1: Summary statistics}

\begin{tabular}{|c|c|c|c|c|c|}
\hline & \multirow[b]{2}{*}{$\begin{array}{l}\text { AlL Zones } \\
\qquad N=722\end{array}$} & \multicolumn{4}{|c|}{ QUARTILES OF THE CHANGE IN EXPOSURE TO ROBOTS } \\
\hline & & $\begin{array}{c}\mathrm{Q} 1 \\
N=304\end{array}$ & $\begin{array}{c}\mathrm{Q} 2 \\
N=202\end{array}$ & $\begin{array}{c}\mathrm{Q} 3 \\
N=129\end{array}$ & $\begin{array}{c}\mathrm{Q} 4 \\
N=87\end{array}$ \\
\hline \multirow{3}{*}{$\begin{array}{l}\text { Census private employment to population ratio } \\
\text { in } 1990\end{array}$} & \multicolumn{5}{|c|}{ Panel A. Outcomes } \\
\hline & 0.354 & 0.317 & 0.357 & 0.363 & 0.376 \\
\hline & {$[0.044]$} & {$[0.039]$} & {$[0.049]$} & {$[0.035]$} & {$[0.029]$} \\
\hline \multirow{2}{*}{ CBP employment to population ratio in 1990} & 0.381 & 0.336 & 0.390 & 0.389 & 0.408 \\
\hline & {$[0.074]$} & {$[0.070]$} & {$[0.084]$} & {$[0.063]$} & {$[0.057]$} \\
\hline \multirow{2}{*}{$\begin{array}{l}\text { Change in Census private employment to } \\
\text { population ratio from } 1990 \text { to } 2007 \text { (in p.p.) }\end{array}$} & 0.294 & 1.486 & 0.418 & -0.599 & -0.117 \\
\hline & {$[2.240]$} & {$[2.336]$} & {$[2.271]$} & {$[2.208]$} & {$[1.564]$} \\
\hline \multirow{2}{*}{$\begin{array}{l}\text { Change in CBP employment to population } \\
\text { ratio from } 1990 \text { to } 2007 \text { (in p.p.) }\end{array}$} & 2.002 & 3.627 & 2.592 & 0.740 & 1.074 \\
\hline & [ 3.791] & [ 4.880$]$ & [ 3.275$]$ & [ 3.547$]$ & [ 2.419] \\
\hline \multirow{2}{*}{$\begin{array}{l}\text { Change of Census log employment from } 1990 \\
\text { to } 2007 \text { (in p.p.) }\end{array}$} & 18.688 & 27.132 & 21.978 & 15.191 & 10.844 \\
\hline & [ 14.838] & [ 16.894] & [ 15.213] & [ 11.001] & [ 9.613] \\
\hline \multirow{2}{*}{$\begin{array}{l}\text { Change of CBP log employment from } 1990 \text { to } \\
2007 \text { (in p.p.) }\end{array}$} & 23.208 & 32.942 & 27.559 & 18.919 & 13.857 \\
\hline & [ 17.439] & [ 21.023] & [ 16.549] & [ 13.146] & [ 10.871] \\
\hline \multirow{2}{*}{ Hourly wages in 1990} & 15.609 & 15.493 & 14.979 & 15.862 & 16.096 \\
\hline & [ 2.493] & [ 3.055$]$ & [ 2.364] & [ 2.337] & [ 2.004] \\
\hline \multirow{5}{*}{$\begin{array}{l}\text { Change in the log of hourly wages from } 1990 \text { to } \\
2007 \text { (in p.p.), adjusted for composition } \\
\text { Change in the log of weekly wages from } 1990 \text { to } \\
2007 \text { (in p.p.), adjusted for composition }\end{array}$} & -3.844 & -1.803 & -1.871 & -5.397 & -6.236 \\
\hline & [ 4.552$]$ & [ 5.354] & [ 4.381] & [ 3.241] & [ 2.969] \\
\hline & -5.252 & -2.047 & -3.480 & -7.236 & -8.135 \\
\hline & [ 5.210] & [ 5.456] & [ 4.885] & [ 3.791] & [ 3.922] \\
\hline & \multicolumn{5}{|c|}{ Panel B. Covariates } \\
\hline \multirow{2}{*}{ Share of employment in manufacturing 1990} & 0.225 & 0.150 & 0.233 & 0.252 & 0.262 \\
\hline & {$[0.079]$} & [ 0.053] & {$[0.073]$} & {$[0.073]$} & {$[0.062]$} \\
\hline \multirow{2}{*}{ Share of employment in durables 1990} & 0.136 & 0.085 & 0.135 & 0.153 & 0.167 \\
\hline & {$[0.059]$} & {$[0.036]$} & {$[0.044]$} & {$[0.049]$} & {$[0.066]$} \\
\hline \multirow{2}{*}{ Exposure to Chinese imports from 1990 to 2007} & 3.363 & 2.229 & 3.667 & 4.165 & 3.392 \\
\hline & [ 2.059] & {$[1.296]$} & [ 2.205] & {$[2.322]$} & {$[1.782]$} \\
\hline \multirow{2}{*}{ Share of employment in routine jobs 1990} & 0.346 & 0.339 & 0.340 & 0.347 & 0.357 \\
\hline & {$[0.026]$} & {$[0.032]$} & {$[0.025]$} & {$[0.020]$} & {$[0.020]$} \\
\hline \multirow{2}{*}{ Exposure to offshoring from 1993 to 2007} & 0.073 & 0.048 & 0.082 & 0.094 & 0.068 \\
\hline & [ 0.083$]$ & {$[0.061]$} & [ 0.095$]$ & [ 0.103] & [ 0.059$]$ \\
\hline \multirow{2}{*}{$\begin{array}{l}\text { Exposure to Mexican imports from } 1991 \text { to } \\
2007\end{array}$} & 1.863 & 1.005 & 1.756 & 1.958 & 2.678 \\
\hline & [ 1.731] & {$[0.850]$} & [ 1.821$]$ & [ 1.012$]$ & [ 2.304] \\
\hline \multirow{2}{*}{ Share of working-age population in 1990} & 0.658 & 0.651 & 0.659 & 0.663 & 0.658 \\
\hline & [ 0.025$]$ & [ 0.035$]$ & {$[0.027]$} & {$[0.020]$} & [ 0.015$]$ \\
\hline \multirow{2}{*}{ Share of population with college in 1990} & 0.193 & 0.196 & 0.200 & 0.187 & 0.190 \\
\hline & {$[0.056]$} & {$[0.063]$} & {$[0.064]$} & {$[0.050]$} & [ 0.047$]$ \\
\hline
\end{tabular}

Notes: Sample means and standard deviations (in brackets) for the entire sample of commuting zones and by (populationweighted) quartiles of the exposure to robots distribution. Panel A includes our main outcome variables, while Panel B is for the main covariates. See text for variable definitions and sources. 
TABLE 2: The impact of the exposure to robots on employment and wages (long differences)

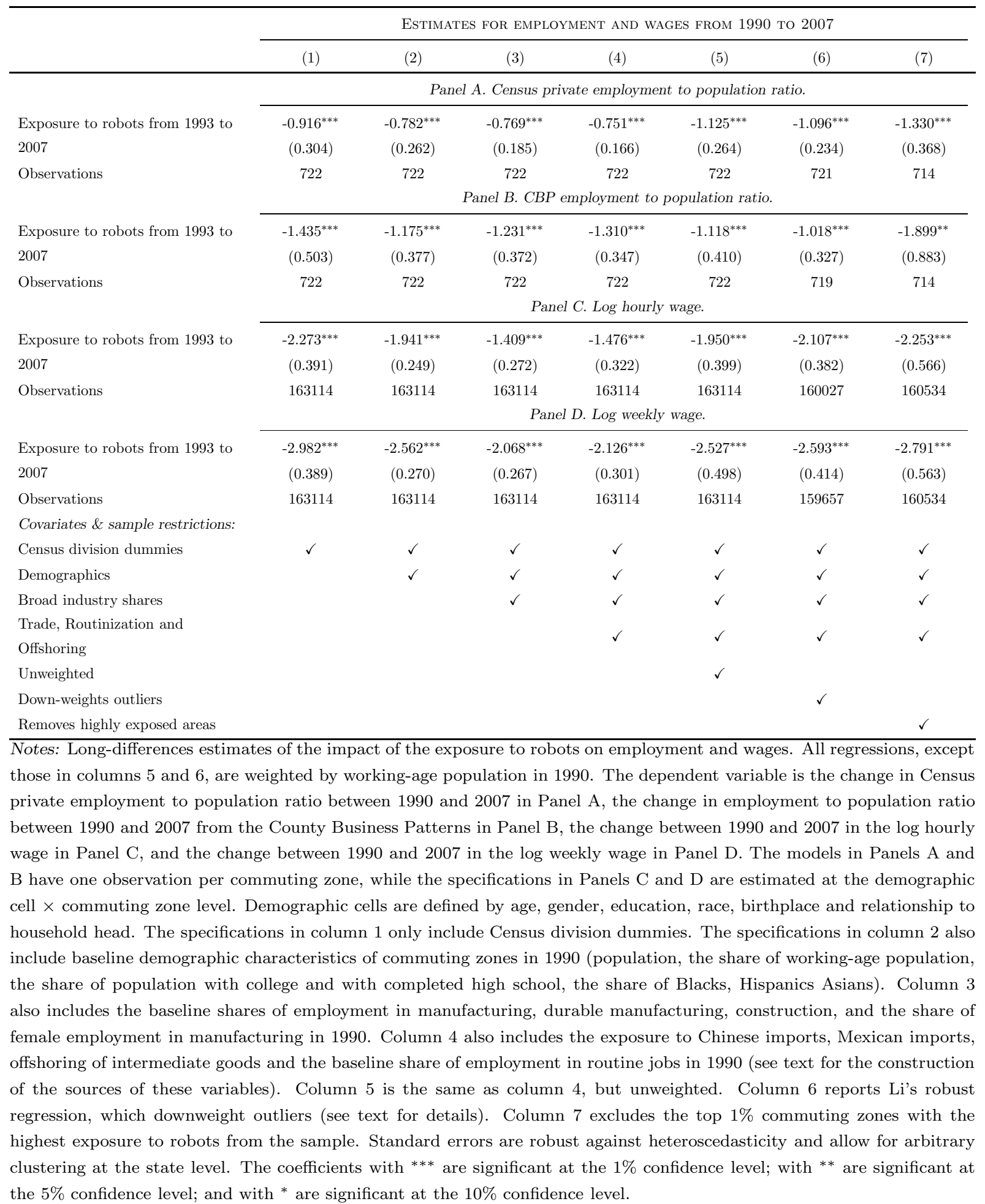


TABLE 3: The impact of the exposure to robots on employment and wages (stacked differences)

\begin{tabular}{|c|c|c|c|c|c|c|}
\hline & \multicolumn{6}{|c|}{ StaCKED-DifFERENCES ESTIMATES 1990-2000 AND 2000-2007 } \\
\hline & $(1)$ & $(2)$ & (3) & $(4)$ & $(5)$ & (6) \\
\hline & \multicolumn{6}{|c|}{ Panel A. Census private employment to population ratio. } \\
\hline Exposure to robots & $\begin{array}{c}-0.951^{* * *} \\
(0.152)\end{array}$ & $\begin{array}{c}-0.953^{* * *} \\
(0.146)\end{array}$ & $\begin{array}{c}-1.384^{* * *} \\
(0.174)\end{array}$ & $\begin{array}{c}-1.346^{* * *} \\
(0.139)\end{array}$ & $\begin{array}{c}-1.249^{* * *} \\
(0.339)\end{array}$ & $\begin{array}{r}-0.613^{* * *} \\
(0.111)\end{array}$ \\
\hline \multirow[t]{2}{*}{ Observations } & 1444 & 1444 & 1444 & 1441 & 1427 & 1444 \\
\hline & \multicolumn{6}{|c|}{ Panel B. CBP employment to population ratio. } \\
\hline Exposure to robots & $\begin{array}{c}-1.891^{* * *} \\
(0.300)\end{array}$ & $\begin{array}{c}-1.958^{* * *} \\
(0.310)\end{array}$ & $\begin{array}{c}-1.877^{* * *} \\
(0.256)\end{array}$ & $\begin{array}{c}-1.695^{* * *} \\
(0.209)\end{array}$ & $\begin{array}{c}-2.459^{* * *} \\
(0.674)\end{array}$ & $\begin{array}{c}-1.922^{* * *} \\
(0.379)\end{array}$ \\
\hline Observations & 1444 & 1444 & 1444 & 1436 & 1427 & 1444 \\
\hline & \multicolumn{6}{|c|}{ Panel C. Log hourly wage. } \\
\hline Exposure to robots & $\begin{array}{c}-1.939^{* * *} \\
(0.342)\end{array}$ & $\begin{array}{c}-1.919^{* * *} \\
(0.375)\end{array}$ & $\begin{array}{c}-2.176^{* * *} \\
(0.513)\end{array}$ & $\begin{array}{c}-1.485^{* * *} \\
(0.436)\end{array}$ & $\begin{array}{c}-2.428^{* *} \\
(0.918)\end{array}$ & $\begin{array}{c}-2.519^{* * *} \\
(0.489)\end{array}$ \\
\hline Observations & \multicolumn{6}{|c|}{ Panel D. Log weekly wage. } \\
\hline Exposure to robots & $\begin{array}{c}-3.266^{* * *} \\
(0.399)\end{array}$ & $\begin{array}{c}-3.200^{* * *} \\
(0.434)\end{array}$ & $\begin{array}{c}-3.979^{* * *} \\
(0.609)\end{array}$ & $\begin{array}{c}-2.471^{* * *} \\
(0.457)\end{array}$ & $\begin{array}{c}-4.117^{* * *} \\
(1.084)\end{array}$ & $\begin{array}{r}-3.734^{* * *} \\
(0.764)\end{array}$ \\
\hline Observations & 326377 & 326377 & 326377 & 317850 & 321643 & 326377 \\
\hline Covariates \& sample restrictions: & & & & & & \\
\hline $\begin{array}{l}\text { Demographic, industry shares and } \\
\text { census division dummies }\end{array}$ & $\checkmark$ & $\checkmark$ & $\checkmark$ & $\checkmark$ & $\checkmark$ & $\checkmark$ \\
\hline Trade, routinization and offshoring & & $\checkmark$ & $\checkmark$ & $\checkmark$ & $\checkmark$ & $\checkmark$ \\
\hline Unweighted & & & $\checkmark$ & & & \\
\hline Down-weights outliers & & & & $\checkmark$ & & \\
\hline Removes highly exposed areas & & & & & $\checkmark$ & \\
\hline Commuting zone fixed effects & & & & & & $\checkmark$ \\
\hline
\end{tabular}

Notes: Stacked-differences estimates of the impact of the exposure to robots on employment and wages. All regressions, except those in columns 3 and 4, are weighted by working-age population in 1990. The dependent variable is the change in the Census private employment to population ratio in Panel A, the change in the employment to population ratio from the County Business Patterns in Panel B, the change in the log hourly wage in Panel C, and he change in the log weekly wage in Panel D. The models in Panels A and B have two observation per commuting zone (1990-2000 and 20002007). The specifications in Panels $C$ and D are estimated at the demographic cell $\times$ commuting zone level and have two observations for each cell (one for the change in wages from 1990 to 2000 and another for the change in wages from 2000 to 2007). Demographic cells are defined by age, gender, education, race, birthplace and relationship to household head. The specifications in column 1 include Census division dummies; baseline demographic characteristics of commuting zones at the beginning of each decade (population, the share of working-age population, the share of population with college and with completed high school, the share of Blacks, Hispanics Asians); and the baseline shares of employment in manufacturing, durable manufacturing, construction, and the share of female employment in manufacturing at the beginning of each decade. Column 2 also includes the exposure to Chinese imports, Mexican imports, offshoring of intermediate goods and the baseline share of employment in routine jobs (see text for the construction of the sources of these variables). Column 3 is the same as column 2, but unweighted. Column 4 reports Li's robust regressions, which downweight outliers (see the text for details). Column 5 excludes the top $1 \%$ commuting zones with the highest exposure to robots from the sample. Column 6 is the same as column 2 but it also includes commuting zone fixed effects. Standard errors are robust against heteroscedasticity and allow for arbitrary clustering and correlation over time at the state level. The coefficients with ${ }^{* * *}$ are significant at the $1 \%$ confidence level; with ${ }^{* *}$ are significant at the $5 \%$ confidence level; and with ${ }^{*}$ are significant at the $10 \%$ confidence level. 
TABLE 4: IV estimates of the change in exposure to robots on employment and wages

\begin{tabular}{|c|c|c|c|c|c|c|c|}
\hline \multirow{5}{*}{$\begin{array}{l}\text { Exposure to robots from } 1993 \text { to } \\
2007\end{array}$} & \multicolumn{7}{|c|}{ IV ESTIMATES FROM 1990 TO 2007} \\
\hline & (1) & (2) & (3) & (4) & (5) & (6) & (7) \\
\hline & \multicolumn{7}{|c|}{ Panel A. First-stage for exposure to robots in the US. } \\
\hline & $2.175^{* * *}$ & $2.178^{* * *}$ & $2.094^{* * *}$ & $2.026^{* * *}$ & $1.535^{* * *}$ & $1.536^{* * *}$ & $1.083^{* * *}$ \\
\hline & $(0.285)$ & $(0.272)$ & $(0.269)$ & $(0.275)$ & $(0.257)$ & $(0.255)$ & $(0.135)$ \\
\hline \multirow[t]{2}{*}{ Observations } & 722 & 722 & 722 & 722 & 722 & 721 & 714 \\
\hline & \multicolumn{7}{|c|}{ Panel B. Census private employment to population ratio. } \\
\hline Instrumented exposure to robots & $-0.421^{* *}$ & $-0.359^{* *}$ & $-0.367^{* * *}$ & $-0.371^{* * *}$ & $-0.733^{* * *}$ & $-0.714^{* * *}$ & $-1.228^{* * *}$ \\
\hline from 1993 to 2007 & $(0.180)$ & $(0.155)$ & $(0.123)$ & $(0.115)$ & $(0.210)$ & $(0.193)$ & $(0.395)$ \\
\hline First-stage $F$ statistic & 58.3 & 64.2 & 60.6 & 54.2 & 35.7 & 36.3 & 64.2 \\
\hline \multirow[t]{2}{*}{ Observations } & 722 & 722 & 722 & 722 & 722 & 721 & 714 \\
\hline & \multicolumn{7}{|c|}{ Panel C. CBP employment to population ratio. } \\
\hline Instrumented exposure to robots & $-0.660^{* *}$ & $-0.540^{* *}$ & $-0.588^{* * *}$ & $-0.647^{* * *}$ & $-0.728^{* * *}$ & $-0.647^{* * *}$ & $-1.754^{* *}$ \\
\hline from 1993 to 2007 & $(0.270)$ & $(0.217)$ & $(0.218)$ & $(0.207)$ & $(0.263)$ & $(0.197)$ & $(0.877)$ \\
\hline First-stage $F$ statistic & 58.3 & 64.2 & 60.6 & 54.2 & 35.7 & 37.1 & 64.2 \\
\hline \multirow[t]{2}{*}{ Observations } & 722 & 722 & 722 & 722 & 722 & 719 & 714 \\
\hline & \multicolumn{7}{|c|}{ Panel D. Log hourly wage. } \\
\hline Instrumented exposure to robots & $-1.043^{* * *}$ & $-0.891^{* * *}$ & $-0.675^{* * *}$ & $-0.732^{* * *}$ & $-1.259^{* * *}$ & $-1.274^{* * *}$ & $-2.062^{* * *}$ \\
\hline from 1993 to 2007 & $(0.257)$ & $(0.196)$ & $(0.173)$ & $(0.219)$ & $(0.337)$ & $(0.352)$ & $(0.471)$ \\
\hline First-stage $F$ statistic & 60.4 & 66.2 & 61.4 & 55.5 & 34.5 & 25.9 & 68.3 \\
\hline \multirow[t]{2}{*}{ Observations } & 163114 & 163114 & 163114 & 163114 & 163114 & 160027 & 160534 \\
\hline & \multicolumn{7}{|c|}{ Panel E. Log weekly wage. } \\
\hline Instrumented exposure to robots & $-1.368^{* * *}$ & $-1.176^{* * *}$ & $-0.991^{* * *}$ & $-1.054^{* * *}$ & $-1.631^{* * *}$ & $-1.571^{* * *}$ & $-2.555^{* * *}$ \\
\hline from 1993 to 2007 & $(0.286)$ & $(0.229)$ & $(0.179)$ & $(0.226)$ & $(0.409)$ & $(0.414)$ & $(0.457)$ \\
\hline First-stage $F$ statistic & 60.4 & 66.2 & 61.4 & 55.5 & 34.5 & 25.7 & 68.3 \\
\hline Observations & 163114 & 163114 & 163114 & 163114 & 163114 & 159657 & 160534 \\
\hline \multicolumn{8}{|l|}{ Covariates \& sample restrictions: } \\
\hline Census division dummies & $\checkmark$ & $\checkmark$ & $\checkmark$ & $\checkmark$ & $\checkmark$ & $\checkmark$ & $\checkmark$ \\
\hline Demographics & & $\checkmark$ & $\checkmark$ & $\checkmark$ & $\checkmark$ & $\checkmark$ & $\checkmark$ \\
\hline Broad industry shares & & & $\checkmark$ & $\checkmark$ & $\checkmark$ & $\checkmark$ & $\checkmark$ \\
\hline $\begin{array}{l}\text { Trade, Routinization and } \\
\text { Offshoring }\end{array}$ & & & & $\checkmark$ & $\checkmark$ & $\checkmark$ & $\checkmark$ \\
\hline Unweighted & & & & & $\checkmark$ & & \\
\hline Down-weights outliers & & & & & & $\checkmark$ & \\
\hline Removes highly exposed areas & & & & & & & $\checkmark$ \\
\hline
\end{tabular}

Notes: IV estimates of the impact of the exposure to robots on employment and wages. All regressions, except those in columns 5 and 6 , are weighted by working-age population in 1990. Panel A shows the first-stage relationship between the exposure to robots computed from data on the adoption of robots by US industries between 2004 and 2007 (converted to a 17-year equivalent change and in terms of robots per thousand people) against the exposure to robots from 1993 to 2007. The dependent variable is the change in Census private employment to population ratio between 1990 and 2007 in Panel B, the change in employment to population ratio between 1990 and 2007 from the County Business Patterns in Panel C, the change between 1990 and 2007 in the log hourly wage in Panel D, and the change between 1990 and 2007 in the log weekly wage in Panel E. The models in Panels A, B and C have one observation per commuting zone, while the specifications in Panels D and $\mathrm{E}$ are estimated at the demographic cell $\times$ commuting zone level. Demographic cells are defined by age, gender, education, race, birthplace and relationship to household head. The specifications in column 1 only include Census division dummies. The specifications in column 2 also include baseline demographic characteristics of commuting zones in 1990 (population, the share of working-age population, the share of population with college and with completed high school, the share of Blacks, Hispanics Asians). Column 3 also includes the baseline shares of employment in manufacturing, durable manufacturing, construction, and the share of female employment in manufacturing in 1990. Column 4 also includes the exposure to Chinese imports, Mexican imports, offshoring of intermediate goods and the baseline share of employment in routine jobs in 1990 (see text for the construction of the sources of these variables). Column 5 is the same as column 4 , but unweighted. Column 6 reports Li's robust regressions, which downweight outliers (see the text for details). Column 7 excludes the top $1 \%$ commuting zones with the highest exposure to robots from the sample. Standard errors are robust against heteroscedasticity and allow for arbitrary clustering at the state level. The coefficients with ${ }^{* * *}$ are significant at the $1 \%$ confidence level; with ${ }^{* *}$ are significant at the $5 \%$ confidence level; and with ${ }^{*}$ are significant at the $10 \%$ confidence level. 
TABle 5: Placebo checks.

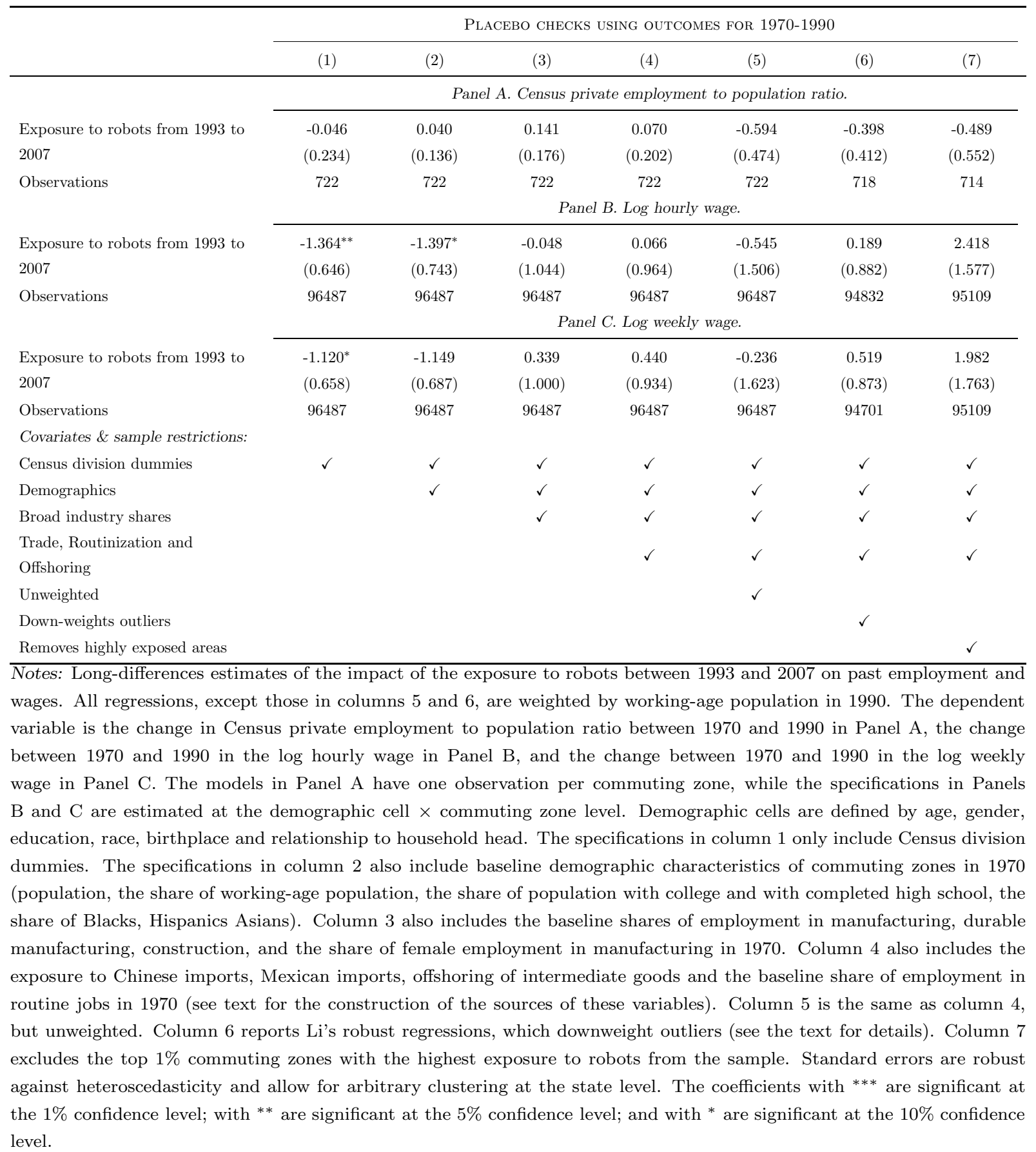


TABLE 6: The impact of the exposure to robots on employment and wages (controlling for the automobile industry)

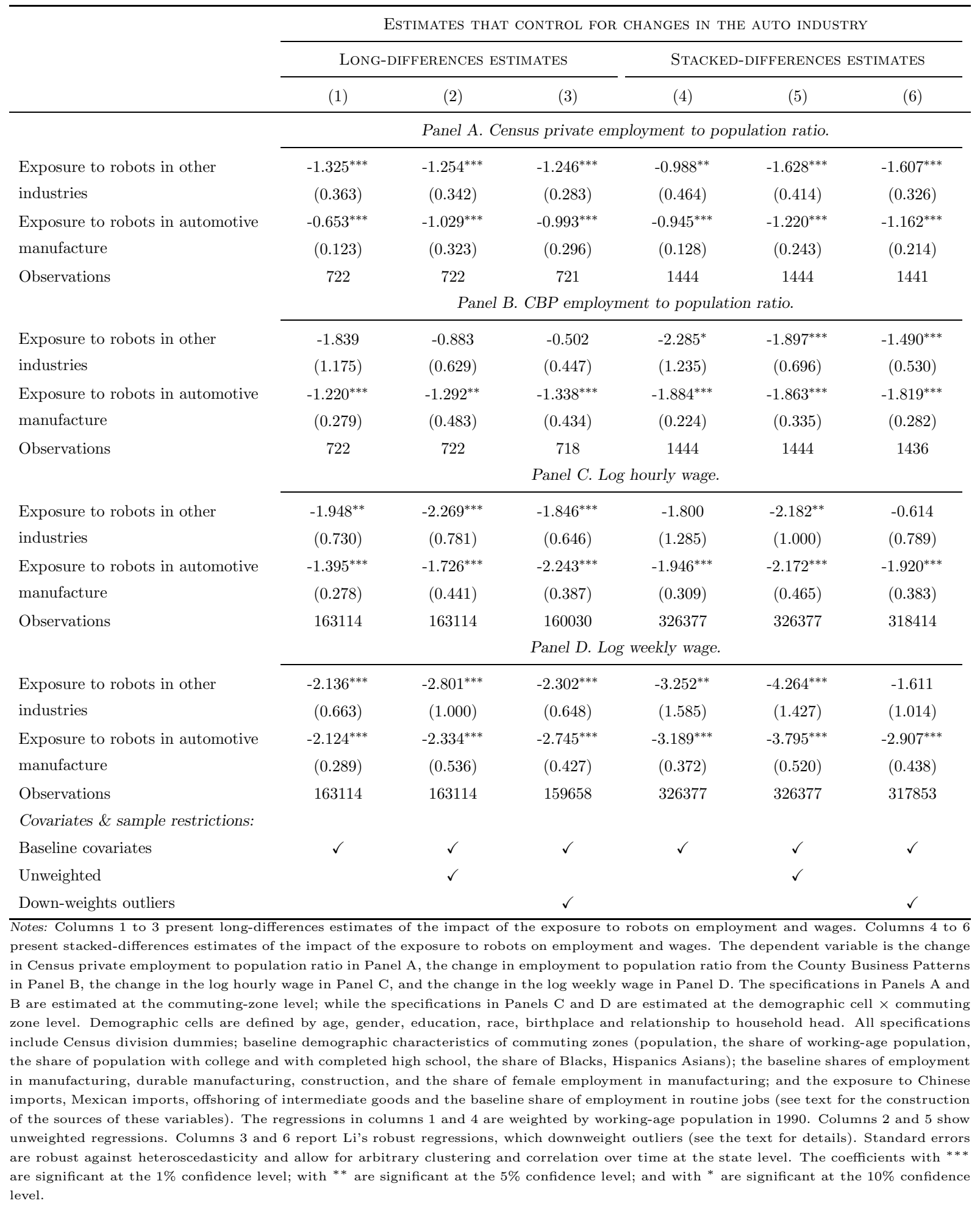


TABLE 7: The impact of the exposure to robots on employment and wages: isolating the impact of robots.

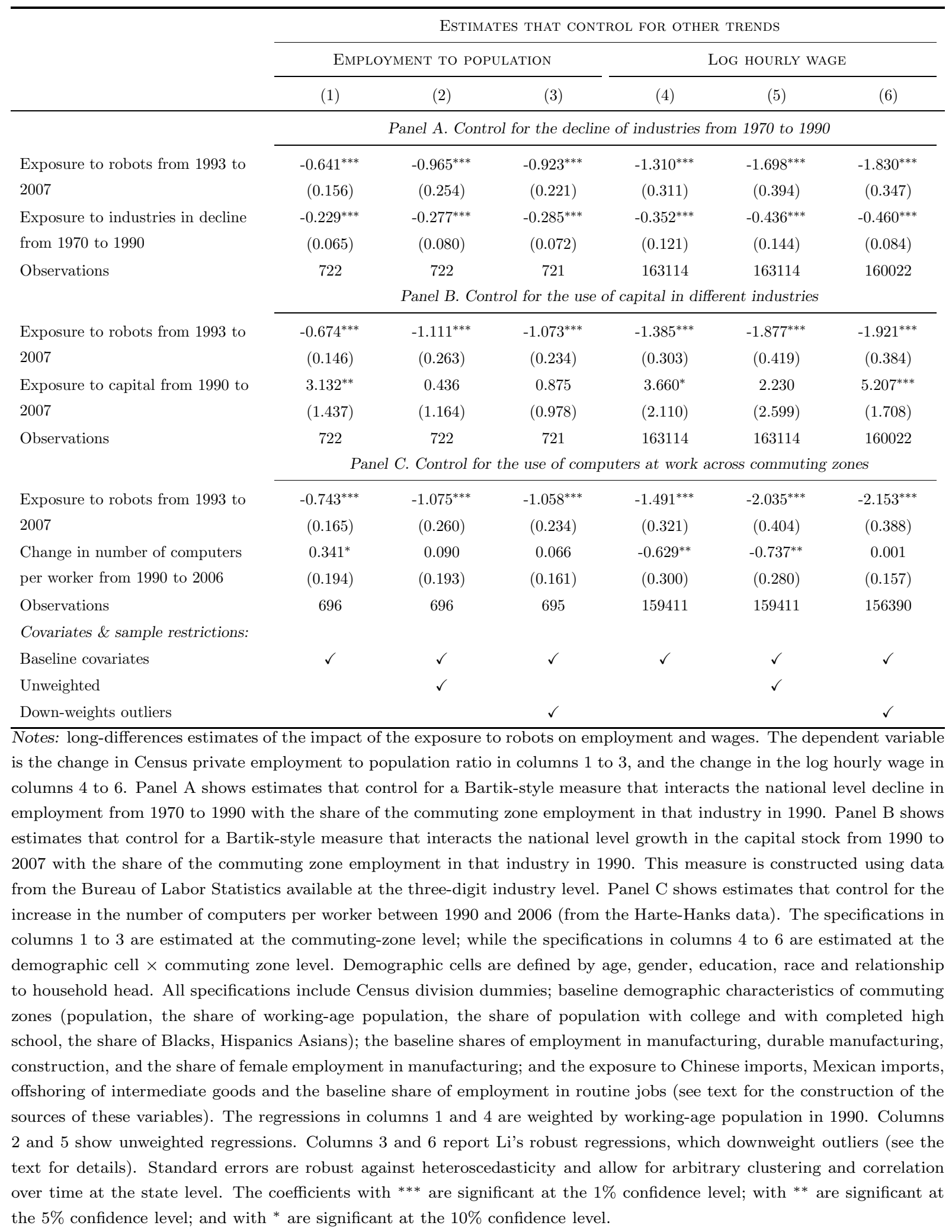


TABLE 8: The impact of the exposure to robots on employment and wages: differential effects on men and women

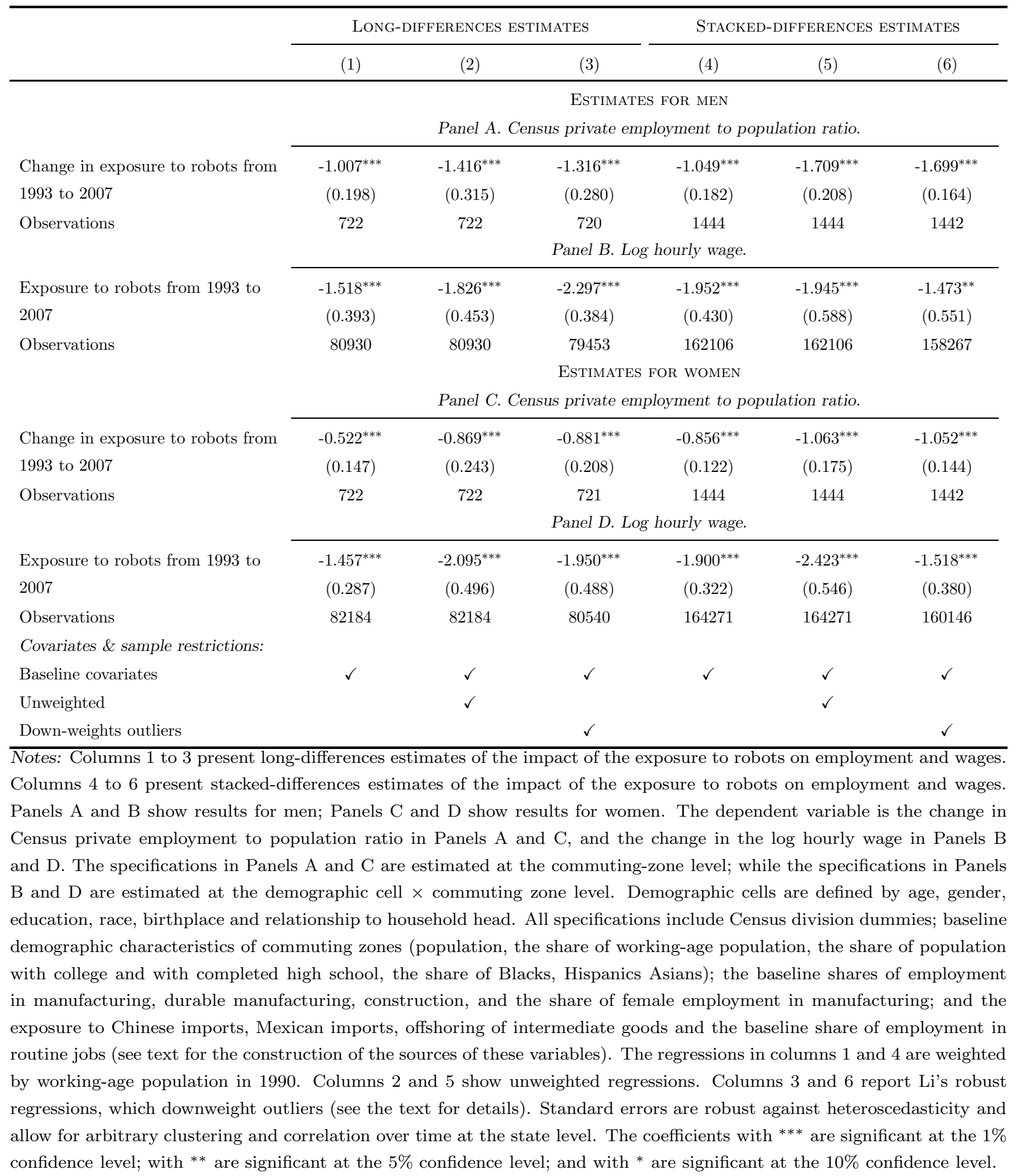


TABLE 9: The impact of the exposure to robots on different types of income

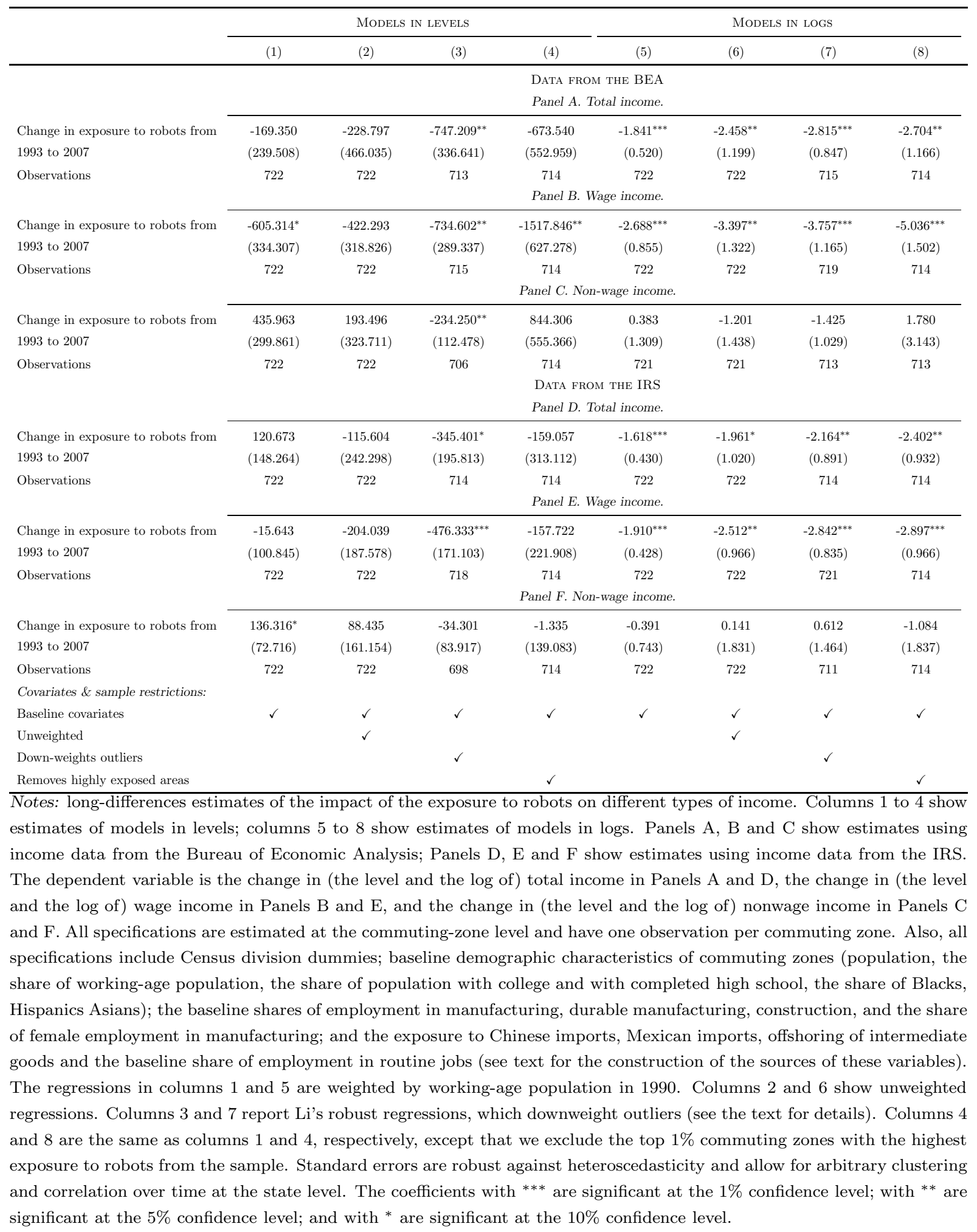




\section{Online Appendix (NOT FOR PUBlicATiOn)}

\section{A1 Proofs for the Autarky Equilibrium}

\section{Proof of Proposition 1:}

Cost minimization for the final product in commuting zone $c$ implies that, for each $i \in \mathcal{I}$,

$$
Y_{c i}=\alpha_{i}^{\sigma} P_{X c i}^{-\sigma} Y_{c}
$$

Moreover, because the economy is in autarky, $X_{c i}=Y_{c i}$ and thus

$$
X_{c i}=\alpha_{i}^{\sigma} P_{X c i}^{-\sigma} Y_{c}
$$

Cost minimization for the production of $X_{c i}$ in turn yields the demands for labor and robots in task $s$ as

$$
l_{c i}(s)=\left\{\begin{array}{cc}
0 & \text { if } s \leq M_{i} \\
\frac{X_{c i}}{A_{c i} \gamma} & \text { if } s>M_{i}
\end{array},\right.
$$

and

$$
r_{c i}(s)=\left\{\begin{array}{cc}
0 & \text { if } s>M_{i} \\
\frac{X_{c i}}{A_{c i}} & \text { if } s \leq M_{i}
\end{array} .\right.
$$

Aggregating across tasks, the demand for labor and robots in industry $i$ are

$$
L_{c i}=\frac{\left(1-M_{i}\right) X_{c i}}{\gamma A_{c i}}=\frac{\alpha_{i}^{\sigma}}{\gamma A_{c i}}\left(1-M_{i}\right) P_{X c i}^{-\sigma} Y_{c} \quad \text { and } \quad R_{c i}=\frac{M_{i} X_{c i}}{A_{c i}}=\frac{\alpha_{i}^{\sigma}}{A_{c i}} M_{i} P_{X c i}^{-\sigma} Y_{c} .
$$

Aggregating the demand for labor across all industries yields the total labor and robot demand in commuting zone $c$ as

$$
L_{c}^{d}=\sum_{i \in \mathcal{I}} \frac{\alpha_{i}^{\sigma}}{\gamma A_{c i}}\left(1-M_{i}\right) P_{X c i}^{-\sigma} Y_{c} \quad \text { and } \quad R_{c}^{d}=\sum_{i \in \mathcal{I}} \frac{\alpha_{i}^{\sigma}}{A_{c i}} M_{i} P_{X c i}^{-\sigma} Y_{c} .
$$

Proposition 1 follows by log differentiating the labor demand in equation (A2)

\section{Existence and Uniqueness of Autarky Equilibrium:}

Because prices are equal to unit costs, we have

$$
P_{X c i}=\frac{1}{A_{c i}}\left(M_{i} Q_{c}+\left(1-M_{i}\right) \frac{W_{c}}{\gamma}\right) .
$$

Using this expression for prices, we can define an autarky equilibrium as follows.

Definition 1 An autarky equilibrium in commuting zone $c$ is given by prices $\left\{P_{X c i}\right\}_{i \in \mathcal{I}}, W_{c}, Q_{c}$ and quantities $L_{c}, R_{c}, Y_{c}$ such that:

- $L_{c}^{d}=L_{c}$ and $R_{c}^{d}=R_{c}$, so that the market for robots and labor clears; 
- factor prices are given by the supply formulas, equation (2);

- product prices, the $P_{X c i}$ 's, are given by the cost-minimizing formula, equation (A3), and satisfy the ideal price index condition,

$$
1=\sum_{i \in \mathcal{I}} \alpha_{i}^{\sigma} P_{X c i}^{1-\sigma}
$$

Proposition A1 An autarky equilibrium exists and is unique.

Proof. Existence and uniqueness of this equilibrium follow using analogous arguments to the static model in Acemoglu and Restrepo (2016).

\section{Proof of Proposition 2:}

To prove this proposition, we use two lemmas that establish how prices and output change as a result of the use of additional robots.

LEMma A1 Let $s_{c L}$ and $s_{c R}$ denote the share of labor and robots, respectively. Then

$$
d \ln Y_{c}=s_{c L} \pi_{c} \sum_{i \in \mathcal{I}} \ell_{c i} \frac{d M_{i}}{1-M_{i}}+s_{c L} d \ln L_{c}+s_{s R} d \ln R_{c} .
$$

Proof. Holding $L_{c}$ and $R_{c}$ constant, the allocation of labor and robots to tasks and sectors maximizes output. Therefore, the envelope theorem implies that:

$$
\begin{aligned}
\left.d \ln Y_{c}\right|_{L_{c}, R_{c}} & =\left.\sum_{i \in \mathcal{I}} s_{c i} d \ln X_{c i}\right|_{L_{c i}, R_{c i}} \\
& =\sum_{i \in \mathcal{I}} s_{c i} \frac{1}{A_{c i} P_{X c i}}\left(\frac{W_{c}}{\gamma}-Q_{c}\right) d M_{i},
\end{aligned}
$$

with $s_{c i}=\frac{P_{X_{c i}} X_{c i}}{Y_{c}}$ denoting the share of industry $i$ in total output.

The previous expression can be rewritten as follows:

$$
\begin{aligned}
\left.d \ln Y_{c}\right|_{L_{c}, R_{c}} & =\sum_{i \in \mathcal{I}} \frac{P_{X c i} X_{c i}}{Y_{c}} \frac{1}{A_{c i} P_{X c i}}\left(\frac{W_{c}}{\gamma}-Q_{c}\right) d M_{i} \\
& =\sum_{i \in \mathcal{I}} \frac{\gamma L_{c i}}{Y_{c}}\left(\frac{W_{c}}{\gamma}-Q_{c}\right) \frac{d M_{i}}{1-M_{i}} \\
& =\sum_{i \in \mathcal{I}} \frac{s_{c L} \gamma L_{c i}}{W_{c} L_{c}}\left(\frac{W_{c}}{\gamma}-Q_{c}\right) \frac{d M_{i}}{1-M_{i}} \\
& =s_{c L} \pi_{c} \sum_{i \in \mathcal{I}} \ell_{c i} \frac{d M_{i}}{1-M_{i}} .
\end{aligned}
$$

An additional application of the envelope theorem yields

$$
\begin{aligned}
d \ln Y_{c} & =\left.d \ln Y_{c}\right|_{L_{c}, R_{c}}+s_{c L} d \ln L_{c}+s_{c R} d \ln R_{c}, \\
& =s_{c L} \pi_{c} \sum_{i \in \mathcal{I}} \ell_{c i} \frac{d M_{i}}{1-M_{i}}+s_{c L} d \ln L_{c}+s_{c R} d \ln R_{c},
\end{aligned}
$$

completing the proof of the lemma. 
Lemma A2 Let $s_{i c L}$ and $s_{i c R}$ denote the share of labor and robots in industry i, respectively. Then:

$$
d \ln P_{X c i}=-s_{i c L} \pi_{c} \frac{d M_{i}}{1-M_{i}}+s_{i c L} d \ln W_{c}+s_{i s R} d \ln Q_{c}
$$

Proof. This lemma follows from differentiating the formula for prices in equation (A3), which yields

$$
d \ln P_{X c i}=\frac{1}{A_{c i} P_{X c i}}\left(Q_{c}-\frac{W_{c}}{\gamma}\right) d M_{i}+s_{i c L} d \ln W_{c}+s_{i s R} d \ln Q_{c} .
$$

We can rewrite this expression as

$$
\begin{aligned}
d \ln P_{X c i} & =-\frac{W_{c}}{\gamma A_{c i} P_{X c i}} \pi_{c} d M_{i}+s_{i c L} d \ln W_{c}+s_{i s R} d \ln Q_{c} \\
& =-\frac{W_{c}\left(1-M_{i}\right)}{\gamma A_{c i} P_{X c i}} \pi_{c} \frac{d M_{i}}{1-M_{i}}+s_{i c L} d \ln W_{c}+s_{i s R} d \ln Q_{c} \\
& =-s_{i c L} \pi_{c} \frac{d M_{i}}{1-M_{i}}+s_{i c L} d \ln W_{c}+s_{i s R} d \ln Q_{c},
\end{aligned}
$$

where in the last step we used the fact that $s_{i c L}=\frac{W_{c}\left(1-M_{i}\right)}{\gamma A_{c i} P_{X c i}}$. The last line establishes the lemma.

To complete the proof of the proposition, we substitute the expressions from these lemmas in the labor demand equation to obtain:

$$
\begin{aligned}
d \ln L_{c}= & -\sum_{i \in \mathcal{I}} \ell_{c i} \frac{d M_{i}}{1-M_{i}}+\sigma \pi_{c} \sum_{i \in \mathcal{I}} s_{i c L} \ell_{c i} \frac{d M_{i}}{1-M_{i}}-\sigma\left(s_{c L} d \ln W_{c}+s_{c R} d \ln Q_{c}\right) \\
& +s_{c L} \pi_{c} \sum_{i \in \mathcal{I}} \ell_{c i} \frac{d M_{i}}{1-M_{i}}+s_{c L} d \ln L_{c}+s_{s R} d \ln R_{c} .
\end{aligned}
$$

In addition, differentiating the equation $Y_{c}=W_{c} L_{c}+Q_{c} R_{c}$ yields

$$
s_{c L} \pi_{c} \sum_{i \in \mathcal{I}} \ell_{c i} \frac{d M_{i}}{1-M_{i}}=s_{c L} d \ln W_{c}+s_{c R} d \ln Q_{c} .
$$

Combining equations (A4) and

(A5) with the supply equations, written in log differential form as

$$
\begin{aligned}
& d \ln W_{c}=s_{c L}\left(d \ln L_{c}+d \ln W_{c}\right)+s_{c R}\left(d \ln R_{c}+d \ln Q_{c}\right)+\varepsilon d \ln L_{c} \\
& d \ln Q_{c}=\eta d \ln R_{c}-\eta s_{c L}\left(d \ln L_{c}+d \ln W_{c}\right)-\eta s_{c R}\left(d \ln R_{c}+d \ln Q_{c}\right),
\end{aligned}
$$

we obtain a system of four equations and four unknowns: $d \ln L_{c}, d \ln R_{c}, d \ln W_{c}$, and $d \ln Q_{c}$. The solution to this linear system of equations is given by the expressions provided in equations (5) and (6), which completes the proof. 


\section{A2 Proofs for Equilibrium with Trade across Commuting ZONES}

\section{Proof of Proposition 3:}

The first-order condition for the consumption aggregate of industry $i$ in commuting zone $d$ yields

$$
Y_{d i}=\alpha_{i}^{\sigma} P_{Y i}^{-\sigma} Y_{d}
$$

Similarly, the demand in commuting zone $d$ for the variety of the product from industry $i$ sourced from commuting zone $c$ is

$$
X_{c d i}=\theta_{c i}^{\lambda} P_{X c i}^{-\lambda} P_{Y i}^{\lambda} Y_{d i}=\alpha_{i}^{\sigma} \theta_{c i}^{\lambda} P_{X c i}^{-\lambda} P_{Y i}^{\lambda-\sigma} Y_{d}
$$

Aggregating across commuting zones, the total demand for the variety of industry $i$ sourced from commuting zone $c$ is

$$
X_{c i}=\sum_{d \in \mathcal{C}} X_{c d i}=\alpha_{i}^{\sigma} \theta_{c i}^{\lambda} P_{X c i}^{-\lambda} P_{Y i}^{\lambda-\sigma} \sum_{d \in \mathcal{C}} Y_{d}
$$

As in the closed economy, the demand for labor and robots in industry $i$ is given by equation (A1). Aggregating across industries, we obtain the total demand for labor and the total demand for robots as

$$
L_{c}^{d}=\sum_{i \in \mathcal{I}} \frac{\alpha_{i}^{\sigma} \theta_{c i}^{\lambda}}{\gamma A_{c i}}\left(1-M_{i}\right) P_{X c i}^{-\lambda} P_{Y i}^{\lambda-\sigma} Y \quad \text { and } \quad R_{c}^{d}=\sum_{i \in \mathcal{I}} \frac{\alpha_{i}^{\sigma} \theta_{c i}^{\lambda}}{A_{c i}} M_{i} P_{X c i}^{-\lambda} P_{Y i}^{\lambda-\sigma} Y
$$

where $Y=\sum_{d \in \mathcal{C}} Y_{d}$ is national output.

Proposition 3 then follows by log differentiating the equation for labor demand in (A6)

Characterization of the Equilibrium When Commuting Zones Trade As in the autarky equilibrium, prices are equal to unit costs given in equation (A3). In addition, now the equilibrium price for the aggregate of the good from industry $i$ is given by its unit cost, that is,

$$
P_{Y i}=\left(\sum_{c \in \mathcal{C}} \theta_{c i}^{\lambda} P_{X c i}^{1-\lambda}\right)^{\frac{1}{1-\lambda}}
$$

This price is common across all commuting zones.

We can then define the equilibrium with trade as follows.

DeFINITION 2 An equilibrium with trade (between commuting zones) is given by a set of prices $\left\{P_{Y i}\right\}_{i \in \mathcal{I}},\left\{P_{X c i}\right\}_{i \in \mathcal{I}, c \in \mathcal{C}},\left\{W_{c}, Q_{c}\right\}_{c \in \mathcal{C}}$ and quantities $\left\{L_{c}, R_{c}, Y_{c}\right\}_{c \in \mathcal{C}}$ and $Y$ such that: 
- for each commuting zone $c \in \mathcal{C}, L_{c}^{d}=L_{c}$ and $R_{c}^{d}=R_{c}$, so that the market for robots and labor clears;

- for each commuting zone $c \in \mathcal{C}$, factor prices are given by the labor supply equation (2);

- for each commuting zone $c \in \mathcal{C}$, the prices variety sourced from that commuting zones, the $P_{X c i}$ 's, are given cost minimization, equation (A3);

- the prices of consumption aggregates, the $P_{Y i}$ 's, are given by cost minimization as in equation (A7), and satisfy the ideal price index condition,

$$
1=\sum_{i \in \mathcal{I}} \alpha_{i}^{\sigma} P_{Y i}^{1-\sigma}
$$

- output in each commuting zone $c \in \mathcal{C}$ is given as

$$
Y_{c}=\sum_{i \in \mathcal{I}} X_{c i} P_{X c i}=\sum_{i \in \mathcal{I}} \alpha_{i}^{\sigma} \theta_{c i}^{\lambda} P_{X c i}^{1-\lambda} P_{Y i}^{\lambda-\sigma} Y
$$

Proposition A2 An equilibrium with trade always exists. Moreover, there exists an $\underline{m}>0$ such that the equilibrium is unique provided that $\left|M_{i}-M_{j}\right|<\underline{m}$.

Proof. Using the formula for prices in equation (A3), we can rewrite the market-clearing conditions in commuting zone $c$ as:

$$
\begin{aligned}
& L_{c}=\sum_{i \in \mathcal{I}} \frac{\alpha_{i}^{\sigma} \theta_{c i}^{\lambda}}{\gamma A_{c i}}\left(1-M_{i}\right)\left(\frac{1}{A_{c i}}\left(M_{i} Q_{c}+\left(1-M_{i}\right) \frac{W_{c}}{\gamma}\right)\right)^{-\lambda} P_{Y i}^{\lambda-\sigma} Y \\
& R_{c}=\sum_{i \in \mathcal{I}} \frac{\alpha_{i}^{\sigma} \theta_{c i}^{\lambda}}{A_{c i}} M_{i}\left(\frac{1}{A_{c i}}\left(M_{i} Q_{c}+\left(1-M_{i}\right) \frac{W_{c}}{\gamma}\right)\right)^{-\lambda} P_{Y i}^{\lambda-\sigma} Y .
\end{aligned}
$$

In addition, substituting for the supply equations and the expression for $Y_{c}$ derived from balance of trade, we get

$$
\begin{aligned}
\left(\frac{W_{c}}{\mathcal{W}_{c}}\right)^{\frac{1}{\varepsilon}}= & \sum_{i \in \mathcal{I}} \frac{\alpha_{i}^{\sigma} \theta_{c i}^{\lambda}}{\gamma A_{c i}}\left(1-M_{i}\right)\left(\frac{1}{A_{c i}}\left(M_{i} Q_{c}+\left(1-M_{i}\right) \frac{W_{c}}{\gamma}\right)\right)^{-\lambda} P_{Y i}^{\lambda-\sigma} Y \times \ldots \\
& \ldots\left(\sum_{i \in \mathcal{I}} \alpha_{i}^{\sigma} \theta_{c i}^{\lambda}\left(\frac{1}{A_{c i}}\left(M_{i} Q_{c}+\left(1-M_{i}\right) \frac{W_{c}}{\gamma}\right)\right)^{1-\lambda} P_{Y i}^{\lambda-\sigma} Y\right)^{\frac{1}{\varepsilon}} \\
\left(\frac{Q_{c}}{\mathcal{Q}_{c}}\right)^{\frac{1}{\eta}}= & \sum_{i \in \mathcal{I}} \frac{\alpha_{i}^{\sigma} \theta_{c i}^{\lambda}}{A_{c i}} M_{i}\left(\frac{1}{A_{c i}}\left(M_{i} Q_{c}+\left(1-M_{i}\right) \frac{W_{c}}{\gamma}\right)\right)^{-\lambda} P_{Y i}^{\lambda-\sigma} Y \times \ldots \\
& \ldots\left(\sum_{i \in \mathcal{I}} \alpha_{i}^{\sigma} \theta_{c i}^{\lambda}\left(\frac{1}{A_{c i}}\left(M_{i} Q_{c}+\left(1-M_{i}\right) \frac{W_{c}}{\gamma}\right)\right)^{1-\lambda} P_{Y i}^{\lambda-\sigma} Y\right)^{-1} .
\end{aligned}
$$


We first show that given $Y$ and $P_{Y i}$ there is a unique equilibrium $\left\{W_{c}^{*}\left[Y, P_{Y i}\right], Q_{c}^{*}\left[Y, P_{Y i}\right]\right\}$. To prove this, let

$$
\zeta_{c i}=\alpha_{i}^{\sigma} \theta_{c i}^{\lambda} A_{c i}^{\lambda-1} P_{Y i}^{\lambda-\sigma} Y>0
$$

We can rewrite the market-clearing conditions in a commuting zone as:

$$
\begin{aligned}
\gamma\left(\frac{W_{c}}{\mathcal{W}_{c}}\right)^{\frac{1}{\varepsilon}} & =\sum_{i \in \mathcal{I}} \zeta_{c i}\left(1-M_{i}\right)\left(M_{i} Q_{c}+\left(1-M_{i}\right) \frac{W_{c}}{\gamma}\right)^{-\lambda}\left(\sum_{i \in \mathcal{I}} \zeta_{c i}\left(M_{i} Q_{c}+\left(1-M_{i}\right) \frac{W_{c}}{\gamma}\right)^{1-\lambda}\right)^{\frac{1}{\varepsilon}} \\
\left(\frac{Q_{c}}{\mathcal{Q}_{c}}\right)^{\frac{1}{\eta}} & =\sum_{i \in \mathcal{I}} \zeta_{c i} M_{i}\left(M_{i} Q_{c}+\left(1-M_{i}\right) \frac{W_{c}}{\gamma}\right)^{-\lambda}\left(\sum_{i \in \mathcal{I}} \zeta_{c i}\left(M_{i} Q_{c}+\left(1-M_{i}\right) \frac{W_{c}}{\gamma}\right)^{1-\lambda}\right)^{-1} .
\end{aligned}
$$

Let as next define: $M=\min _{i \in \mathcal{I}}\left\{M_{i}\right\}, m_{i}=M_{i}-M \geq 0, P_{c}=M Q_{c}+(1-M) W_{c} / \gamma$ and $\Delta_{c}=Q_{c}-W_{c} / \gamma$. We can rewrite the above equations as a system of equations in $P_{c}$ and $\Delta_{c}$ as follows:

$$
\begin{aligned}
P_{c}= & (1-M) \mathcal{W}_{c} \gamma^{-1-\varepsilon}\left[\sum_{i \in \mathcal{I}} \zeta_{c i}\left(1-M_{i}\right)\left(P_{c}+m_{i} \Delta_{c}\right)^{-\lambda}\left(\sum_{i \in \mathcal{I}} \zeta_{c i}\left(P_{c}+m_{i} \Delta_{c}\right)^{1-\lambda}\right)^{\frac{1}{\varepsilon}}\right]^{\varepsilon} \\
& +M \mathcal{Q}_{c}\left[\sum_{i \in \mathcal{I}} \zeta_{c i} M_{i}\left(P_{c}+m_{i} \Delta_{c}\right)^{-\lambda}\left(\sum_{i \in \mathcal{I}} \zeta_{c i}\left(P_{c}+m_{i} \Delta_{c}\right)^{1-\lambda}\right)^{-1}\right]^{\eta}, \\
\Delta_{c}= & \left.\mathcal{Q}_{c}\left[\sum_{i \in \mathcal{I}} \zeta_{c i} M_{i}\left(P_{c}+m_{i} \Delta_{c}\right)^{-\lambda}\left(\sum_{i \in \mathcal{I}} \zeta_{c i}\left(P_{c}+m_{i} \Delta_{c}\right)^{1-\lambda}\right)^{-1}\right]^{\eta}\right]^{\eta} \\
& -\mathcal{W}_{c} \gamma^{-1-\varepsilon}\left[\sum_{i \in \mathcal{I}} \zeta_{c i}\left(1-M_{i}\right)\left(P_{c}+m_{i} \Delta_{c}\right)^{-\lambda}\left(\sum_{i \in \mathcal{I}} \zeta_{c i}\left(P_{c}+m_{i} \Delta_{c}\right)^{1-\lambda}\right)^{\frac{1}{\varepsilon}}\right]^{\varepsilon}
\end{aligned}
$$

We now prove that there exists an $\bar{m}>0$, such that, for $\max _{i} m_{i}<\bar{m}$ the system of equations (A8) and (A9) has a unique solution. We show this using the implicit function theorem. Let $m$ designate the vector of $m_{i}$ 's and $\zeta_{c}$ the vector of $\zeta_{c i}$ 's. When $m=0$, equation (A8) becomes

$$
P_{c}=(1-M)^{1+\varepsilon} \mathcal{W}_{c} \gamma^{-1-\varepsilon} P_{c}^{-\lambda(1+\varepsilon)+1}\left[\sum_{i \in \mathcal{I}} \zeta_{c i}\right]^{1+\varepsilon}+M^{1+\eta} P_{c}^{-\eta}
$$

This equation uniquely determines a value for $P_{c}$ independent of $m$, which we denote by $P_{c}^{o}$. In addition, this value of $P_{c}^{o}$ can be substituted into equation (A9) to determine a unique $\Delta_{c}$, which we denote by $\Delta_{c}^{o}>0$ :

$$
\Delta_{c}=M^{1+\eta} P_{c}^{-\eta}-(1-M)^{1+\varepsilon} \mathcal{W}_{c} \gamma^{-1-\varepsilon} P_{c}^{-\lambda(1+\varepsilon)+1}\left[\sum_{i \in \mathcal{I}} \zeta_{c i}\right]^{1+\varepsilon}
$$

(Assumption 1 ensures that $\Delta_{c}^{o}>0$, which in turn requires $\mathcal{W}_{c}$ to be small relative to $\mathcal{Q}_{c}$, so that labor is scarce and expensive relative to robots). 
The previous argument shows that at $m=0$, equations (A8) and (A9) have a unique solution $\left\{P_{c}^{o}, \Delta_{c}^{o}\right\}$. Moreover, the equations (A8) and (A9) are continuously differentiable in the neighborhood of $m=0$, implying that the Jacobian of the system of equations is not zero (equation (A2) only depends on $P_{c}$; equation (A2) is monotone in $\Delta_{c}$ ). Thus, the implicit function theorem applies and implies that there exists an $\bar{m}>0$ and unique functions $P_{c}(m ; \zeta)$ and $\Delta_{c}(m ; \zeta)$ that solve equations (A8) and (A9) for $\max _{i} m_{i}<\bar{m}$. Moreover, the functions $P_{c}(m ; \zeta)$ and $\Delta_{c}(m ; \zeta)$ are continuously differentiable for $m<\bar{m}$, and equation (A2) establishes that $P_{c}^{o}$ is increasing in $\zeta$ and that

$$
\sum_{i \in \mathcal{I}} \frac{\partial P_{c}^{o}}{\partial P_{Y i}} \frac{P_{Y i}}{P_{c}^{o}}<\frac{\lambda-\sigma}{\lambda}
$$

Because the functions $P_{c}(m ; \zeta)$ and $\Delta_{c}(m ; \zeta)$ are continuous differentiable for $\max _{i} m_{i}<\bar{m}$, the function $P_{c i}(m ; \zeta)=P_{c}(m ; \zeta)+m_{i} \Delta_{c}(m ; \zeta)$ inherits these properties near $m=0$. Thus, there exists a $\underline{m} \in(0, \bar{m}]$ such that, for $\max _{i} m_{i}<\underline{m}$, the function $P_{c i}(m ; \zeta)=P_{c}(m ; \zeta)+m_{i} \Delta_{c}(m ; \zeta)$ is increasing in $\zeta$ for all $i$ and

$$
\sum_{i \in \mathcal{I}} \frac{\partial P_{c i}(m ; \zeta)}{\partial P_{Y i}} \frac{P_{Y i}}{\left.P_{c i}(m ; \zeta)\right)}<\frac{\lambda-\sigma}{\lambda}
$$

To complete the proof, we demonstrate that there is a unique output and vector of industry prices that are consistent with equilibrium. Let $P_{Y}$ denote the vector $\left(P_{Y 1}, \ldots, P_{Y|\mathcal{I}|}\right)$, and also let $P_{c i}\left(P_{Y} ; Y\right)=P_{c}(m ; \zeta)+m_{i} \Delta_{c}(m ; \zeta)$ be the unique equilibrium price, whose existence and uniqueness we just proved. We now establish that, holding $Y$ constant, there is a unique vector of equilibrium prices $P_{Y i}$. In particular, we show that there is a unique vector of prices that satisfies equation (A7), and which can be written as:

$$
P_{Y i}=g\left(P_{Y} ; Y\right) \equiv\left(\sum_{c \in \mathcal{C}} \theta_{c i}^{\lambda} A_{c i}^{\lambda-1} P_{c i}\left(P_{Y} ; Y\right)^{1-\lambda}\right)^{\frac{1}{1-\lambda}} .
$$

The elasticity of $g\left(P_{Y} ; Y\right)$ with respect to $P_{Y}$ is

$$
\sum_{j \in \mathcal{I}} \frac{\partial g\left(P_{Y} ; Y\right)}{\partial P_{Y_{j}}} \frac{P_{Y j}}{g\left(P_{Y} ; Y\right)}=\sum_{c \in \mathcal{C}} \chi_{c i} \sum_{j \in \mathcal{I}} \frac{\partial P_{c i}\left(P_{Y} ; Y\right)}{\partial P_{Y j}} \frac{P_{Y j}}{P_{c i}\left(P_{Y} ; Y\right)}<\frac{\lambda-\sigma}{\lambda}<1 .
$$

Here, $\chi_{c i}$ denotes the share of varieties from commuting zone $c$ in industry $i$, which satisfies $\sum_{c} \chi_{c i}=1$. The first inequality follows from equation (A10).

Let $p_{Y i}=\ln P_{Y i}$ and $\ln p_{Y}$ be the vector of $\log$ prices. We can then rewrite the system for prices as:

$$
p_{y}=\widetilde{g}\left(p_{y} ; Y\right)
$$


where $\widetilde{g}$ is such that all row vectors in $\nabla_{p_{y}} \widetilde{g}$ have positive entries and sum to less than $\frac{\lambda-\sigma}{\lambda}$. This implies that the spectral norm of the matrix $\nabla_{p_{y}} \widetilde{g}$, which we denote by $\rho\left(\nabla_{p_{y}} \widetilde{g}\right)$, is less than $\frac{\lambda-\sigma}{\lambda}$. This follow from the fact that for any norm $\|\cdot\|$ we have $\rho\left(\nabla_{p_{y}} \widetilde{g}\right)<\left\|\nabla_{p_{y}} \widetilde{g}\right\|$. Taking the $\|A\|_{\infty}$ norm, we can conclude that $\rho\left(\nabla_{p_{y}} \widetilde{g}\right)$ is less than the maximum over the sum of the absolute value of the elements in a row, which is less than $\frac{\lambda-\sigma}{\lambda}$.

To establish that the equation $p_{Y}=g\left(p_{Y} ; Y\right)$ has a unique solution, note that

$$
\left\|g(p ; Y)-g\left(p^{\prime} ; Y\right)\right\|_{1}<\rho\left(\nabla_{p_{y}} \widetilde{g}\right) \cdot\left\|p-p^{\prime}\right\|_{1}
$$

where $\|\cdot\|_{1}$ denotes the $L_{1}$ norm. We can prove this inequality as follows: let $q_{i}$ be a vector equal to $p$ up to its $i-1$ th coordinate, and equal to $p^{\prime}$ from there on. The mean value theorem implies that there is a vector $c_{i}$ in the line segment between $q_{i}$ and $q_{i+1}$ such that $g\left(q_{i} ; Y\right)-g\left(q_{i+1} ; Y\right)=\nabla_{p_{y}} \widetilde{g}\left(c_{i}\right)\left(q_{i}-q_{i+1}\right)$. Thus, we have

$$
\begin{aligned}
\left\|g(p ; Y)-g\left(p^{\prime} ; Y\right)\right\|_{1} & =\left\|\sum_{i=1}^{|\mathcal{I}|} g\left(q_{i} ; Y\right)-g\left(q_{i+1} ; Y\right)\right\|_{1} \\
& <\sum_{i=1}^{|\mathcal{I}|}\left\|\nabla_{p_{y}} \widetilde{g}\left(c_{i}\right)\left(q_{i}-q_{i+1}\right)\right\|_{1} \\
& <\rho\left(\nabla_{p_{y}} \widetilde{g}\right) \sum_{i=1}^{|\mathcal{I}|}\left\|p_{i}-p_{i}^{\prime}\right\|_{1} \\
& =\rho\left(\nabla_{p_{y}} \widetilde{g}\right)\left\|p-p^{\prime}\right\|_{1} .
\end{aligned}
$$

This inequality ensures that the mapping $g\left(p_{Y} ; Y\right)$ is a contraction, and thus implies the existence and uniqueness of $p_{Y}$. In addition, because $g\left(p_{Y} ; Y\right)$ is increasing in $Y$, the resulting prices, the $P_{Y i}(Y)$ 's, are all increasing in $Y$ as well.

The last step is to show there is a unique $Y$. This follows from the ideal price index condition and the fact that each $P_{Y i}(Y)$ is increasing in $Y$ :

$$
1=\left(\sum_{i \in \mathcal{I}} \alpha_{i}^{\sigma} P_{Y i}(Y)^{1-\sigma}\right)^{\frac{1}{1-\sigma}}
$$

Because the right-hand side is increasing in $Y$, the ideal price index condition defines a unique value for it.

We next state and prove the analogue of Proposition 2 in the presence of trade across commuting zones. Since in our empirical work, we focus on the case where $M_{i} \approx 0$ for all $i$, we assume $M_{i}=M$ in the next proposition as well, significantly simplifying the expressions. We then use this result to derive the mapping between our model with trade and our empirical specifications. In what follows, as in the proof of Proposition A2, we use $\chi_{c i}$ to denote the share 
of varieties from commuting zone $c$ in the total production of industry $i$, and $\pi$ to denote the average of the $\pi_{c}$ 's across commuting zones.

Proposition A3 Consider the economy with trade between commuting zones and suppose that $M_{i}=M$. Then

$$
\begin{aligned}
d \ln L_{c}= & \left(\frac{(1+\eta)+(1+\eta)\left(1-s_{c L}\right)(\sigma-\lambda) / \lambda}{(1+\varepsilon)+(1+\eta)\left(1-s_{c L}\right) /\left(s_{c L} \lambda\right)} \pi_{c}-\frac{(1+\eta)+(1+\eta)\left(1-s_{c L}\right) /\left(s_{c L} \lambda\right)}{(1+\varepsilon)+(1+\eta)\left(1-s_{c L}\right) /\left(s_{c L} \lambda\right)}\right) \sum_{i} \ell_{c i} \frac{d M_{i}}{1-M} \\
& +\frac{(1+\eta)\left(1-s_{c L}\right) /\left(s_{c L} \lambda\right)}{(1+\varepsilon)+(1+\eta)\left(1-s_{c L}\right) /\left(s_{c L} \lambda\right)}(\sigma-\lambda) \sum_{i} \ell_{c i}\left(\sum_{d} \chi_{d i}\left(s_{d L} \pi_{d}-s_{L} \pi\right)\right) \frac{d M_{i}}{1-M} \\
& +\frac{(1+\eta)\left(1-s_{c L}\right) /\left(s_{c L} \lambda\right)}{(1+\varepsilon)+(1+\eta)\left(1-s_{c L}\right) /\left(s_{c L} \lambda\right)}(\sigma-\lambda)\left(s_{L} \pi-s_{c L} \pi_{c}\right) \sum_{i} \ell_{c i} \frac{d M_{i}}{1-M} \\
& +\frac{(1+\eta)\left(1-s_{c L}\right) /\left(s_{c L} \lambda\right)}{(1+\varepsilon)+(1+\eta)\left(1-s_{c L}\right) /\left(s_{c L} \lambda\right)}\left(\left.d \ln Y\right|_{L_{c}, R_{c} f i x e d}+G_{c}\right), \\
d \ln W_{c}= & \left(\frac{1+\eta+\left(1+\eta\left(1-s_{c L}\right)\right)(\sigma-\lambda) / \lambda}{1+(1+\eta)\left(1-s_{c L}\right) /\left(s_{c L} \lambda(1+\varepsilon)\right)} \pi_{c}-\frac{\eta-\eta / \lambda+\varepsilon(1+\eta) /\left(s_{c L} \lambda(1+\varepsilon)\right)}{1+(1+\eta)\left(1-s_{c L}\right) /\left(s_{c L} \lambda(1+\varepsilon)\right)}\right) \sum_{i} \ell_{c i} \frac{d M_{i}}{1-M} \\
& +\frac{\left(1+\eta\left(1-s_{c L}\right)\right)}{1+(1+\eta)\left(1-s_{c L}\right) /\left(s_{c L} \lambda(1+\varepsilon)\right)}(\sigma-\lambda) \sum_{i} \ell_{c i}\left(\sum_{d} \chi_{d i}\left(s_{d L} \pi_{d}-s_{L} \pi\right)\right) \frac{d M_{i}}{1-M} \\
& +\frac{\left(1+\eta\left(1-s_{c L}\right)\right) /\left(s_{c L} \lambda\right)}{1+(1+\eta)\left(1-s_{c L}\right) /\left(s_{c L} \lambda(1+\varepsilon)\right)}(\sigma-\lambda)\left(s_{L} \pi-s_{c L} \pi_{c}\right) \sum_{i} \ell_{c i} \frac{d M_{i}}{1-M} \\
& +\frac{\left(1+\eta\left(1-s_{c L}\right)\right) /\left(s_{c L} \lambda\right)}{1+(1+\eta)\left(1-s_{c L}\right) /\left(s_{c L} \lambda(1+\varepsilon)\right)}\left(\left.d \ln Y\right|_{L_{c}, R_{c} f i x e d}+G_{c}\right),
\end{aligned}
$$

where

$$
G_{c}=\left(\sum_{d \in \mathcal{C}} s_{d}\left(s_{d L} d \ln L_{d}+s_{d R} d \ln R_{d}\right)+(\lambda-\sigma) \sum_{i} \ell_{c i} \sum_{d \in \mathcal{C}} \chi_{d i}\left(s_{d L} d \ln W_{d}+s_{d R} d \ln Q_{d}\right)\right)
$$

corresponds to the impact of national changes in prices and quantities on commuting zone $c$.

Proof. First observe that when $M_{i}=M$,

$$
A_{c i} P_{X c i}=M Q_{c}+(1-M) \frac{W_{c}}{\gamma}=P_{c},
$$

where recall that $P_{c}$ is the effective cost of production in commuting zone $c$, which is common across industries (because $M_{i}=M$ ).

Moreover, in this case the share of labor in industry $i$ in commuting zone $c$ is also common across industries, i.e.,

$$
s_{i c L}=\frac{W_{c} L_{c i}}{P_{X c i} X_{c i}}=\frac{W_{c}(1-M) X_{c i}}{\gamma A_{c i} P_{X c i} X_{c i}}=(1-M) \frac{W_{c}}{\gamma P_{c}}=s_{c L},
$$

Equation (A1) then implies that

$$
\ell_{c i}=\frac{L_{c i}}{L_{c}}=\frac{R_{c i}}{R_{c}}=\frac{X_{c i} P_{X c i}}{Y_{c}}
$$


Log differentiating the demand for labor then yields

$$
\begin{aligned}
d \ln L_{c}= & -\sum_{i \in \mathcal{I}} \ell_{c i} \frac{d M_{i}}{1-M}+\lambda s_{c L} \pi_{c} \sum_{i \in \mathcal{I}} \ell_{c i} \frac{d M_{i}}{1-M}-\lambda\left(s_{c L} d \ln W_{c}+s_{c R} d \ln Q_{c}\right) \\
& +(\sigma-\lambda) \sum_{i \in \mathcal{I}} \ell_{c i} \sum_{d \in \mathcal{C}} \chi_{d i} s_{d L} \pi_{d} \frac{d M_{i}}{1-M}+(\lambda-\sigma) \sum_{i \in \mathcal{I}} \ell_{c i} \sum_{d \in \mathcal{C}} \chi_{d i}\left(s_{d L} d \ln W_{d}+s_{d R} d \ln Q_{d}\right) \\
& +d \ln Y,
\end{aligned}
$$

where $d \ln P_{X c i}$ has been replaced from equation (A2). Similarly, we also have

$$
d \ln P_{Y i}=-\sum_{c \in \mathcal{C}} \chi_{c i}\left(s_{c L} \pi_{c} \sum_{i \in \mathcal{I}} \ell_{c i} \frac{d M_{i}}{1-M_{i}}\right)+s_{c L} d \ln W_{c}+s_{s R} d \ln Q_{c}
$$

which follows by taking a total differential of equation (A7) and once again substituting for $d \ln P_{X c i}$.

We next derive an expression for $d \ln Y$ as follows:

$$
\begin{aligned}
d \ln Y & =\left.d \ln Y\right|_{L_{c}, R_{c}}+\sum_{d \in \mathcal{C}} s_{d}\left(s_{d L} d \ln L_{d}+s_{d R} d \ln R_{d}\right) \\
& =\left.\sum_{d \in \mathcal{C}} s_{d} d \ln Y_{d}\right|_{L_{c}, R_{c}}+\sum_{d \in \mathcal{C}} s_{d}\left(s_{d L} d \ln L_{d}+s_{d R} d \ln R_{d}\right) \\
& =\sum_{d \in \mathcal{C}} s_{d} s_{c L} \pi_{c} \sum_{i \in \mathcal{I}} \ell_{c i} \frac{d M_{i}}{1-M}+\sum_{d \in \mathcal{C}} s_{d}\left(s_{d L} d \ln L_{d}+s_{d R} d \ln R_{d}\right),
\end{aligned}
$$

which follows from Lemma A1 and the envelope theorem.

Substituting for $d \ln Y$ from the previous expression, factor demands can be simplified as follows:

$$
\begin{aligned}
d \ln L_{c}= & -\sum_{i \in \mathcal{I}} \ell_{c i} \frac{d M_{i}}{1-M}+\lambda s_{c L} \pi_{c} \sum_{i \in \mathcal{I}} \ell_{c i} \frac{d M_{i}}{1-M}-\lambda\left(s_{c L} d \ln W_{c}+s_{c R} d \ln Q_{c}\right) \\
& +(\sigma-\lambda) \sum_{i \in \mathcal{I}} \ell_{c i} \sum_{d \in \mathcal{C}} \chi_{d i} s_{d L} \pi_{d} \frac{d M_{i}}{1-M}+\left.d \ln Y\right|_{L_{c}, R_{c}}+G_{c}
\end{aligned}
$$

and

$$
\begin{aligned}
d \ln R_{c}= & \left(1-\pi_{c}\right) \frac{s_{c L}}{s_{c R}} \sum_{i \in \mathcal{I}} \ell_{c i} \frac{d M_{i}}{1-M}+\lambda s_{c L} \pi_{c} \sum_{i \in \mathcal{I}} \ell_{c i} \frac{d M_{i}}{1-M}-\lambda\left(s_{c L} d \ln W_{c}+s_{c R} d \ln Q_{c}\right) \\
& +(\sigma-\lambda) \sum_{i \in \mathcal{I}} \ell_{c i} \sum_{d \in \mathcal{C}} \chi_{d i} s_{d L} \pi_{d} \frac{d M_{i}}{1-M}+\left.d \ln Y\right|_{L_{c}, R_{c}}+G_{c} .
\end{aligned}
$$

Combining equations (A14) and (A15) with the supply equations, written in log differential form as

$$
\begin{aligned}
& d \ln W_{c}=s_{c L}\left(d \ln L_{c}+d \ln W_{c}\right)+s_{c R}\left(d \ln R_{c}+d \ln Q_{c}\right)+\varepsilon d \ln L_{c} \\
& d \ln Q_{c}=\eta d \ln R_{c}-\eta s_{c L}\left(d \ln L_{c}+d \ln W_{c}\right)-\eta s_{c R}\left(d \ln R_{c}+d \ln Q_{c}\right),
\end{aligned}
$$


we obtain a system of four equations in four unknowns: $d \ln L_{c}, d \ln R_{c}, d \ln W_{c}$, and $d \ln Q_{c}$. The solution to this linear system of equations is given by the expressions provided in equations (A11) and (A12), which completes the proof.

We now present two corollaries of Proposition A3, which motivate our empirical specifications.

Corollary 1 Suppose $M_{i}=M$. Then, in an equilibrium with trade, we have

$$
\begin{aligned}
d \ln L_{c}= & \left(\frac{(1+\eta)+(1+\eta)\left(1-s_{c L}\right)(\sigma-\lambda) / \lambda}{(1+\varepsilon)+(1+\eta)\left(1-s_{c L}\right) /\left(s_{c L} \lambda\right)} \pi-\frac{(1+\eta)+(1+\eta)\left(1-s_{c L}\right) /\left(s_{c L} \lambda\right)}{(1+\varepsilon)+(1+\eta)\left(1-s_{c L}\right) /\left(s_{c L} \lambda\right)}\right) \sum_{i \in \mathcal{I}} \ell_{c i} \frac{d M_{i}}{1-M} \\
& +\frac{(1+\eta)\left(1-s_{c L}\right) /\left(s_{c L} \lambda\right)}{(1+\varepsilon)+(1+\eta)\left(1-s_{c L}\right) /\left(s_{c L} \lambda\right)}\left(\left.d \ln Y\right|_{L_{c}, R_{c} \text { fixed }}+G_{c}\right)+\mathcal{O}\left(\max _{c}\left|s_{L} \pi-s_{c L} \pi_{c}\right|\right), \\
d \ln W_{c}= & \left(\frac{(1+\eta)+\left(1+\eta\left(1-s_{c L}\right)\right)(\sigma-\lambda) / \lambda}{1+(1+\eta)\left(1-s_{c L}\right) /\left(s_{c L} \lambda(1+\varepsilon)\right)} \pi-\frac{\eta-\eta / \lambda+\varepsilon(1+\eta) /\left(s_{c L} \lambda(1+\varepsilon)\right)}{1+(1+\eta)\left(1-s_{c L}\right) /\left(s_{c L} \lambda(1+\varepsilon)\right)}\right) \sum_{i \in \mathcal{I}} \ell_{c i} \frac{d M_{i}}{1-M} \\
& +\frac{\left(1+\eta\left(1-s_{c L}\right)\right) /\left(s_{c L} \lambda\right)}{1+(1+\eta)\left(1-s_{c L}\right) /\left(s_{c L} \lambda(1+\varepsilon)\right)}\left(\left.d \ln Y\right|_{L_{c}, R_{c} \text { fixed }}+G_{c}\right)+\mathcal{O}\left(\max _{c}\left|s_{L} \pi-s_{c L} \pi_{c}\right|\right) .
\end{aligned}
$$

Corollary 2 Suppose $M_{i}=M$ and $\pi_{c}=\pi$. Then, in an equilibrium with trade, we have $s_{c L}=s_{L}$, and

$$
\begin{aligned}
d \ln L_{c}= & \left(\frac{(1+\eta)+(1+\eta)\left(1-s_{L}\right)(\sigma-\lambda) / \lambda}{(1+\varepsilon)+(1+\eta)\left(1-s_{L}\right) /\left(s_{L} \lambda\right)} \pi-\frac{(1+\eta)+(1+\eta)\left(1-s_{L}\right) /\left(s_{L} \lambda\right)}{(1+\varepsilon)+(1+\eta)\left(1-s_{L}\right) /\left(s_{L} \lambda\right)}\right) \sum_{i \in \mathcal{I}} \ell_{c i} \frac{d M_{i}}{1-M} \\
& +\frac{(1+\eta)\left(1-s_{L}\right) /\left(s_{L} \lambda\right)}{(1+\varepsilon)+(1+\eta)\left(1-s_{L}\right) /\left(s_{L} \lambda\right)}\left(\left.d \ln Y\right|_{L_{c}, R_{c} f i x e d}+G_{c}\right), \\
d \ln W_{c}= & \left(\frac{(1+\eta)+\left(1+\eta\left(1-s_{L}\right)\right)(\sigma-\lambda) / \lambda}{1+(1+\eta)\left(1-s_{L}\right) /\left(s_{L} \lambda(1+\varepsilon)\right)} \pi-\frac{\eta-\eta / \lambda+\varepsilon(1+\eta) /\left(s_{L} \lambda(1+\varepsilon)\right)}{1+(1+\eta)\left(1-s_{L}\right) /\left(s_{L} \lambda(1+\varepsilon)\right)}\right) \sum_{i \in \mathcal{I}} \ell_{c i} \frac{d M_{i}}{1-M} \\
& +\frac{\left(1+\eta\left(1-s_{L}\right)\right) /\left(s_{L} \lambda\right)}{1+(1+\eta)\left(1-s_{L}\right) /\left(s_{L} \lambda(1+\varepsilon)\right)}\left(\left.d \ln Y\right|_{L_{c}, R_{c} \text { fixed }}+G_{c}\right) .
\end{aligned}
$$

Our empirical specifications for the model with trade between commuting zones, in particular, the expressions in (11), follow from the latter corollary under the assumptions we utilize in mapping our model to data- $-M_{i} \approx 0$ and $\pi_{c} \approx \pi$. Notice that the third expression for both the change in employment and wages in a commuting zone become part of the residual, since they do not project on our measure of exposure to robots, $\sum_{i \in \mathcal{I}} \ell_{c i} \frac{d M_{i}}{1-M}$.

The previous two corollaries characterize how employment and wages in a commuting zone change (in an equilibrium with trade between commuting zones) in response to the spread of robots. We next turn to the aggregate effects of robots. In this proposition and what follows, we use the following notation: for a variable $X_{c}$, we use $\mathbb{E}\left[X_{c}\right]$ denote its average across commuting zones, i.e., $\mathbb{E}\left[X_{c}\right]=\sum_{c} s_{c} X_{c}$.

Proposition A4 Suppose that $M_{i}=M$ and $\pi_{c}=\pi$. Then, in an equilibrium with trade 
between commuting zones, we have the following aggregate effects of robots:

$$
\begin{aligned}
\mathbb{E}\left[d \ln L_{c}\right] & =\left(\frac{1+\eta}{1+\varepsilon} \pi-\frac{1+\eta}{1+\varepsilon}\right) \mathbb{E}\left[\sum_{i \in \mathcal{I}} \ell_{c i} \frac{d M_{i}}{1-M}\right] . \\
\mathbb{E}\left[d \ln W_{c}\right] & =((1+\eta) \pi-\eta) \mathbb{E}\left[\sum_{i \in \mathcal{I}} \ell_{c i} \frac{d M_{i}}{1-M}\right] .
\end{aligned}
$$

Proof. As already noted, when $\pi_{c}=\pi$, we have $s_{c L}=s_{L}$. Then the labor demand equation can be rewritten as

$$
\begin{aligned}
d \ln L_{c}= & -\sum_{i \in \mathcal{I}} \ell_{c i} \frac{d M_{i}}{1-M}+\lambda s_{L} \pi \sum_{i \in \mathcal{I}} \ell_{c i} \frac{d M_{i}}{1-M}-\lambda\left(s_{L} d \ln W_{c}+s_{R} d \ln Q_{c}\right) \\
& +(\sigma-\lambda) \sum_{i \in \mathcal{I}} \ell_{c i} d \ln P_{Y i}+d \ln Y .
\end{aligned}
$$

Aggregating this equation across commuting zones and using the formula for $d \ln Y$ derived in equation (A13), we obtain

$$
\begin{aligned}
\mathbb{E}\left[d \ln L_{c}\right]= & -\mathbb{E}\left[\sum_{i \in \mathcal{I}} \ell_{c i} \frac{d M_{i}}{1-M}\right]+\lambda s_{L} \pi \mathbb{E}\left[\sum_{i \in \mathcal{I}} \ell_{c i} \frac{d M_{i}}{1-M}\right]-\lambda\left(s_{L} \mathbb{E}\left[d \ln W_{c}\right]+s_{R} \mathbb{E}\left[d \ln Q_{c}\right]\right) \\
& +(\sigma-\lambda) \mathbb{E}\left[\sum_{i \in \mathcal{I}} \ell_{c i} d \ln P_{Y i}\right]+s_{L} \pi \mathbb{E}\left[\sum_{i \in \mathcal{I}} \ell_{c i} \frac{d M_{i}}{1-M}\right]+s_{L} \mathbb{E}\left[d \ln L_{c}\right]+s_{R} \mathbb{E}\left[d \ln R_{c}\right] .
\end{aligned}
$$

In addition, we also have

$$
\begin{aligned}
\mathbb{E}\left[\sum_{i \in \mathcal{I}} \ell_{c i} d \ln P_{Y i}\right] & =\sum_{c} \sum_{i \in \mathcal{I}} s_{c} \ell_{c i} d \ln P_{Y i} \\
& =\sum_{i \in \mathcal{I}}\left(\sum_{c} s_{c} s_{c i}\right) d \ln P_{Y i} \\
& =\sum_{i \in \mathcal{I}} \frac{P_{Y_{i}} Y_{i}}{Y} d \ln P_{Y i} \\
& =0 .
\end{aligned}
$$

The last equality follows because the prices $\left\{P_{Y i}\right\}_{i \in \mathcal{I}}$ satisfy the ideal price index condition.

Thus, the labor demand equation simplifies to:

$$
\begin{aligned}
\mathbb{E}\left[d \ln L_{c}\right]= & -\mathbb{E}\left[\sum_{i \in \mathcal{I}} \ell_{c i} \frac{d M_{i}}{1-M}\right]+\lambda s_{L} \pi \mathbb{E}\left[\sum_{i \in \mathcal{I}} \ell_{c i} \frac{d M_{i}}{1-M}\right]-\lambda\left(s_{L} \mathbb{E}\left[d \ln W_{c}\right]+s_{R} \mathbb{E}\left[d \ln Q_{c}\right]\right) \\
& +s_{L} \pi \mathbb{E}\left[\sum_{i \in \mathcal{I}} \ell_{c i} \frac{d M_{i}}{1-M}\right]+s_{L} \mathbb{E}\left[d \ln L_{c}\right]+s_{R} \mathbb{E}\left[d \ln R_{c}\right]
\end{aligned}
$$


Likewise, for robots we get:

$$
\begin{aligned}
\mathbb{E}\left[d \ln R_{c}\right]= & (1-\pi) \frac{s_{L}}{s_{R}} \mathbb{E}\left[\sum_{i \in \mathcal{I}} \ell_{c i} \frac{d M_{i}}{1-M}\right]+\lambda s_{L} \pi \mathbb{E}\left[\sum_{i \in \mathcal{I}} \ell_{c i} \frac{d M_{i}}{1-M}\right]-\lambda\left(s_{L} \mathbb{E}\left[d \ln W_{c}\right]+s_{R} \mathbb{E}\left[d \ln Q_{c}\right]\right) \\
& +s_{L} \pi \mathbb{E}\left[\sum_{i \in \mathcal{I}} \ell_{c i} \frac{d M_{i}}{1-M}\right]+s_{L} \mathbb{E}\left[d \ln L_{c}\right]+s_{R} \mathbb{E}\left[d \ln R_{c}\right] .
\end{aligned}
$$

Combining equations (A21) and (A22) with the aggregated versions of the supply equations in (A16), i.e.,

$$
\begin{aligned}
& \mathbb{E}\left[d \ln W_{c}\right]=s_{L}\left(\mathbb{E}\left[d \ln L_{c}\right]+\mathbb{E}\left[d \ln W_{c}\right]\right)+s_{R}\left(\mathbb{E}\left[d \ln R_{c}\right]+\mathbb{E}\left[d \ln Q_{c}\right]\right)+\varepsilon \mathbb{E}\left[d \ln L_{c}\right] \\
& \mathbb{E}\left[d \ln Q_{c}\right]=\eta \mathbb{E}\left[d \ln R_{c}\right]-\eta s_{L}\left(\mathbb{E}\left[d \ln L_{c}\right]+\mathbb{E}\left[d \ln W_{c}\right]\right)-\eta s_{R}\left(\mathbb{E}\left[d \ln R_{c}\right]+\mathbb{E}\left[d \ln Q_{c}\right]\right),
\end{aligned}
$$

we once again obtain a system of four equations in four unknowns: $\mathbb{E}\left[d \ln L_{c}\right], \mathbb{E}\left[d \ln R_{c}\right], \mathbb{E}\left[d \ln W_{c}\right]$, and $\mathbb{E}\left[d \ln Q_{c}\right]$. The solution to this linear system of equations is given by the expressions provided in equations (A19) and (A20), which completes the proof. 
TABLE A1: Robot adoption by industry in Europe and the United States

\begin{tabular}{|c|c|c|c|c|c|c|c|c|c|c|c|}
\hline & \multicolumn{8}{|c|}{ USE OF INDUSTRIAL ROBOTS IN EUROPE } & \multirow{2}{*}{\multicolumn{3}{|c|}{$\begin{array}{l}\text { Use of industrial Robots } \\
\text { IN the United States }\end{array}$}} \\
\hline & \multicolumn{4}{|c|}{ 30Th PERCENTILE } & \multicolumn{4}{|c|}{ MEAN } & & & \\
\hline & 1993 & 2004 & 2007 & 2014 & 1993 & 2004 & 2007 & 2014 & 2004 & 2007 & 2014 \\
\hline \multicolumn{12}{|l|}{ Extractive: } \\
\hline 1. Agriculture, forestry and fishing & 0.000 & 0.004 & 0.010 & 0.029 & 0.000 & 0.073 & 0.102 & 0.161 & 0.002 & 0.005 & 0.037 \\
\hline 2. Mining and quarrying & 0.000 & 0.000 & 0.000 & 0.028 & 0.175 & 1.889 & 1.788 & 1.238 & 0.002 & 0.006 & 0.061 \\
\hline \multicolumn{12}{|l|}{ Manufacturing: } \\
\hline 3. Food and Beveradges & 0.163 & 1.778 & 2.668 & 6.776 & 0.434 & 2.714 & 4.643 & 8.730 & 2.906 & 3.919 & 6.169 \\
\hline 4. Textiles & 0.032 & 0.071 & 0.148 & 0.154 & 0.333 & 0.779 & 0.797 & 0.946 & 0.002 & 0.007 & 0.048 \\
\hline 5. Wood and furniture & 0.250 & 2.217 & 2.348 & 2.155 & 2.682 & 6.956 & 8.028 & 6.731 & 0.012 & 0.025 & 0.241 \\
\hline 6. Paper & 0.007 & 0.197 & 0.246 & 0.273 & 0.186 & 0.530 & 0.717 & 0.907 & 0.001 & 0.003 & 0.110 \\
\hline 7. Plastic and chemicals & 0.957 & 8.515 & 13.523 & 13.497 & 2.917 & 14.314 & 18.872 & 17.828 & 5.122 & 6.950 & 9.906 \\
\hline 8. Glass and ceramics & 0.182 & 1.096 & 2.451 & 1.409 & 0.743 & 2.724 & 3.731 & 4.404 & 0.115 & 0.234 & 0.673 \\
\hline 9. Basic metals & 0.146 & 1.723 & 2.505 & 4.406 & 2.237 & 4.132 & 5.258 & 7.613 & 0.000 & 0.000 & 7.170 \\
\hline 10. Metal machinery & 1.340 & 3.020 & 5.031 & 3.994 & 2.824 & 4.369 & 5.684 & 8.230 & 0.000 & 0.002 & 2.373 \\
\hline 11. Metal products & 4.516 & 5.520 & 9.421 & 10.599 & 7.090 & 12.182 & 16.149 & 17.432 & 7.487 & 9.495 & 8.289 \\
\hline 12. Electronics & 1.050 & 1.893 & 2.622 & 2.701 & 2.411 & 6.160 & 6.980 & 5.580 & 5.713 & 8.657 & 13.109 \\
\hline 13. Automotive & 9.238 & 19.478 & 30.816 & 47.101 & 17.557 & 62.897 & 73.936 & 80.865 & 69.007 & 85.722 & 117.721 \\
\hline 14. Other vehicles & 0.044 & 0.503 & 0.719 & 1.580 & 2.540 & 4.520 & 3.344 & 2.735 & 0.052 & 0.120 & 0.542 \\
\hline 15. Other manufacturing & 0.603 & 2.038 & 1.102 & 1.703 & 3.508 & 4.025 & 3.379 & 4.018 & 0.838 & 1.176 & 8.288 \\
\hline \multicolumn{12}{|l|}{ Remaining industries: } \\
\hline 16. Electricity, gas, water supply & 0.000 & 0.000 & 0.024 & 0.085 & 0.000 & 0.067 & 0.103 & 0.219 & 0.000 & 0.000 & 0.027 \\
\hline 17. Construction & 0.000 & 0.007 & 0.023 & 0.053 & 0.000 & 0.044 & 0.061 & 0.097 & 0.003 & 0.007 & 0.020 \\
\hline 18. Education, research and development & 0.000 & 0.117 & 0.159 & 0.214 & 0.024 & 0.404 & 0.465 & 0.448 & 0.011 & 0.014 & 0.064 \\
\hline 19. Other non-manufacturing industries & 0.000 & 0.000 & 0.000 & 0.001 & 0.000 & 0.000 & 0.000 & 0.006 & 0.000 & 0.000 & 0.004 \\
\hline
\end{tabular}


TABLE A2: The impact of the exposure to robots on the location of integrators.

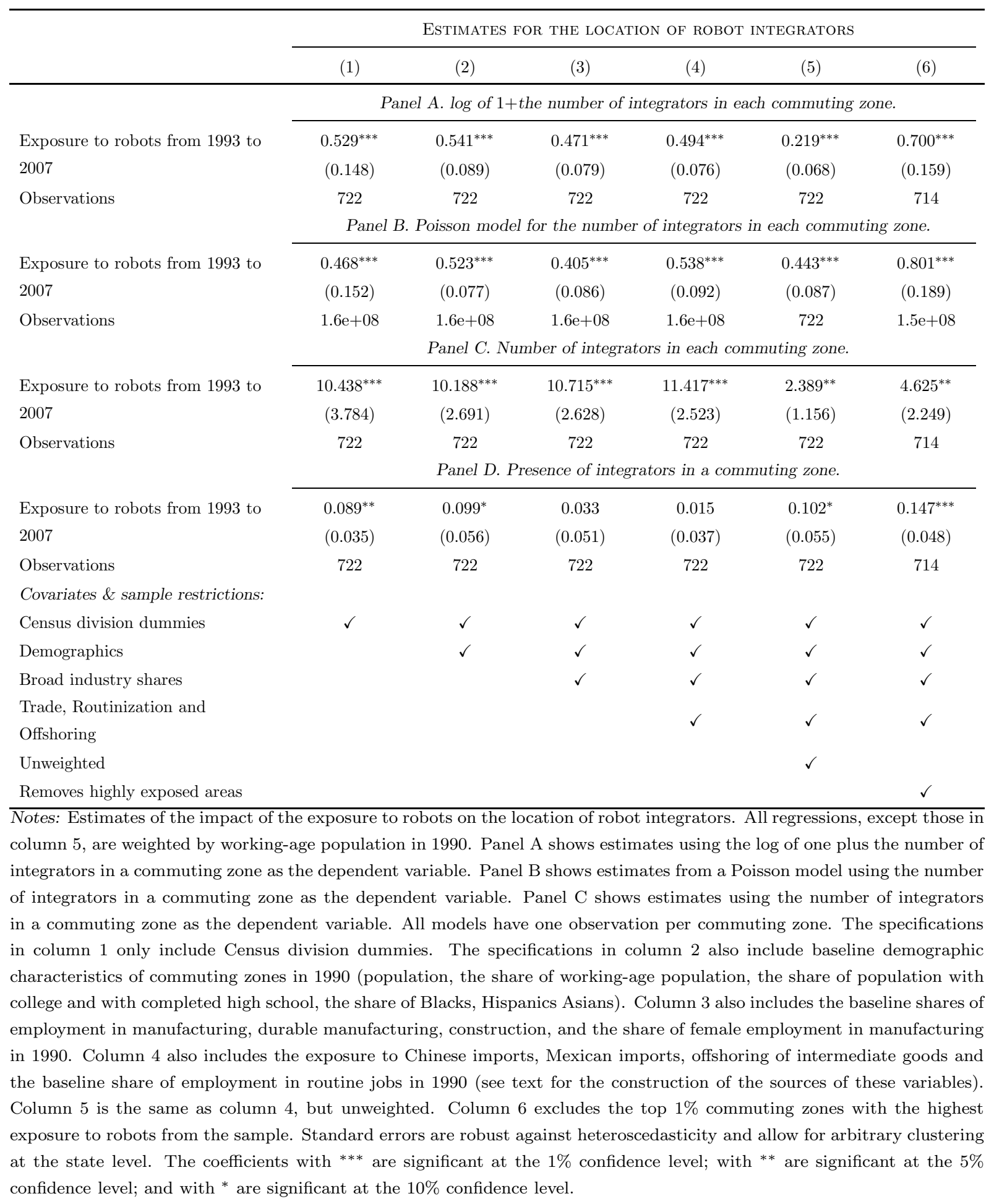


TABLE A3: The impact of the exposure to robots on employment (long-differences going beyond 2007)

\begin{tabular}{|c|c|c|c|c|c|c|}
\hline & \multicolumn{3}{|c|}{ LONG DIFFERENCES FROM 1990 TO 2010} & \multicolumn{3}{|c|}{ LONG DIFFERENCES FROM 1990 TO 2014} \\
\hline & (1) & $(2)$ & (3) & $(4)$ & $(5)$ & $(6)$ \\
\hline & \multicolumn{6}{|c|}{ Panel A. Census private employment to population ratio. } \\
\hline Exposure to robots & $\begin{array}{c}-0.876^{* * *} \\
(0.159)\end{array}$ & $\begin{array}{c}-1.190^{* * *} \\
(0.268)\end{array}$ & $\begin{array}{c}-1.238^{* * *} \\
(0.229)\end{array}$ & $\begin{array}{c}-0.321^{* *} \\
(0.130)\end{array}$ & $\begin{array}{c}-0.571^{* * *} \\
(0.208)\end{array}$ & $\begin{array}{c}-0.566^{* * *} \\
(0.183)\end{array}$ \\
\hline Observations & \multicolumn{6}{|c|}{ Panel B. CBP employment to population ratio. } \\
\hline Exposure to robots & $\begin{array}{c}-1.348^{* * *} \\
(0.338)\end{array}$ & $\begin{array}{c}-0.943^{* *} \\
(0.366)\end{array}$ & $\begin{array}{c}-0.971^{* * *} \\
(0.292)\end{array}$ & $\begin{array}{c}-0.625^{* * *} \\
(0.222)\end{array}$ & $\begin{array}{l}-0.437 \\
(0.280)\end{array}$ & $\begin{array}{c}-0.534^{* *} \\
(0.221)\end{array}$ \\
\hline Observations & \multicolumn{6}{|c|}{ Panel C. Log hourly wage. } \\
\hline Exposure to robots & $\begin{array}{c}-2.029^{* * *} \\
(0.245)\end{array}$ & $\begin{array}{c}-1.961^{* * *} \\
(0.288)\end{array}$ & $\begin{array}{c}-2.330^{* * *} \\
(0.242)\end{array}$ & $\begin{array}{c}-1.831^{* * *} \\
(0.244)\end{array}$ & $\begin{array}{c}-1.659^{* * *} \\
(0.292)\end{array}$ & $\begin{array}{c}-1.853^{* * *} \\
(0.287)\end{array}$ \\
\hline Observations & \multicolumn{6}{|c|}{ Panel D. Log weekly wage. } \\
\hline Exposure to robots & $\begin{array}{c}-2.789^{* * *} \\
(0.258)\end{array}$ & $\begin{array}{c}-2.492^{* * *} \\
(0.445)\end{array}$ & $\begin{array}{c}-2.578^{* * *} \\
(0.314)\end{array}$ & $\begin{array}{c}-2.119^{* * *} \\
(0.257)\end{array}$ & $\begin{array}{c}-1.967^{* * *} \\
(0.422)\end{array}$ & $\begin{array}{c}-1.837^{* * *} \\
(0.319)\end{array}$ \\
\hline Observations & 165026 & 165026 & 162002 & 144101 & 144101 & 142149 \\
\hline Covariates \& sample re & & & & & & \\
\hline Baseline covariates & $\checkmark$ & $\checkmark$ & $\checkmark$ & $\checkmark$ & $\checkmark$ & $\checkmark$ \\
\hline Unweighted & & $\checkmark$ & & & $\checkmark$ & \\
\hline Down-weights outliers & & & $\checkmark$ & & & $\checkmark$ \\
\hline $\begin{array}{l}\text { Notes: Long-difference } \\
\text { variable is the change i } \\
6 \text { ) in Panel A, the chan } \\
\text { County Business Patte } \\
\text { wage in Panel C, and t } \\
\text { The models in Panels } \\
\text { estimated at the demog } \\
\text { birthplace and relation } \\
\text { characteristics of comm } \\
\text { and with completed hig } \\
\text { durable manufacturing, } \\
\text { imports, Mexican impo } \\
\text { for the construction of } \\
\text { population in 1990. Co } \\
\text { downweight outliers (se } \\
\text { clustering and correlati } \\
\text { with ** are significant }\end{array}$ & $\begin{array}{l}\text { of the impac } \\
\text { vate employ } \\
\text { ment to pop } \\
\text { B, the chan } \\
\text { etween } 1990 \\
\text { one observ } \\
\text { commuting } \\
\text { ehold head. } \\
\text { (population, } \\
\text { share of Bla } \\
\text {, and the sh } \\
\text { g of interme } \\
\text { of these var } \\
5 \text { show unw } \\
\text { details). St } \\
\text { at the state } \\
\text { nfidence leve }\end{array}$ & $\begin{array}{l}\text { the expos } \\
\text { t to popul } \\
\text { tion ratio b } \\
\text { between } 19 \\
2010 \text { (or } \\
\text { n per com } \\
\text { e level. De } \\
\text { specificatic } \\
\text { share of y } \\
\text { Hispanics } \\
\text { of female } \\
\text { e goods an } \\
\text { es). The r } \\
\text { ted regress } \\
\text { lard errors } \\
\text { el. The co } \\
\text { nd with } *\end{array}$ & $\begin{array}{l}\text { to robots } \\
\text { n ratio betw } \\
\text { veen } 1990 \text { an } \\
\text { and } 2010 \text { (o } \\
4 \text { in columns } \\
\text { ing zone, wh } \\
\text { graphic cells } \\
\text { include Cen } \\
\text { king-age pop } \\
\text { ans); the bas } \\
\text { loyment in } \\
\text { he baseline s } \\
\text { essions in co } \\
\text { s. Columns } \\
\text { robust agair } \\
\text { ients with * }\end{array}$ & $\begin{array}{l}\text { employmer } \\
2010 \text { (or } 20 \\
2014 \text { in coll } \\
4 \text { to } 6 \text { ) in th } \\
\text { le the specif } \\
\text { are defined } \\
\text { as division d } \\
\text { ation, the s } \\
\text { ine shares of } \\
\text { anufacturin } \\
\text { are of emplo } \\
\text { mns } 1 \text { and } \\
\text { and } 6 \text { repor } \\
t \text { heterosced }\end{array}$ & $\begin{array}{l}\text { nd wages. } \\
0 \text { (or } 2014 \\
\text { n columns } \\
\text { s } 4 \text { to } 6 \text { ) } \\
\text { g weekly } \\
\text { ons in Pal } \\
\text { ge, gender } \\
\text { mies; base } \\
\text { of popula } \\
\text { ployment i } \\
\text { nd the exp } \\
\text { ent in rout } \\
\text { e weightec } \\
\text { 's robust r } \\
\text { city and al }\end{array}$ & $\begin{array}{l}\text { e dependent } \\
\text { columns } 4 \text { to } \\
6 \text { ) from the } \\
\text { ee log hourly } \\
\text { in Panel D. } \\
\text { C and D are } \\
\text { ucation, race, } \\
\text { demographic } \\
\text { with college } \\
\text { anufacturing, } \\
\text { e to Chinese } \\
\text { jobs (see text } \\
\text { working-age } \\
\text { ssions, which } \\
\text { for arbitrary } \\
\text { fidence level; }\end{array}$ \\
\hline
\end{tabular}


TABLE A4: The impact of the exposure to robots on various labor market outcomes

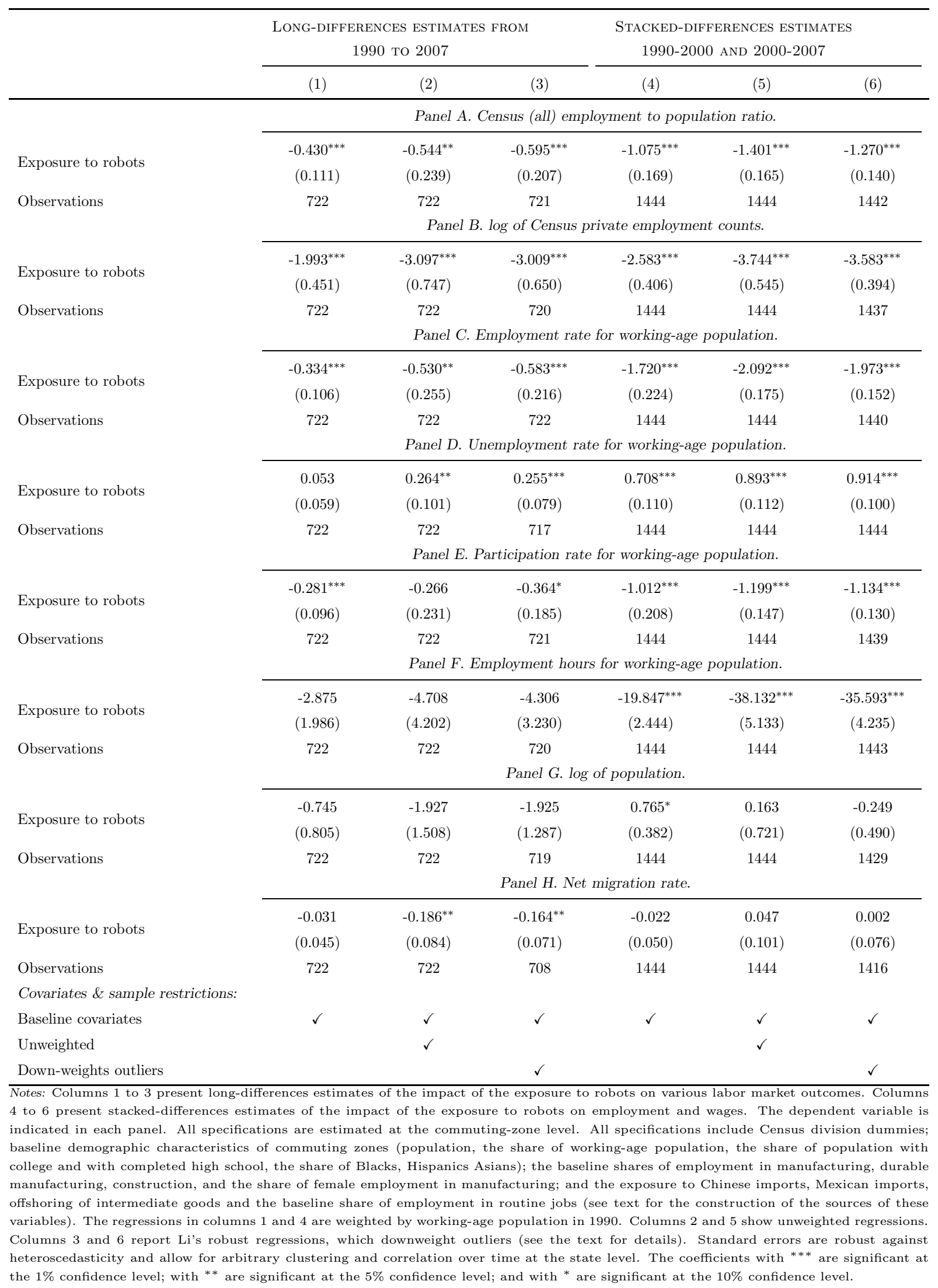


TABLE A5: The impact of the exposure to robots and other contemporaneous shocks on employment

\begin{tabular}{|c|c|c|c|c|c|c|}
\hline & \multicolumn{6}{|c|}{ Estimates for Census PRIVATE EMPloyment to POPUlation Ratios } \\
\hline & (1) & $(2)$ & (3) & $(4)$ & $(5)$ & (6) \\
\hline \multirow[b]{2}{*}{$\begin{array}{l}\text { Exposure to robots from } 1993 \text { to } \\
2007\end{array}$} & \multicolumn{6}{|c|}{ Panel A. Long differences from 1990 to 2007.} \\
\hline & $\begin{array}{c}-0.782^{* * *} \\
(0.262)\end{array}$ & $\begin{array}{c}-0.769^{* * *} \\
(0.185)\end{array}$ & $\begin{array}{c}-0.785^{* * *} \\
(0.184)\end{array}$ & $\begin{array}{c}-0.777^{* * *} \\
(0.189)\end{array}$ & $\begin{array}{c}-0.775^{* * *} \\
(0.187)\end{array}$ & $\begin{array}{c}-0.751^{* * *} \\
(0.166)\end{array}$ \\
\hline $\begin{array}{l}\text { Share of manufacture employment } \\
\text { in } 1990\end{array}$ & & $\begin{array}{c}-30.350^{* * *} \\
(4.630)\end{array}$ & $\begin{array}{c}-28.982^{* * *} \\
(5.227)\end{array}$ & $\begin{array}{c}-28.890^{* * *} \\
(5.194)\end{array}$ & $\begin{array}{c}-30.172^{* * *} \\
(5.290)\end{array}$ & $\begin{array}{c}-23.240^{* * *} \\
(5.147)\end{array}$ \\
\hline Exposure to Chinese imports & & & $\begin{array}{l}-0.046 \\
(0.059)\end{array}$ & $\begin{array}{l}-0.043 \\
(0.063)\end{array}$ & $\begin{array}{l}-0.044 \\
(0.063)\end{array}$ & $\begin{array}{l}-0.095 \\
(0.060)\end{array}$ \\
\hline Exposure to Mexican imports & & & & $\begin{array}{l}-0.010 \\
(0.025)\end{array}$ & $\begin{array}{l}-0.012 \\
(0.025)\end{array}$ & $\begin{array}{c}0.012 \\
(0.028)\end{array}$ \\
\hline Exposure to offshoring & & & & & $\begin{array}{c}0.860 \\
(1.378)\end{array}$ & $\begin{array}{c}0.209 \\
(1.362)\end{array}$ \\
\hline $\begin{array}{l}\text { Share of employment in routine } \\
\text { jobs inin } 1990\end{array}$ & & & & & & $\begin{array}{c}-18.655^{* * *} \\
(5.834)\end{array}$ \\
\hline \multirow[t]{2}{*}{ Observations } & 722 & 722 & 722 & 722 & 722 & 722 \\
\hline & \multicolumn{6}{|c|}{ Panel B. Stacked differences from 1990-2000 and 2000-2007. } \\
\hline $\begin{array}{l}\text { Exposure to robots from } 1993 \text { to } \\
2007\end{array}$ & $\begin{array}{c}-1.128^{* * *} \\
(0.211)\end{array}$ & $\begin{array}{c}-0.951^{* * *} \\
(0.152)\end{array}$ & $\begin{array}{c}-0.965^{* * *} \\
(0.140)\end{array}$ & $\begin{array}{c}-0.926^{* * *} \\
(0.152)\end{array}$ & $\begin{array}{c}-0.920^{* * *} \\
(0.148)\end{array}$ & $\begin{array}{c}-0.953^{* * *} \\
(0.146)\end{array}$ \\
\hline $\begin{array}{l}\text { Share of manufacture employment } \\
\text { in } 1990\end{array}$ & & $\begin{array}{c}-21.262^{* * *} \\
(4.618)\end{array}$ & $\begin{array}{c}-18.584^{* * *} \\
(4.111)\end{array}$ & $\begin{array}{c}-18.880^{* * *} \\
(4.001)\end{array}$ & $\begin{array}{c}-20.017^{* * *} \\
(4.377)\end{array}$ & $\begin{array}{c}-16.893^{* * *} \\
(4.280)\end{array}$ \\
\hline Exposure to Chinese imports & & & $\begin{array}{c}-0.154^{* * *} \\
(0.032)\end{array}$ & $\begin{array}{c}-0.131^{* * *} \\
(0.047)\end{array}$ & $\begin{array}{c}-0.131^{* * *} \\
(0.048)\end{array}$ & $\begin{array}{c}-0.159^{* * *} \\
(0.046)\end{array}$ \\
\hline Exposure to Mexican imports & & & & $\begin{array}{l}-0.062 \\
(0.064)\end{array}$ & $\begin{array}{l}-0.064 \\
(0.065)\end{array}$ & $\begin{array}{l}-0.042 \\
(0.064)\end{array}$ \\
\hline Exposure to offshoring & & & & & $\begin{array}{c}1.374 \\
(0.994)\end{array}$ & $\begin{array}{c}1.155 \\
(0.921)\end{array}$ \\
\hline $\begin{array}{l}\text { Share of employment in routine } \\
\text { jobs in } 1990\end{array}$ & & & & & & $\begin{array}{r}-10.486^{*} \\
(5.276)\end{array}$ \\
\hline Observations & 1444 & 1444 & 1444 & 1444 & 1444 & 1444 \\
\hline $\begin{array}{l}\text { Notes: Panel A presents long-differ } \\
\text { employment. Panel B presents stac } \\
\text { shocks on employment. The depe } \\
\text { specification in column } 1 \text { includes } \\
\text { (population, the share of working- } \\
\text { share of Blacks, Hispanics Asians) } \\
\text { manufacturing, construction, and } \\
\text { Chinese imports (computed as a } \\
\text { Mexican imports (computed as a B } \\
\text { offshoring of intermediate inputs (c } \\
\text { baseline share of employment in ro } \\
\text { errors are robust against heterosce } \\
\text { The coefficients with }{ }^{* * *} \text { are signi } \\
\text { with }{ }^{*} \text { are significant at the } 10 \%\end{array}$ & $\begin{array}{l}\text { ces estimat } \\
\text { d-difference } \\
\text { lent variab } \\
\text { ensus divisi } \\
\text { populatio } \\
\text { Column } 2 \\
\text { e share of } \\
\text { tik-style m } \\
\text { tik-style m } \\
\text { aputed as a } \\
\text { ine jobs. A } \\
\text { sticity and } \\
\text { ant at the }\end{array}$ & $\begin{array}{l}\text { the impact } \\
\text { timates of } \\
\text { the chang } \\
\text { te share of } \\
\text { includes th } \\
\text { le employn } \\
\text { are from fo } \\
\text { re from fou } \\
\text { tik-style m } \\
\text { ecifications } \\
\text { confidence } 1\end{array}$ & $\begin{array}{l}\text { the exposul } \\
\text { impact of t } \\
\text { Census p } \\
\text { aseline den } \\
\text { ulation wit } \\
\text { aseline sha } \\
t \text { in manuf } \\
\text { digit indust } \\
\text { git industry } \\
\text { ure from for } \\
\text { e weighted } \\
\text { y clusterin } \\
\text { l; with }{ }^{* *}\end{array}$ & $\begin{array}{l}\text { o robots and } \\
\text { xposure to } \\
\text { te employn } \\
\text { raphic char } \\
\text { ollege and y } \\
\text { of employm } \\
\text { aring. Colu } \\
\text { data). Colu } \\
\text { ta). Colum } \\
\text { ligit industr } \\
\text { working-age } \\
\text { td correlatic } \\
\text { significant a }\end{array}$ & $\begin{array}{l}\text { her conteml } \\
\text { ots and oth } \\
\text { to popula } \\
\text { eristics of c } \\
\text { completed } \\
\text { in manufa } \\
3 \text { includes } \\
4 \text { includes } \\
\text { includes th } \\
\text { ata). Colun } \\
\text { pulation in } \\
\text { ver time a } \\
\text { he } 5 \% \text { conf }\end{array}$ & $\begin{array}{l}\text { ary shocks on } \\
\text { ontemporary } \\
\text { muting zones } \\
\text { h school, the } \\
\text { ring, durable } \\
\text { exposure to } \\
\text { exposure to } \\
\text { xposure tothe } \\
\text { includes the } \\
90 . \text { Standard } \\
\text { le state level. } \\
\text { ice level; and }\end{array}$ \\
\hline
\end{tabular}


TABLE A6: The impact of the exposure to robots on employment and wages (controlling for exports from Germany, Japan and South Korea)

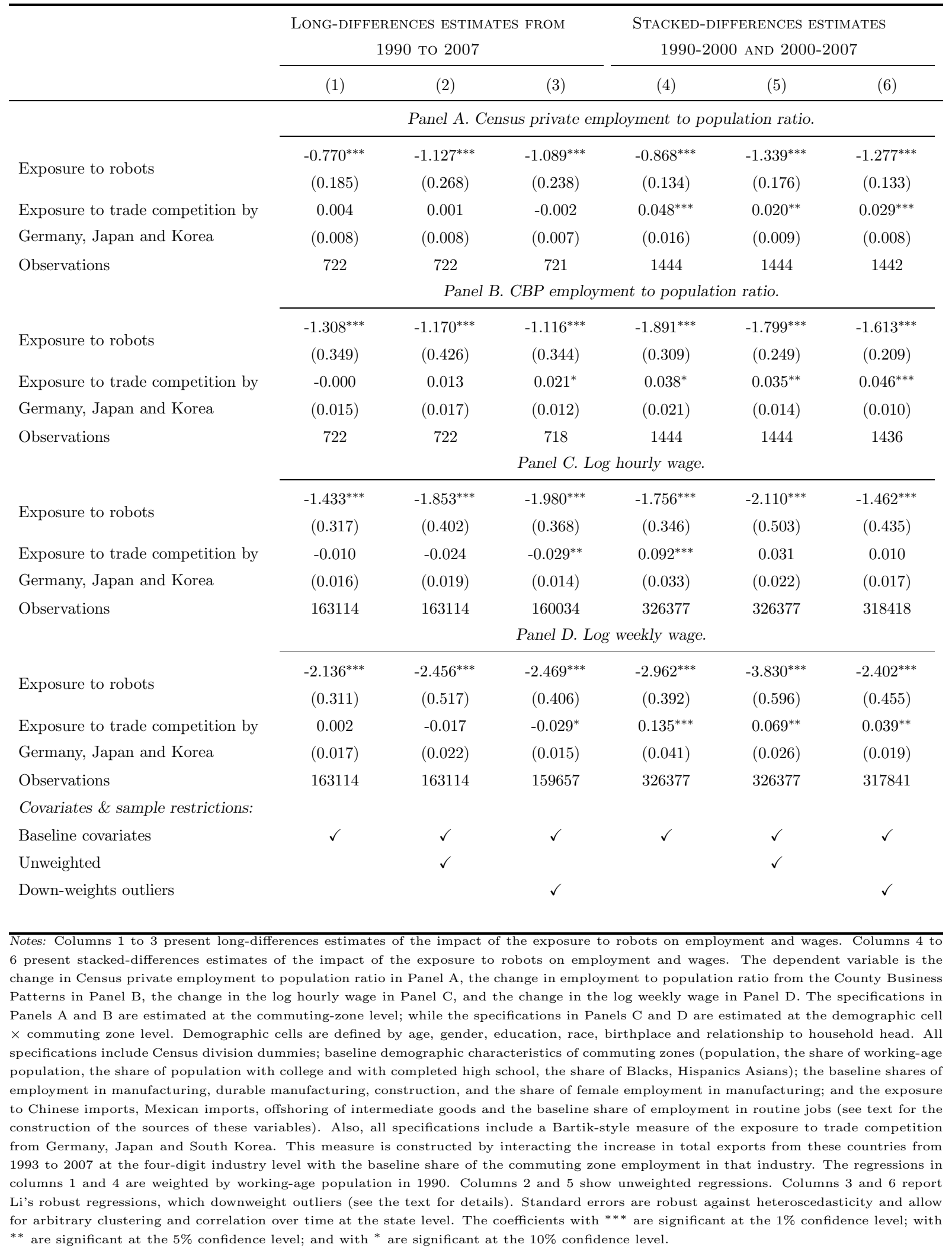


TABLE A7: The impact of the exposure to robots on employment (estimates at the demographic cell $\times$ commuting zone level)

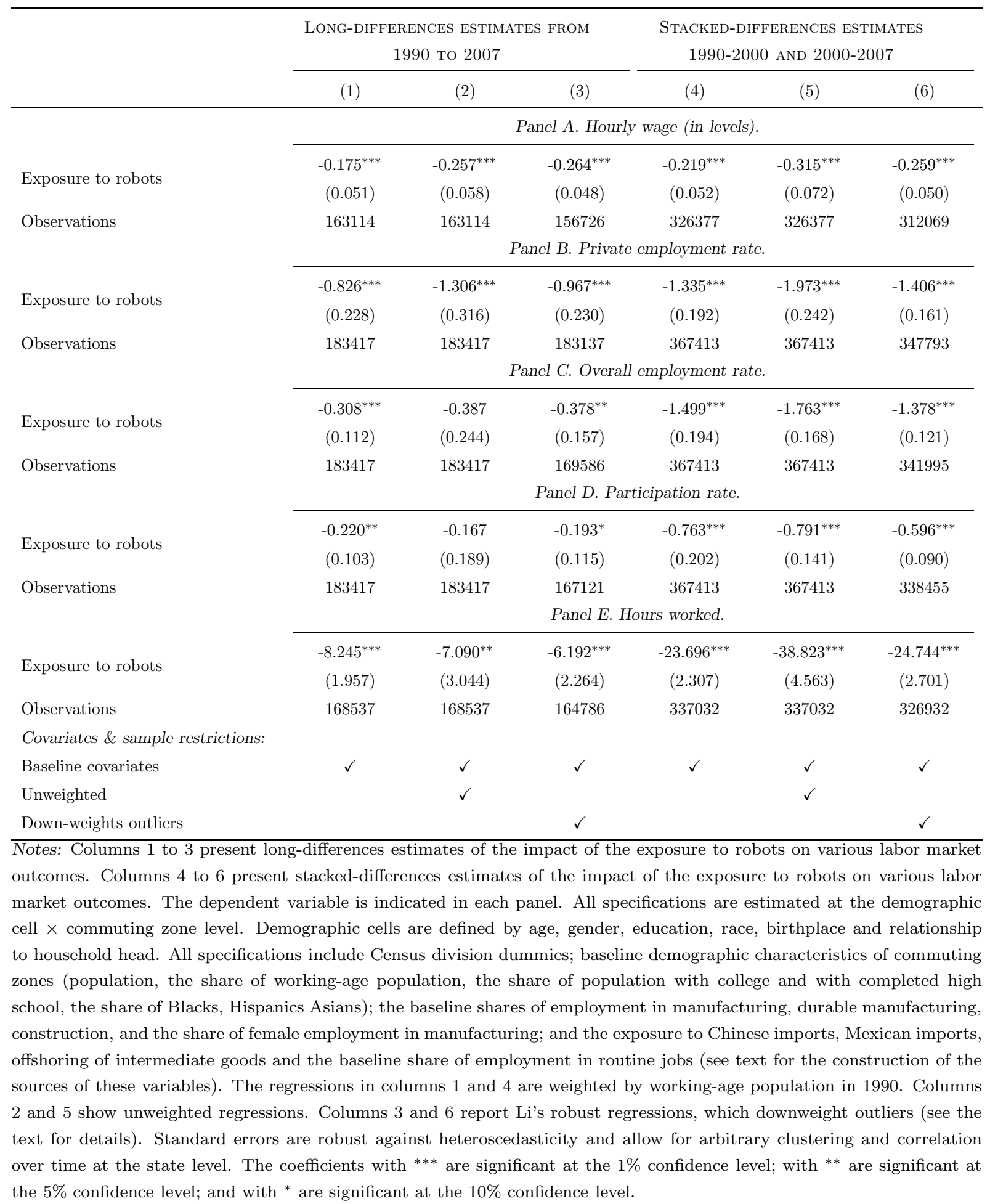


TABLE A8: OLS and IV estimates of the exposure to robots on employment between 2004-2007 and 2004-2010.

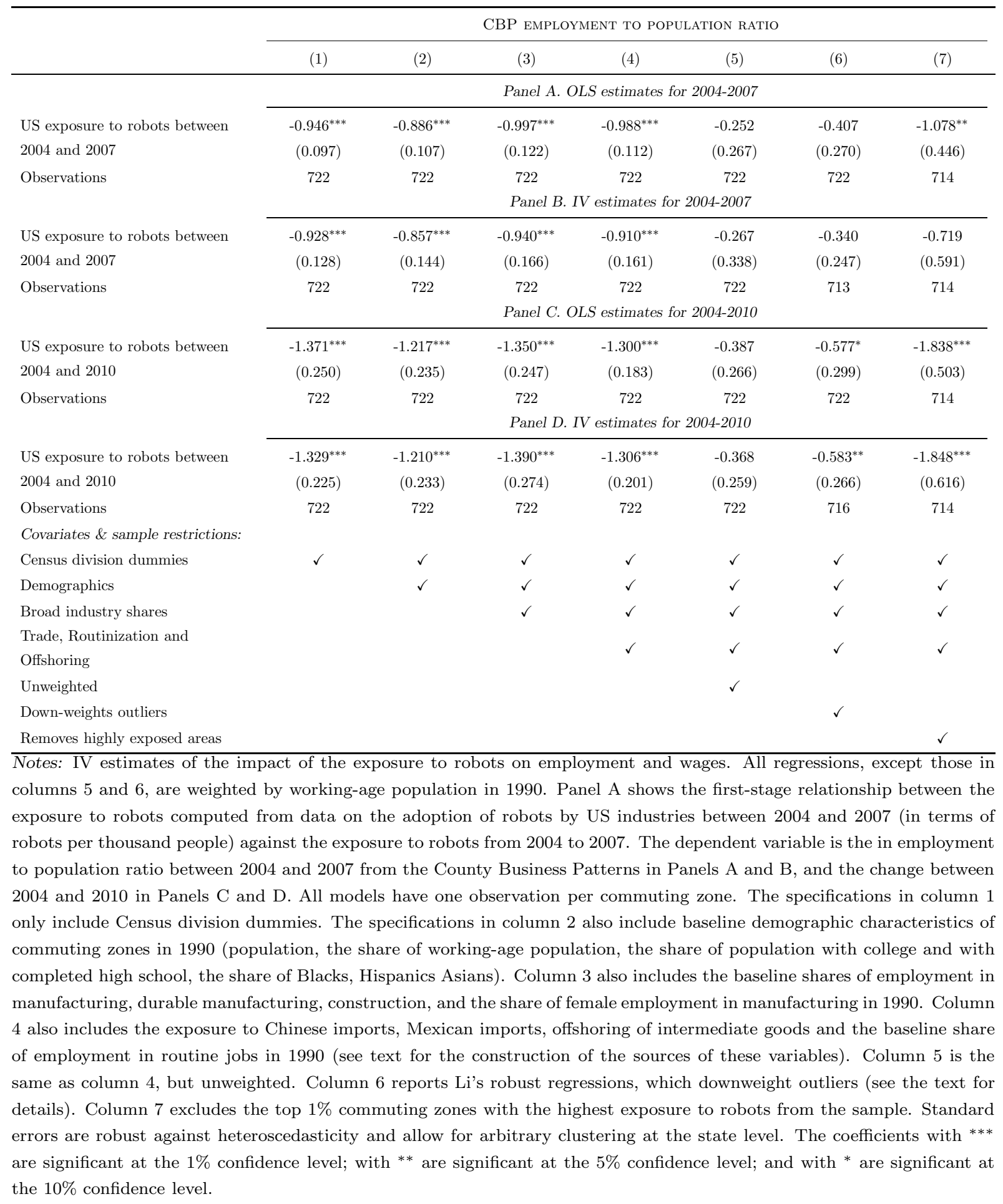


TABLE A9: The impact of the exposure to robots on employment and wages (controlling for IT capital).

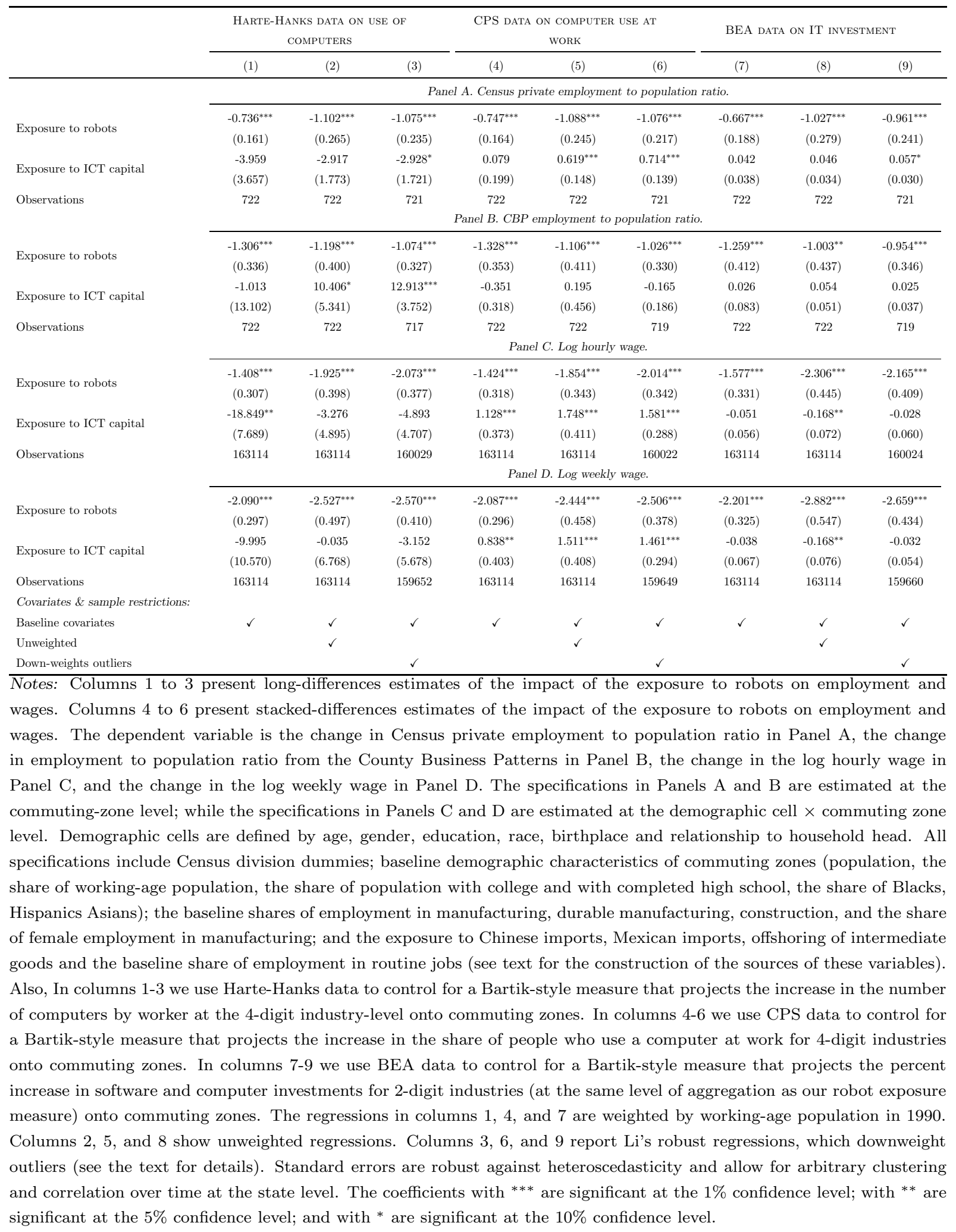


TABLE A10: The impact of the exposure to robots on employment and wages (controlling for mean reversion).

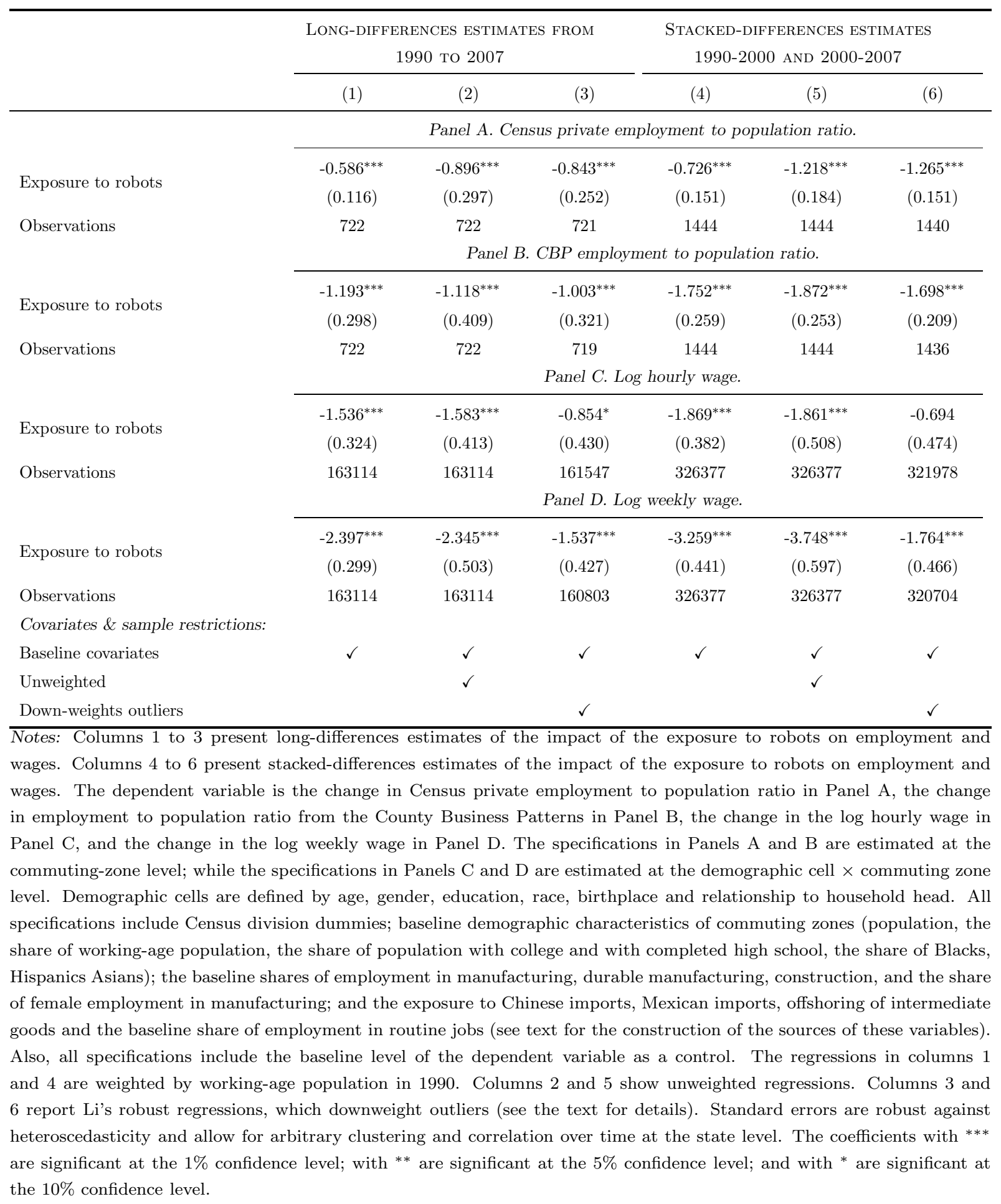


TABLE A11: The impact of the exposure to robots on employment and wages (additional covariates and LASSO)

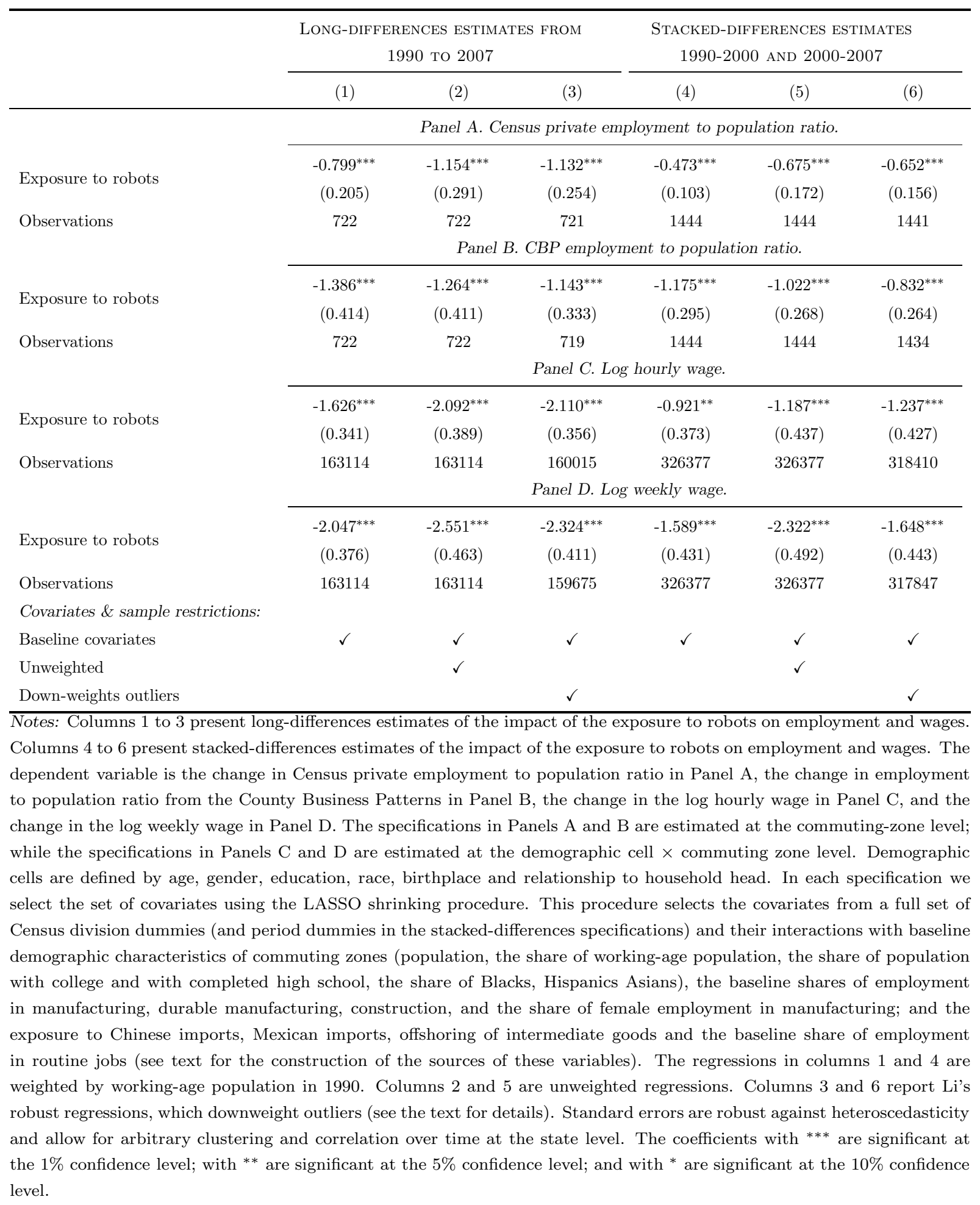


TABLE A12: The impact of the exposure to robots on employment and wages (including state trends)

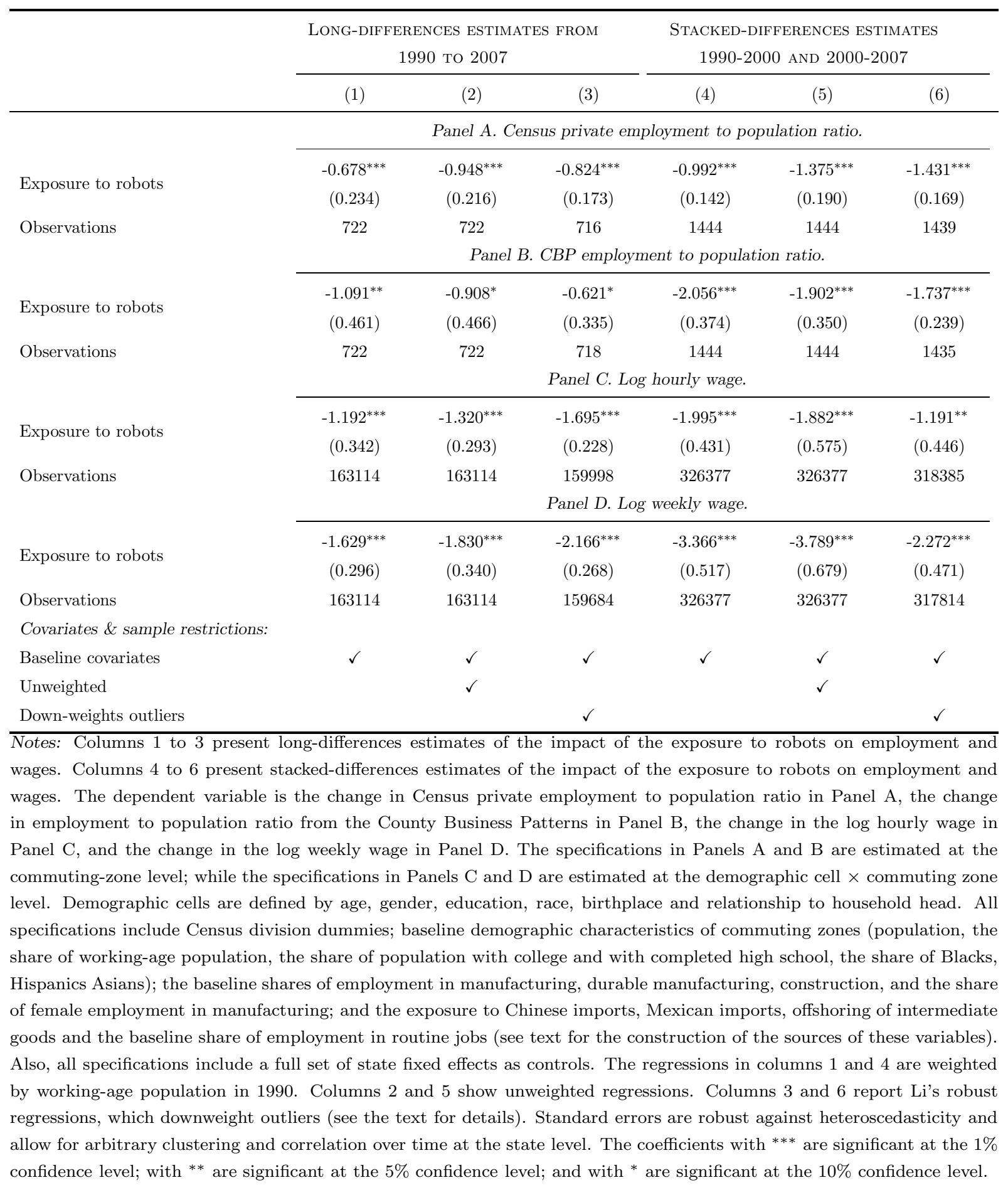


TABLE A13: The impact of the exposure to robots (with 1980 and 1990 baseline) on employment and wages

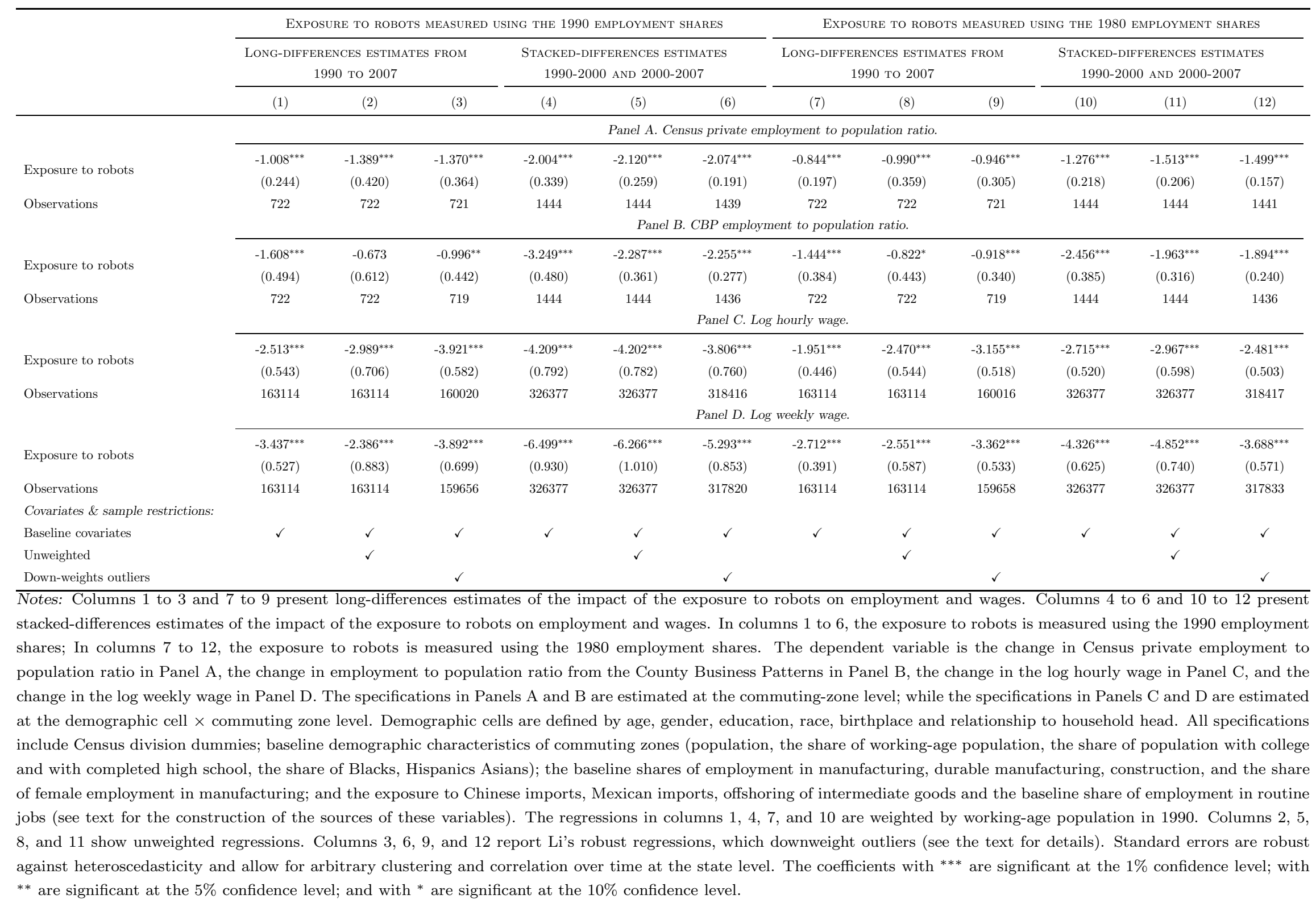


TABLE A14: The impact of alternative exposure to robots measures on employment and wages

\begin{tabular}{|c|c|c|c|c|c|c|c|c|c|c|c|c|}
\hline & \multicolumn{6}{|c|}{ ESTIMATES FOR THE EMPLOYMENT TO POPULATION RATIO } & \multicolumn{6}{|c|}{ ESTIMATES FOR THE LOG HOURLY WAGE } \\
\hline & \multicolumn{3}{|c|}{$\begin{array}{c}\text { LONG-DIFFERENCES ESTIMATES FROM } \\
1990 \text { TO } 2007\end{array}$} & \multicolumn{3}{|c|}{$\begin{array}{l}\text { StaCKED-DifFERENCES Estimates } \\
\text { 1990-2000 AND 2000-2007 }\end{array}$} & \multicolumn{3}{|c|}{$\begin{array}{l}\text { LONG-DIFFERENCES ESTIMATES FROM } \\
1990 \text { TO } 2007\end{array}$} & \multicolumn{3}{|c|}{$\begin{array}{c}\text { StaCKED-DifFERENCES ESTIMATES } \\
\text { 1990-2000 AND 2000-2007 }\end{array}$} \\
\hline & (1) & $(2)$ & (3) & (4) & (5) & (6) & (7) & (8) & (9) & $(10)$ & $(11)$ & $(12)$ \\
\hline & \multicolumn{12}{|c|}{ Panel A. Exposure to robots defined by the average use of robots among European countries. } \\
\hline Exposure to robots & $\begin{array}{c}-0.274^{* * *} \\
(0.068)\end{array}$ & $\begin{array}{l}-0.486^{* * *} \\
(0.135)\end{array}$ & $\begin{array}{l}-0.472^{* * *} \\
(0.122)\end{array}$ & $\begin{array}{c}-0.351^{* * *} \\
(0.075)\end{array}$ & $\begin{array}{c}-0.638^{* * *} \\
(0.129)\end{array}$ & $\begin{array}{l}-0.584^{* * *} \\
(0.100)\end{array}$ & $\begin{array}{c}-0.566^{* * *} \\
(0.135)\end{array}$ & $\begin{array}{c}-0.866^{* * *} \\
(0.179)\end{array}$ & $\begin{array}{l}-0.938^{* * *} \\
(0.175)\end{array}$ & $\begin{array}{c}-0.732^{* * *} \\
(0.141)\end{array}$ & $\begin{array}{c}-1.055^{* * *} \\
(0.190)\end{array}$ & $\begin{array}{c}-0.908^{* * *} \\
(0.191)\end{array}$ \\
\hline Observations & \multicolumn{12}{|c|}{ Panel B. Exposure to robots defined by the average use of robots among Denmark, Finland, France and Sweden. } \\
\hline Exposure to robots & $\begin{array}{c}-0.506^{* * *} \\
(0.111)\end{array}$ & $\begin{array}{c}-0.657^{* * *} \\
(0.172)\end{array}$ & $\begin{array}{c}-0.653^{* * *} \\
(0.149)\end{array}$ & $\begin{array}{c}-0.635^{* * *} \\
(0.119)\end{array}$ & $\begin{array}{c}-0.834^{* * *} \\
(0.185)\end{array}$ & $\begin{array}{c}-0.772^{* * *} \\
(0.150)\end{array}$ & $\begin{array}{c}-0.951^{* * *} \\
(0.209)\end{array}$ & $\begin{array}{c}-1.279^{* * *} \\
(0.248)\end{array}$ & $\begin{array}{c}-1.339^{* * *} \\
(0.230)\end{array}$ & $\begin{array}{c}-1.207^{* * *} \\
(0.260)\end{array}$ & $\begin{array}{c}-1.515^{* * *} \\
(0.328)\end{array}$ & $\begin{array}{c}-1.185^{* * *} \\
(0.317)\end{array}$ \\
\hline Observations & 722 & 722 & 721 & $\begin{array}{c}1444 \\
\text { Panel C. } 1\end{array}$ & $\begin{array}{l}1444 \\
\text { sure to rob }\end{array}$ & $\begin{array}{c}1442 \\
\text { lefined by } t\end{array}$ & $\begin{array}{c}163114 \\
\text { 30th percent }\end{array}$ & $\begin{array}{c}163114 \\
\text { mong Eurol }\end{array}$ & $\begin{array}{c}160031 \\
\text { countries. }\end{array}$ & 326377 & 326377 & 318430 \\
\hline Exposure to robots & $\begin{array}{c}-0.751^{* * *} \\
(0.166)\end{array}$ & $\begin{array}{c}-1.125^{* * *} \\
(0.264)\end{array}$ & $\begin{array}{l}-1.096^{* * *} \\
(0.234)\end{array}$ & $\begin{array}{c}-0.953^{* * *} \\
(0.146)\end{array}$ & $\begin{array}{c}-1.384^{* * *} \\
(0.174)\end{array}$ & $\begin{array}{c}-1.346^{* * *} \\
(0.139)\end{array}$ & $\begin{array}{l}-1.476^{* * *} \\
(0.322)\end{array}$ & $\begin{array}{c}-1.950^{* * *} \\
(0.399)\end{array}$ & $\begin{array}{l}-2.107^{* * *} \\
(0.382)\end{array}$ & $\begin{array}{c}-1.919^{* * *} \\
(0.375)\end{array}$ & $\begin{array}{c}-2.176^{* * *} \\
(0.513)\end{array}$ & $\begin{array}{c}-1.485^{* * *} \\
(0.436)\end{array}$ \\
\hline Observations & \multicolumn{12}{|c|}{ Panel D. Exposure to robots defined by the 50th percentile among European countries. } \\
\hline Exposure to robots & $\begin{array}{c}-0.443^{* * *} \\
(0.106)\end{array}$ & $\begin{array}{c}-0.759^{* * *} \\
(0.196)\end{array}$ & $\begin{array}{c}-0.735^{* * *} \\
(0.177)\end{array}$ & $\begin{array}{l}0.277^{* *} \\
(0.132)\end{array}$ & $\begin{array}{l}-0.136 \\
(0.202)\end{array}$ & $\begin{array}{l}-0.047 \\
(0.157)\end{array}$ & $\begin{array}{c}-0.896^{* * *} \\
(0.208)\end{array}$ & $\begin{array}{c}-1.292^{* * *} \\
(0.270)\end{array}$ & $\begin{array}{c}-1.438^{* * *} \\
(0.262)\end{array}$ & $\begin{array}{c}0.406 \\
(0.247)\end{array}$ & $\begin{array}{l}-0.231 \\
(0.362)\end{array}$ & $\begin{array}{l}-0.336 \\
(0.276)\end{array}$ \\
\hline Observations & \multicolumn{12}{|c|}{ Panel E. Exposure to robots defined by the 90th percentile among European countries. } \\
\hline Exposure to robots & $\begin{array}{c}-0.144^{* * *} \\
(0.035)\end{array}$ & $\begin{array}{l}-0.220^{* * *} \\
(0.062)\end{array}$ & $\begin{array}{l}-0.219^{* * *} \\
(0.054)\end{array}$ & $\begin{array}{c}-0.229^{* * *} \\
(0.055)\end{array}$ & $\begin{array}{c}-0.305^{* * *} \\
(0.062)\end{array}$ & $\begin{array}{c}-0.278^{* * *} \\
(0.049)\end{array}$ & $\begin{array}{c}-0.294^{* * *} \\
(0.069)\end{array}$ & $\begin{array}{c}-0.468^{* * *} \\
(0.086)\end{array}$ & $\begin{array}{l}-0.469^{* * *} \\
(0.080)\end{array}$ & $\begin{array}{c}-0.452^{* * *} \\
(0.112)\end{array}$ & $\begin{array}{c}-0.571^{* * *} \\
(0.108)\end{array}$ & $\begin{array}{c}-0.503^{* * *} \\
(0.103)\end{array}$ \\
\hline Observations & \multicolumn{12}{|c|}{ Panel F. Exposure to robots excluding robots used in manufacturing car parts. } \\
\hline Exposure to robots & $\begin{array}{c}-0.442^{* * *} \\
(0.105)\end{array}$ & $\begin{array}{c}-0.695^{* * *} \\
(0.179)\end{array}$ & $\begin{array}{c}-0.681^{* * *} \\
(0.159)\end{array}$ & $\begin{array}{c}-0.572^{* * *} \\
(0.111)\end{array}$ & $\begin{array}{c}-0.908^{* * *} \\
(0.170)\end{array}$ & $\begin{array}{c}-0.836^{* * *} \\
(0.134)\end{array}$ & $\begin{array}{c}-0.878^{* * *} \\
(0.201)\end{array}$ & $\begin{array}{c}-1.268^{* * *} \\
(0.250)\end{array}$ & $\begin{array}{c}-1.343^{* * *} \\
(0.239)\end{array}$ & $\begin{array}{c}-1.135^{* * *} \\
(0.231)\end{array}$ & $\begin{array}{c}-1.520^{* * *} \\
(0.277)\end{array}$ & $\begin{array}{c}-1.278^{* * *} \\
(0.286)\end{array}$ \\
\hline $\begin{array}{l}\text { Observations } \\
\text { Covariates \& sample re }\end{array}$ & 722 & 722 & 721 & 1444 & 1444 & 1442 & 163114 & 163114 & 160033 & 326377 & 326377 & 318427 \\
\hline Baseline covariates & $\checkmark$ & $\checkmark$ & $\checkmark$ & $\checkmark$ & $\checkmark$ & $\checkmark$ & $\checkmark$ & $\checkmark$ & $\checkmark$ & $\checkmark$ & $\checkmark$ & $\checkmark$ \\
\hline Unweighted & & $\checkmark$ & & & $\checkmark$ & & & $\checkmark$ & & & $\checkmark$ & \\
\hline Down-weights outliers & & & $\checkmark$ & & & $\checkmark$ & & & $\checkmark$ & & & $\checkmark$ \\
\hline
\end{tabular}

the impact of the exposure to robots on employment and wages. In columns 1 to 6 , the dependent variable is the change in the private employment to population ratio from the Census; In columns 7 to 12 , the dependent variable is the change in the log hourly wage from the Census. The specifications in columns 1 to 6 are estimated at the commuting-zone level; while the specifications in columns 7 to 12 are estimated at the demographic cell $\times$ commuting zone level. Demographic cells are defined by age, gender, education, race, birthplace and relationship to household head. The exposure to robots is measured using the average adoption of robots among European countries in Panel A; the average adoption among Denmark, Finland, France and Sweden in Panel B; the 30th percentile among European countries in Panel C; the 50th percentile among European countries in Panel D; the 90th percentile among European countries in Panel E; and the average adoption of robots among European countries but excluding robots employed in the production of intermediate car parts in Panel F. All specifications include Census division dummies; baseline demographic characteristics of commuting zones (population, the share of working-age population, the share of population with college and with completed high school, the share of Blacks, Hispanics Asians); the baseline shares of employment in manufacturing, durable manufacturing, construction, and the share of female employment in manufacturing; and the exposure to Chinese imports, Mexican imports, offshoring of intermediate goods and the baseline share of employment in routine jobs (see text for the construction of the sources of these variables). The regressions in columns $1,4,7$, and 10 are weighted by working-age population in 1990 . Columns $2,5,8$, and 11 show unweighted regressions. Columns 3, 6, 9, and 12 report Li's robust regressions, which downweight outliers (see the text for details). Standard errors are robust against heteroscedasticity and allow for arbitrary clustering and correlation over time at the state level. The coefficients with ${ }^{* * *}$ are significant at the $1 \%$ confidence level; with ${ }^{* *}$ are significant at the $5 \%$ confidence level; and with ${ }^{*}$ are significant at the $10 \%$ confidence level. 